\title{
Performance-Based Consumer Law
}

\author{
Lauren E. Willis $\dagger$
}

In a growing number of consumer transactions, firms exploit consumer confusion and promote poor buying choices. Consumer law generally responds with disclosure and design rules aimed at aligning consumer and firm interests. But with modern experimental and data-analysis techniques, firms can run circles around these rules. The process for enacting disclosure and design rules leaves regulators tied to slow, circumscribed responses. What is needed is a new regulatory instrument that can accomplish two objectives. First, it should unite the interests of firms with the goals of regulators through performance standards for consumer comprehension or suitable consumer product use, thereby redirecting the creative potential of the private sector (much like emissions standards do for pollu. tion reduction). Second, the new regulatory instrument should institutionalize a monitoring system that provides feedback on actual consumer comprehension and product choices, which can be used to improve both the marketplace and regulation in a virtuous cycle.

This Article suggests a fresh approach to consumer law, one that has been tried piecemeal in consumer regulation but without an express intellectual foundation-until now. The principal aim of the approach is modest-to bring consumer transactions in line with consumer expectations. Its broader objective is more ambitious-to make the law as agile as firms are. Performance-based consumer law has the potential to incentivize firms to educate rather than obfuscate, develop product designs that align with consumer expectations rather than defy them, and channel consumers toward products that are suitable for the consumers' circumstances. Moreover, even if performance-based regulation does not directly lead to dramatic gains in consumer comprehension or to marked declines in unsuitable uses of consumer products, the process of establishing and implementing such regulation promises dividends for improving traditional forms of regulation. But performance-based consumer law is more than a technocratic exercise. It is based on-and its operation would reinscribe-a normative vision of consumer law that places consumers at the center.

This Article is particularly timely in at least three respects. First, it answers the question implicitly asked by recent critiques of mandated disclosure: What should we do instead? Second, it plots a promising course for the young Consumer Financial Protection Bureau that is plainly authorized by the Dodd-Frank Act.

$\dagger$ Professor of Law, Loyola Law School-Los Angeles. For helpful discussions, I thank Glenn Cohen, Christine Desan, Howell Jackson, Ted Mermin, Sasha Natapoff, Todd Rakoff, J.B. Ruhl, Joe Singer, Cass Sunstein, and participants at workshops at law schools at Harvard, the University of Connecticut, Vanderbilt, Northeastern, the University of Tulsa, and Loyola-Los Angeles. I also thank research assistants Josef Weimholt and Alec Harris. 
Third, the policy structure it proposes would be helpful in several areas in which policymakers are currently at a loss for what to do, including personal-data privacy, opaque consumer-product pricing schemes, and drug marketing to consumers.

INTRODUCTION 1311

I. WHY EXPAND OUR CURRENT TOOL SET? ............................................. 1316

A. The Problem: Misaligned Interests ............................................... 1317

B. The Regulatory Race: Disclosure Mandates ................................. 1321

C. The Regulatory Race: Product-Design Regulation .......................... 1327

II. Bringing Performance-Based Regulation to Consumer Law ........... 1330

A. Background on Performance-Based Regulation ............................ 1330

B. Benefits of Successful Performance-Based Consumer Law ............ 1335

1. Comprehension standards: enlisting firms to educate consumers...

2. Suitability standards: internalizing the cost of dashboard opacity.

C. Mechanics of Performance-Based Consumer Law........................ 1345

1. Legal authority. ............................................................ 1345

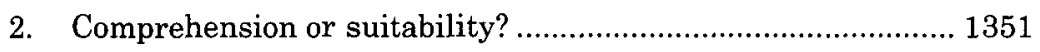

3. Standards, benchmarks, and testing................................. 1355

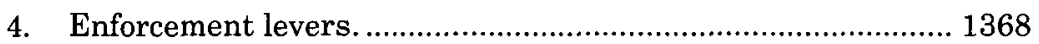

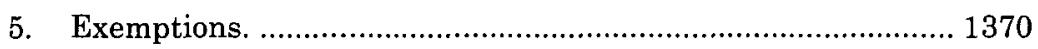

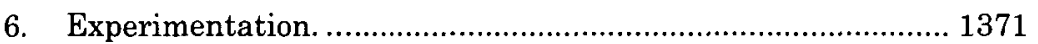

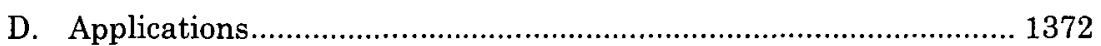

1. Personal-data collection and use ............................................. 1373

2. Consumer credit products: overdraft. .................................... 1380

3. OTC drugs in the postapproval period................................... 1386

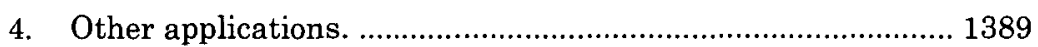

III. Why Performance-Based Tools Could Fail, and Why We Should ESTABLISH AND IMPLEMENT THEM ANYWAY ......................................... 1393

A. Performance-Based Consumer Law: Objections and Replies ......... 1393

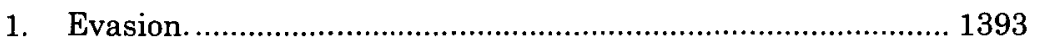

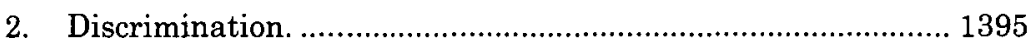

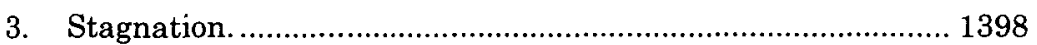

B. Benefits of Trying Performance-Based Consumer Law ................. 1399

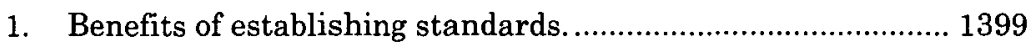

2. Benefits of field-testing consumers........................................ 1400

3. A cumulative benefit: crowding in better regulation. .............. 1402

Conclusion: Putting Consumers at the Center of CONSUMER LaW ......... 1407 


\section{INTRODUCTION}

In a growing number of consumer transactions today, firms exploit consumer confusion and promote poor buying choices. The resulting transactions are often lousy, whether one uses autonomy, welfare, or fairness as the metric. Disclosure and product-design ${ }^{1}$ rules, both of which focus on the actions of firms, have failed to solve this problem. While regulators seem intent on doubling down on disclosure, firms' ability to frame consumer reception of mandated disclosures ultimately hamstrings this project. Regulation of transaction terms can be impotent as well, because firms often reformulate products to evade prescriptive design rules. Moreover, the speed with which firms foil disclosure and design regulation will only increase in the device-mediated world of big data. Consumer law-limited institutionally to slow, circumscribed responses-trails behind firms. The time is ripe for a fresh approach.

In other areas, most notably environmental regulation, prescriptive regulation has been supplemented with performancebased regulation monitored through ongoing field-testing. Rather than the law dictating that a factory smokestack must incorporate a particular scrubber, the law sets limits on a firm's emissions and the firm can then determine how to meet those limits. By uniting the goals of the firm with the goals of the regulator, the regulator is able to harness the firm's innovation in finding ways to meet those goals. By continually monitoring the outcome of interest, regulators obtain systematic information that they can use both to stop problems before substantial harm is done and to make regulation more effective. Performancebased regulation is thus more functional and more adaptive than prescriptive regulation.

Two ways in which we might apply this regulatory paradigm to consumer transactions are comprehension standards and suitability standards. Consumer-comprehension standards that firms could meet by whatever means they see fit are an intuitive move from disclosure mandates. Field-testing of each

1 "Product" as used herein includes services and other consumer market transactions, such as the exchange of personal data for website access. "Product" and "transaction" are used interchangeably. 
firm's customers ${ }^{2}$ would assess whether consumers understand the key costs and risks of the transactions in which they are engaged. If every customer were tested, firms could be prohibited from imposing on a customer those product features that she did not understand. If samples of customers were tested, performance benchmarks for the proportion of customers who must demonstrate comprehension could be set based on, for example, the nature of the market. Firms could be penalized for failing to meet benchmarks and rewarded for exceeding them. Alternatively, evidence that a firm's customers were engaging in transactions that they did not comprehend might trigger scrutiny for or constitute proof of unfair, deceptive, or abusive conduct or be used as a remedy for such conduct.

What would this look like in practice? Take fees, such as overdraft fees on bank account debit card transactions, for example. While the law requires that fees be disclosed to consumers, nothing ensures that consumers understand each fee or are aware of each fee at the time that they could use this knowledge. A comprehension performance standard might require that at least 80 percent of consumers who are paying a given fee know the existence and amount of the fee at the time that they are deciding whether to take the action that will commit them to paying it. To assess performance, regulators or third-party auditors might survey a random sample of a firm's customers who have just incurred the fee. Failure to meet the 80 percent benchmark might result in a penalty, such as requiring the firm to disgorge fees or portions thereof over a look-back period. Exceeding the benchmark might result in a longer interval before the firm's next performance test.

Comprehension performance standards do not aspire to create a world in which all consumers understand everything about the transactions in which they engage. Consumers do not want to live in such a world. ${ }^{3}$ But when consumer decisional

2 "Customer" as used herein means a consumer who has exchanged money or personal data in a transaction with a firm.

3 See Cass R. Sunstein, Choosing Not to Choose ${ }^{2} 6$ (Feb 10, 2014), archived at http://perma.cc/2K8U.WW84 (stating that active choosing among all possible features of a product imposes a large burden on consumers); Barry Schwartz, The Tyranny of Choice, Scientific Am 71, 73 (Apr 2004). See also Omri Ben-Shahar and Carl E. Schneider, More Than You Wanted to Know: The Failure of Mandated Disclosure 64-66 (Princeton 2014) (discussing evidence that consumers do not want to know everything about the decisions 
autonomy is our paramount goal, either because that autonomy is intrinsically valuable or because it is a cost-effective way to assure consumer welfare, firms ought to be required to ensure that their customers comprehend what the firms have sold them.

Suitability requirements are more appropriate when consumers do not want to decide for themselves, or when the cost of achieving comprehension exceeds its benefits. Suitability standards would be closer to traditional substantive regulation but more flexible. Regulators or firms themselves (with public oversight) might define suitable and unsuitable uses of products. Suitability might be required of every transaction (as securities law currently requires for broker and investment-adviser recommendations to retail investors ${ }^{4}$ ). But testing every transaction for suitability would often be prohibitively expensive, and ad hoc and ex post enforcement would create only limited incentives for firm compliance. It would be better to set performance benchmarks for the proportion of the firm's customers that must use the products or features suitably (or at least not unsuitably) and then field-test a sample of the firm's customers to assess whether the benchmarks are met. Enforcement levers could include, for example: fines; rewards; licensing consequences; regulator scrutiny; or liability for unfair, deceptive, or abusive conduct.

An example of suitability-performance regulation would be to extend the existing system for moving a drug from prescription to over-the-counter (OTC) status. Before a drug can be broadly sold without a prescription today, it must be offered OTC on a trial basis in a few OTC settings. ${ }^{5}$ Purchasers are then tested to determine whether the drug is indicated for their symptoms and not contraindicated by their personal conditions, and whether they are taking the drug as the label directs. If the drug passes this "actual use" testing, it can be broadly sold OTC.

they make). The paradox here is that consumer meta-autonomy requires that consumers not exercise complete decisional autonomy.

4 See Hanly $v$ Securities and Exchange Commission, 415 F2d 589, 597 (2d Cir 1969). Rather than being subject to periodic field-testing, securities' suitability forms the basis for ex post enforcement actions and litigation.

5 See Peter Barton Hutt, Richard A. Merrill, and Lewis A. Grossman, Food and Drug Law: Cases and Materials 531 (Foundation 3d ed 2007); Andrea Leonard-Segal, et al, Unique Role of Consumer Studies in Nonprescription Drug Development, $49 \mathrm{~J} \mathrm{Am}$ Pharmacists Assoc 670, 671 (2009). 
A fulsome performance-based system would require that this testing be periodically repeated in the field after the drug is released for OTC sale. This would capture the effects of marketing and changes in consumer beliefs or habits over time. Fines or suspension of OTC-sales privileges might be imposed as a penalty for failing to meet suitability benchmarks.

Performance-based consumer law moves regulators' focus from firms' actions to the effects of those actions on consumers. Rather than asking whether a firm delivered a disclosure or structured a product in a particular manner, performance-based regulation asks whether consumers understand the transaction and whether the transaction is appropriate for the consumers engaged in it. This is not the first article to suggest imposing consumer-comprehension ${ }^{6}$ or suitability requirements on firms, ${ }^{7}$ nor is it the first to suggest testing consumers for comprehension. ${ }^{8}$ Some areas of consumer law already incorporate elements of performance-based regulation. ${ }^{9}$ But this Article is the first to

6 Professors Howard Beales, Richard Craswell, and Steven C. Salop suggested the use of comprehension standards for regulating consumer product claims thirty years ago but did not develop the idea. See Howard Beales, Richard Craswell, and Steven C. Salop, The Efficient Regulation of Consumer Information, 24 J L \& Econ 491, 530 (1981) (explaining that firms can convey information to consumers more effectively and at a lower cost than regulators). See also Jeff Sovern, Preventing Future Economic Crises through Consumer Protection Law or How the Truth in Lending Act Failed the Subprime Borrowers, 71 Ohio St L J 761, 821 (2010) (suggesting that lenders be barred "from completing [mortgage] loans until they could demonstrate that a significant proportion of their borrowers understood the terms of their loans," but not developing the idea); M. Ryan Calo, Against Notice Skepticism in Privacy (and Elsewhere), 87 Notre Dame L Rev 1027, 1067 (2012) (suggesting comprehension goals for privacy disclosures but not developing the idea). Professors Michael S. Barr, Sendhil Mullainathan, and Eldar Shafir suggest moving from financial-product disclosure rules to a standard requiring firms to "meaningfully convey[] the information required for a typical consumer to make a reasonable judgment," but they suggest that compliance be assessed using a judge- or regulator-made "objective reasonableness test" rather than using comprehension testing of firms' actual customers. Michael S. Barr, Sendhil Mullainathan, and Eldar Shafir, Behaviorally Informed Financial Services Regulation *7 (New America Foundation, Oct 2008), archived at http://perma.cc/BJF7-9W3Y.

7 Professors Kathleen C. Engel and Patricia A. McCoy have suggested that ex post enforcement of suitability standards be used to regulate consumer mortgage lending. See Kathleen C. Engel and Patricia A. McCoy, A Tale of Three Markets: The Law and Economics of Predatory Lending, 80 Tex L Rev 1255, 1337-38 (2002).

8 Professors Ian Ayres and Alan Schwartz have suggested periodic field-based consumer-comprehension testing in the specific context of information privacy. See Ian Ayres and Alan Schwartz, The No-Reading Problem in Consumer Contract Law, 66 Stan L Rev 545, 579-80 (2014). The remedy they propose-clearer and more-conspicuous disclosure-is not in keeping with a performance-based approach to law.

9 See Part II.A. 
develop a broad performance-based approach to consumer law in which comprehension and suitability standards and consumer testing are productively located. ${ }^{10}$

Performance-based consumer law together with ongoing field-testing has the potential to incentivize firms to educate rather than obfuscate, to develop simple and intuitive product designs that align with, rather than defy, consumer expectations, and to channel consumers toward products that are suitable for consumers' circumstances. Performance-based regulation ought not supplant disclosure and design regulation. Among other things, disclosure rules serve a standardizing function that facilitates comprehension and design regulation addresses thirdparty harms that are likely to persist even when consumers engage in transactions that they comprehend well and that are suitable for their own situations. Thus, Part I of this Article makes the case that comprehension and suitability standards should supplement the consumer law regulatory toolbox. Part II roughly maps how these instruments might operate, using privacy, overdraft, OTC drugs, and other examples.

Because the aim of this Article is conceptual, it leaves detailed execution plans to future work-and the devil may well lie in those details. ${ }^{11}$ But in addition to examining potential pitfalls of performance-based consumer law, Part III suggests payoffs that the process of designing and implementing comprehension

10 A type of performance-based regulation of consumer markets has also been suggested by Professor Stephen D. Sugarman and his coauthor Nirit Sandman in the context of foods that pose high health risks. See generally Stephen D. Sugarman, Salt, High Blood Pressure, and Performance-Based Regulation, 3 Reg \& Governance 84 (2009); Stephen D. Sugarman and Nirit Sandman, Fighting Childhood Obesity through Performance-Based Regulation of the Food Industry, 56 Duke L J 1403 (2007). However, their proposals focus on minimizing social costs, whereas the proposal here focuses on the particular goals of consumer law: maximizing consumer decisional autonomy, enhancing individual or household welfare, and assuring intraconsumer fairness.

11 This Article also sets aside political economy issues. Firms are not going to like consumer law performance standards, at least in the short run. Slapping a disclosure on a product is easier than ensuring that consumers understand a product. Although suitability standards can allow firms to meet a broader range of consumer needs than product-design regulation permits, firms will often prefer the certainty of design regulation, particularly while the mechanics of suitability standards are being worked out. Thomas P. Brown, a leading financial-services attorney, has already registered his opposition to comprehension standards. See Thomas P. Brown, Disclosure-an Unappreciated Tool in the CFPB's Arsenal, 8 Berkeley Bus L J 209, 215-18 (2011). But restricting policymaking to regulations that firms do not oppose allows firms rather than citizens to govern, a result that is incompatible with democracy. 
and suitability standards would produce even if performancebased regulation does not directly lead to dramatic gains in consumer comprehension or marked declines in unsuitable uses of consumer products. The process of establishing performance standards would provide a new lens through which to focus on the goals of consumer law, a lens that places consumers rather than the actions of firms at the center. The process of testing for compliance with performance standards would produce data about how to meet those goals in a continually evolving marketplace, even if performance-based regulation is not the best way to do so. The Article ends by concluding that performance-based regulation should be undertaken as a purposeful experiment, one that promises to be a bridge to more efficacious forms of consumer law.

\section{WHY EXPAND OUR CURRENT TOOL SET?}

The metagoals of consumer law include consumer decisional autonomy in the marketplace; ${ }^{12}$ market transactions that optimize consumer welfare; ${ }^{13}$ and intraconsumer fairness, particularly for disadvantaged consumers. ${ }^{14}$ The primary tools conventionally used to achieve these ends are disclosure and design regulation. This Part discusses the challenges posed by the

12 Consumer decisional autonomy is the ability, within resource constraints and the limits of market offerings, to select which market transactions to engage in based on an accurate understanding of the costs, benefits, and risks of a transaction. Complete decisional autonomy is never possible. One will never know and be able to incorporate into decisions all the costs, benefits, and risks of a product-but that is the aspiration.

13 Optimizing consumer welfare is also beyond what consumer law can achieve, but consumer law can be used to help consumers shop among products to ensure that the market tends to produce consumer surplus. More conservatively, consumer law aims to eliminate unsuitable product transactions (the purchase of a product by a consumer for whom the product's expected costs and risks outweigh its expected benefits).

14 The Consumer Financial Protection Bureau (CFPB), for example, has a statutory purpose of "ensuring ... that markets for consumer financial products and services are fair, transparent, and competitive." 12 USC $\$ 5511(\mathrm{a})$. The fairness metagoal is reflected in the antidiscrimination laws applicable to consumer transactions. See, for example, 15 USC $§ 1691$ (prohibiting discrimination in consumer lending); 42 USC $\S 2000$ a (prohibiting discrimination in certain retail consumer transactions); Cal Civ Code $\$ 51.6$ (prohibiting gender-based price discrimination in consumer transactions). The fairness metagoal is also demonstrated in the felicity of various consumer doctrines for the vulnerable consumer. See, for example, 15 USC $\$ 1692$ e (prohibiting the use of a "false, deceptive, or misleading representation or means in connection with the collection of any debt"); Clomon v Jackson, 988 F2d 1314, 1318 (2d Cir 1993) (adopting the widely used "least sophisticated consumer" standard for $§ 1692 \mathrm{e}$ violations). 
modern consumer marketplace and explains why disclosure and design regulation are unlikely to meet these challenges.

\section{A. The Problem: Misaligned Interests}

In broad-brush terms, the premise of consumer market transactions is that consumers will make welfare-optimizing decisions, either because individuals have an accurate understanding of the costs, benefits, and risks of transactions and can compare these to their own needs and tastes to arrive at the best choice, or because consumers' needs and tastes are relatively homogeneous and there is a sufficient proportion of savvy consumers in the marketplace to incentivize firms to design their products to maximize consumer welfare. ${ }^{15}$ This premise holds for some subset of consumer transactions or attributes thereof. For example, if a payment product does not function well on a dayto-day basis, such as when a particular prepaid debit card is not accepted by many merchants, consumers will switch to another card, giving issuers an incentive to create broad merchant networks for their cards.

There is, however, an expanding universe of transactions in which the interests of consumers and firms are not well aligned. This universe is expanding for two technology-related reasons: consequential features of transactions are becoming too opaque and changeable for many consumers to shop well for themselves, and market structure renders consumers unable to benefit from other consumers' shopping. Consumer law currently facilitates rather than ameliorates the effects of these technological changes.

For consumers to understand and take adequate account of consequential costs and risks of transactions, the transactions must be transparent and usable at the dashboard. A product or transaction exhibits "dashboard transparency" when what must be understood to make a welfare-enhancing decision about the transaction is simple, intuitive, and quickly perceived. "Dashboard usability" is the quality of not demanding

15 See Alan Schwartz and Louis L. Wilde, Imperfect Information in Markets for Contract Terms: The Examples of Warranties and Security Interests, 69 Va L Rev 1387, 1462 (1983) (suggesting that an informed minority can ensure that the market provides terms that benefit all consumers). But see R. Ted Cruz and Jeffrey J. Hinck, Not My Brother's Keeper: The Inability of an Informed Minority to Correct for Imperfect Information, 47 Hastings L J 635, 672-75 (1996) (explaining the limits of an informed minority's ability to ensure that other consumers receive beneficial terms). 
that consumers exercise a great deal of self-control or overcome heuristics and biases in their reasoning processes to select transactions well. In many instances, dashboard transparency and usability require "under-the-hood complexity," meaning complexity that the consumer does not need to understand to make a good product choice. For example, a fully amortizing, fixed-rate, level-payment mortgage has only a few simple moving parts that consumers need to understand even though amortization and maintaining a fixed rate when the cost of funds is variable are both financially complex. A nonamortizing adjustablerate mortgage is simpler under the hood, but less transparent and usable at the dashboard-consumers must understand more, exercise greater self-control, and avoid common decisional biases such as excessive time discounting in order to make good decisions about these loans.

Firms have incentives to offer products that are opaque and unusable at the dashboard. As work by Professor Oren Bar-Gill and joint work by Professors Xavier Gabaix and David Laibson famously show, firms shroud prices and other undesirable product features and design products to exploit willpower and rationality limits. ${ }^{16}$ For example, because consumers often poorly account for long-term or uncertain consequences when making decisions, firms have an incentive to sell products laden with contingent or back-end costs-this is why printers are cheap, but toner cartridges are expensive, for example. Even when a firm does not intentionally design its products or marketing and sales methods to impede consumer decisionmaking, firms rarely have incentives to help consumers make better decisions with respect to opaque terms. For example, issuers use dozens of pricing structures for prepaid debit cards, making it difficult for consumers to understand and compare card prices. ${ }^{17}$

Moreover, as Professor Russell Korobkin explains well, to survive in a competitive market, firms must often design nonsalient product features to benefit firms at the expense of

16 See Oren Bar-Gill, Seduction by Contract: Law, Economics, and Psychology in Consumer Markets 19 (Oxford 2012); Xavier Gabaix and David Laibson, Shrouded Attributes, Consumer Myopia, and Information Suppression in Competitive Markets, $121 \mathrm{Q}$ J Econ 505, 510 (2006).

17 See Loaded with Uncertainty: Are Prepaid Cards a Smart Alternative to Checking Accounts? *2, 7-8 (The Pew Charitable Trusts, Sept 2012), archived at http://perma.cc/U4MC-VJZW. 
consumers. ${ }^{18}$ 'This is not the firms' fault; it is the result of limited consumer knowledge, skills, rationality, and cognitivewillpower bandwidth, ${ }^{19}$ combined with the market imperative on firms to exploit these weaknesses or lose out to competitors who do. For example, when banks attempted to replace a loss in regressively distributed overdraft revenue with a transparent and more fairly distributed monthly fee for using bank account debit cards, consumers fled. ${ }^{20}$ Consumers who incurred overdraft fees fled because they did not incorporate into their decisions an accurate projection of the overdraft fees that they would pay and therefore misperceived accounts with monthly fees as more expensive. Consumers who did not incur overdraft fees fled because they accurately perceived the monthly fee as more expensive than "free" banking subsidized by overdraft fees paid by other consumers.

When firms receive an advantage due to consumer misunderstanding, all three metagoals of consumer law are frustrated. Consumers cannot exercise decisional autonomy because they do not understand product costs and risks and therefore do not incorporate these into their decisions accurately. Consumers cannot capture transaction surplus and will at times even engage in negative-value transactions because they cannot make good product decisions. Regressive cross subsidies from generally poorer to generally wealthier consumers can result, because poorer consumers usually have less cognitive-willpower bandwidth with which to navigate dashboard complexity and take contingent or future consequences into consideration. ${ }^{21}$ To the extent that the wealthier end of the market is competitive, competition can drive firms to offer products that subsidize wealthier consumers at the expense of poorer consumers. ${ }^{22}$

18 See Russell Korobkin, Bounded Rationality, Standard Form Contracts, and Unconscionability, 70 U Chi L Rev 1203, 1234-36 (2003).

19 Willpower and cognitive capacity function as a single resource in the brain, such that if willpower is taxed then so is cognition, and vice versa. See Roy F. Baumeister, et al, Free Will in Consumer Behavior: Self-Control, Ego Depletion, and Choice, 18 J Consumer Psych 4, 8-11 (2008).

20 See Eric Dash, Banks Quietly Ramping Up Costs to Consumers (NY Times, Nov 13, 2011), archived at http://perma.cc/WWE9-S2ZL ("Bank of America abandoned its $\$ 5$ a month debit card usage fee in late October amid a firestorm of criticism.”).

21 See Sendhil Mullainathan and Eldar Shafir, Scarcity:" Why Having Too Little Means So Much 65 (Times Books 2013).

22 See Lauren E. Willis, When Nudges Fail: Slippery Defaults, 80 U Chi L Rev 1155, 1184-85 (2013) (explaining the regressive cross subsidy created by overdraft fees); Scott 
Transactions presenting this misaligned-interests problem are increasing in frequency for several reasons. First, technology and market structure allow firms to make more complex products and more variations of them, and to alter these products more quickly. Whereas once there were just a couple standardized types of mortgages, the late 1990s brought a profusion of mortgage types and the life cycle of each formulation was short. Consumers could not use information provided by firms, social knowledge, or personal experience to select a mortgage well.

Second, firms can selectively target this multitude of complex and volatile product offerings using diverse marketing scripts to ever-narrower consumer segments, allowing firms to better exploit individual consumer knowledge, skill, rationality, and cognitive-willpower bandwidth limits. With big data and the presence of computers, cell phones, and other devices intermediating consumer transactions, firms can tailor marketing, products, and prices to a single consumer in real time. As marketers explain, "To fully understand your customer or prospects requires a collection of multiple data points that can include demographic, purchase history, customer service requests, lifecycle stage, [and] browse and cross-channel engagement behavior data." ${ }^{23}$ In addition, marketers suggest that

you must have real-time data [about] ... what your customers are doing now, where they are located, and how they are engaging with your brand (which channels and devices)-all of this data allows the marketer to understand their customer's current context ... which in turn enables them to engage customers with hyper-personalized communications that fit their needs in the present moment. ${ }^{24}$

For example, firms now engage in "price optimization," the use of real-time consumer data to determine who will likely price

Schuh, Oz Shy, and Joanna Stavins, Who Gains and Who Loses from Credit Card Pay. ments? Theory and Calibrations *2 (Federal Reserve Bank of Boston, Aug 31, 2010), archived at http://perma.cc/93JQ-GK2R (documenting the regressive effect of credit card rewards programs).

23 Katrina Conn, Moving beyond Basic Personalization to Real-Time Marketing (ClickZ, Jan 7, 2014), archived at http://perma.cc/8XHJ-4WKQ. "Channel" refers to paper mailing, internet browser, mobile phone, or other means through which marketers reach consumers.

24 Id. See also Present Tense Marketing: Engaging Consumers for a Constantly Connected World (StrongView), archived at http://perma.cc/RE84-RXSP. 
shop and who will not, based on their personal characteristics, predicted mood, and behavior in the moment. ${ }^{25}$ Such tactics prevent consumers from relying on the market to push quality up and prices down. Instead, each consumer must navigate the market alone.

\section{B. The Regulatory Race: Disclosure Mandates}

The disclosure model of regulation contemplates various transmission paths through which disclosed information might improve consumer well-being. The most obvious is that consumers-or at least enough of them to discipline the market-might each use informational disclosures combined with knowledge of their own situations, needs, and preferences to make welfareenhancing decisions. ${ }^{26}$ However, as most comprehensively and entertainingly described by Professors Omri Ben-Shahar and Carl Schneider, mandated disclosure routinely has little or no positive impact on consumer marketplace decisions and can even lead consumers astray. ${ }^{27}$

Scholars and regulators have generally attributed disclosure's failures to bounded consumer rationality and willpower. ${ }^{28}$ Yet they continue to tinker, trusting that they can overcome

25 See Herb Weisbaum, Data Mining Is Now Used to Set Insurance Rates; Critics Cry Foul (CNBC, Apr 16, 2014), archived at http://perma.cc/9LRC-EWW5 (explaining that the insurance industry has started using price optimization to set rates); Price $O p$ timization (Earnix), archived at http://perma.cc/HYF6-N77P (offering a service that allows banks to "[a]nalyze the price elasticity of each customer profile and uncover the efficient pricing frontier for each product in [their] portfolio").

26 Alternatively, uninformed consumers might follow advice from third parties who have digested the information in disclosures. But third parties are often misinformed or biased and consumers often cannot or do not use the third parties well. See The Truth about Angie's List, Yelp, and More: Ratings Services Promise Unbiased Reviews of Local Businesses. Do They Deliver?, Consumer Rpts 6, 6-7 (Aug 2013) (finding that businesses commonly manipulate user reviews to positively skew their own ratings).

27 See generally Ben-Shahar and Schneider, More Than You Wanted to Know (cited in note 3). A recent study indicates that a new disclosure of the monthly payment amount necessary to pay off a credit card's balance in thirty-six months increased the number of cardholders who made a payment of that size. However, the study was unable to conclusively determine "whether the nudge affected overall repayment behavior" because some cardholders may have increased their payments while others decreased them. Sumit Agarwal, et al, Regulating Consumer Financial Products: Evidence from Credit Cards, 130 Q J Econ 111, 152 (2015).

28 See, for example, Cass R. Sunstein, Boundedly Rational Borrowing, $73 \mathrm{U}$ Chi L Rev 249, 260-61 (2006). 
these bounds..$^{29}$ What remain surprisingly underappreciated are the dynamic effects of firms' responses to disclosures. Firms sabotage disclosures by: (1) ferreting out situations in which consumers are particularly unlikely to be influenced by disclosures; (2) physically framing consumer receipt of disclosures to minimize their influence; (3) psychologically framing consumer receipt of disclosures to minimize their influence; (4) altering the product to make disclosures less useful; and (5) offering consumers alternative ways to select the product, rather than through examination of the disclosure. Disclosure regulation can control the format in which selected information is presented, but it cannot control the frame in which the consumer receives-and ultimately may not perceive-this information.

The first method for sabotaging disclosure-ferreting out consumers in situations in which disclosure is likely to be ineffective-is becoming increasingly sophisticated in the devicemediated age. The late twentieth century saw mortgage sellers fishing for disclosure-insensitive prospects by mailing "live checks" that, when cashed, would result in loans at exorbitant interest rates; the consumers who cashed the checks were good prospects for a high-priced mortgage. ${ }^{30}$ Firms today leverage big data to reach the consumers who are most likely to be receptive to advertising at the precise moments when they are most likely to be receptive and most likely to ignore disclosures. ${ }^{31}$ For example, positive moods can lead consumers to ignore risks, potentially making disclosures of risks ineffective. ${ }^{32}$ Therefore, firms track consumers as they play online games and then target advertisements to the moments when consumers are experiencing

29 See, for example, Cass R. Sunstein, Empirically Informed Regulation, 78 U Chi L Rev 1349, 1366-87 (2011).

30 See Promoting Homeownership by Ensuring Liquidity in the Subprime Mortgage Market, Joint Hearing before the Senate Subcommittee on Financial Institutions and Consumer Credit and the Subcommittee on Housing and Community Opportunity of the Committee on Financial Services, 108th Cong, 2d Sess 104, 110 (2004) (statement of Assistant Attorney General Pamela Kogut, Office of the Attorney General of Massachusetts) (explaining that the practices of mortgage lenders included "luring" mortgage customers through live checks).

31 For a nice overview of how firms engage in market manipulation, see generally Ryan Calo, Digital Market Manipulation, 82 Geo Wash L Rev 995 (2014).

32 See Punam Anand Keller, Isaac M. Lipkus, and Barbara K. Rimer, Depressive Realism and Health Risk Accuracy: The Negative Consequences of Positive Mood, $29 \mathrm{~J}$ Consumer Rsrch 57, 65-67 (2002); Eric J. Johnson and Amos Tversky, Affect, Generalization, and the Perception of Risk, 45 J Personality \& Soc Psych 20, 29-30 (1983). 
success or defeat to take advantage of the consumers' likely positive or negative moods in the advertising pitch. ${ }^{33}$ As experimental manipulations of user mood by social networking and dating sites have highlighted, firms can even influence consumer mood. ${ }^{34}$

Firms can also hide disclosures or divert consumer attention from them. Paper disclosures are surrounded by a stack of other documents and online disclosures can appear below or beyond the first screen. A more sophisticated example comes from AT\&T's addition of a mandatory arbitration clause to its contract with its customers: it designed the envelope, cover letter, and amended contract through extensive market testing to ensure that most consumers would not open the envelope, or that if they did open it, they would not read beyond the cover letter. ${ }^{35}$ To take another example, a reminder about privacy concerns delivered just before subjects make a choice that will determine whether their personal information is revealed leads subjects to behave in more privacy-protective ways. But adding just a fifteen-second delay between the privacy disclosure and the loading of the next webpage where the subjects make the choice that implicates privacy eliminates the privacy-protective effect of the disclosure on a subject's choices. ${ }^{36}$ Even idle conversation reduces a subject's comprehension of disclosures. ${ }^{37}$

33 See Michael Carney, MediaBrix Enables Targeted Advertising during Moments of Positive and Negative Emotion in Social Games (PandoDaily, Apr 18, 2013), archived at http://perma.cc/5N7T-NLZK. See also New Beauty Study Reveals Days, Times and Occasions When U.S. Women Feel Least Attractive (PHD Media, Oct 2, 2013), archived at http://perma.cc/6C6T-QUES (reporting on research showing that women feel the least attractive on Mondays between the hours of 5:00 a.m. and 9:00 a.m., or after 10:00 p.m., as well as when they are sick, stressed, or tired, and suggesting that marketers of beauty products take advantage of these windows).

34 See generally Adam D.I. Kramer, Jamie E. Guillory, and Jeffrey T. Hancock, Experimental Evidence of Massive-Scale Emotional Contagion through Social Networks, 111 Proceedings Natl Academy Sci 8788 (2014). See also Stewart Shapiro, Deborah J. MacInnis, and C. Whan Park, Understanding Program-Induced Mood Effects: Decoupling Arousal from Valence, $31 \mathrm{~J}$ Advertising 15, 17 (2002) (describing the cognitive mechanisms by which advertisements affect mood).

35 See Ting $v$ AT\&T, 319 F3d 1126, 1134 (9th Cir 2003).

36 See Idris Adjerid, et al, Sleights of Privacy: Framing, Disclosures, and the Limits of Transparency *8-9, archived at http://perma.cc/45R2-NB4Y.

37 See, for example, Debra Pogrund Stark, Jessica M. Choplin, and Mark A. Leboeuf, Ineffective in Any Form: How Confirmation Bias and Distractions Undermine Improved Home-Loan Disclosures, 122 Yale L J Online 377, 388-89 (2013) (finding that disclosures previously developed by the United States Department of Housing and Urban Development to improve mortgage comprehension succeeded somewhat 
Psychologically, advertising and sales talk can frame consumers' thought processes when they approach disclosures. Blatant sales tactics such as claims of scarcity ("Better act fast!") or "unbeatable" offers are common because they are effective. ${ }^{38}$ Persuasive sales methods can also be subtle. A former loan broker explains how apparently idle chitchat is not so idle:

$[\mathrm{Y}]$ ou tell the loan salesperson you want the loan to upgrade a room. He or she will ask you why, and you innocently will say that you want your daughter to have a nice new room. "Oh, really, what color?" asks the loan arranger. Purple, you say.

Rest assured, as the process moves along, the salesperson ... will continuously remind you that your goal is to "paint a nice new purple room." The salesman seems to . . truly care that the room is done professionally to ensure your daughter's complete happiness.

It's easy to forget that your goal is not a purple room, it's a loan at the best price and terms possible. ${ }^{39}$

Trust in a salesperson or in a brand may lead a consumer to misinterpret a disclosure in a way that favors the outcome suggested by the salesperson or advertising, ${ }^{40}$ or to skip looking at disclosures at all.41 One study found that consumers' perception and comprehension of contraindication disclosures decline when a brand name is added to OTC-drug packaging. ${ }^{42}$

Firms design products and purchase processes to stymie consumer comprehension of disclosures or to encourage consumers to ignore disclosures. When some price components must be

when subjects examined the disclosures in silence, but that improvement diminished when the experimenter engaged the subject in conversation).

38 See Robert B. Cialdini, Influence: Science and Practice 203-08 (Allyn and Bacon 4th ed 2006); Anick Bosmans and Luk Warlop, How Vulnerable Are Consumers to Blatant Persuasion Attempts? *7, archived at http://perma.cc/YZX4-WUCD.

39 Dieter Brunner, The Mistakes Borrowers Make, and How to Avoid Them: A Mortgage Geek Tells All (ConsumerAffairs, June 6, 2006), archived at http://perma.cc/Y7N6 -A99M.

40 See Cialdini, Influence at 238 (cited in note 38 ).

41 See Jesse R. Catlin, Cornelia Pechmann, and Eric P. Brass, The Influence of Need for Cognition and Principal Display Panel Factors on Over-the-Counter Drug Facts Label Comprehension, 27 Health Commun 264, 268-70 (2012).

42 See id. 
prominently disclosed, firms fold more of the cost of the product into less-visible components. ${ }^{43}$ Comprehension of all relevant features of a product that is complex at the dashboard requires complex disclosures, and complex disclosures are poorly understood. ${ }^{44}$ Firms shape purchasing processes to ensure that consumers sink significant costs into the effort-and perhaps switch from a decisionmaking to an implementation mindset-before receiving the disclosure. For example, consumers must often select and download a device application ("app") before they can learn how much personal data the app will collect about them; by that time they may already be committed to the purchase and will mindlessly click through the disclosure screen. ${ }^{45}$ Firms can ensure that social pressures discourage consumers from examining disclosures. For example, at chronically understaffed carrental counters, consumers have serious social pressure from the line standing behind them to not read the contract.

Perhaps most powerfully, firms can offer consumers alternative bases for making a decision that require less time and effort than comprehension of a disclosure would entail. For example, after the "nutrition facts" label appeared on packaged foods, firms short-circuited this detailed mandated disclosure by offering consumers front-of-package nutrition claims, culminating in the infamous "Smart Choices" checkmark that graced even Fudgsicles and Froot Loops.46 Among other things, front-ofpackage nutrition claims divert consumers from examining the

43 See, for example, Comments to the Federal Reserve Board: Truth in LendingProposed Rule *32 (National Consumer Law Center, Dec 24, 2009), archived at http://perma.cc/EHZ5-MBT9 (explaining how the exclusion of third-party fees from the calculation of the annual percentage rate (APR) that lenders must disclose under the Truth in Lending Act has "led to an explosion of bizarre third-party fees, including $\$ 50$ e-mail fees, multiple charges for courier fees, sometimes amounting to hundreds of dollars, and 'fax review fees"').

44 See Lauren E. Willis, Decisionmaking and the Limits of Disclosure: The Problem of Predatory Lending; Price, 65 Md L Rev 707, 790-91 (2006).

45 See Adrienne Porter Felt, et al, Android Permissions: User Attention, Comprehension, and Behavior *12 (2012), archived at http://perma.cc/SXD9-4GZZ; Serge Egelman, et al, Timing Is Everything? The Effects of Timing and Placement of Online Privacy Indicators *6 (2009), archived at http://perma.cc/UR2G-7337.

46 See William Neuman, For Your Health, Froot Loops (NY Times, Sept 4, 2009), archived at http://perma.cc/B6ML-EA4B; Christina A. Roberto, et al, Choosing Front-ofPackage Food Labelling Nutritional Criteria: How Smart Were 'Smart Choices'?, 15 Pub Health Nutrition 262, 262 (2012) (finding that "[m]ore than 60\% of foods that received the 'Smart Choices' label did not meet standard nutritional criteria for a 'healthy' food choice"). 
mandated disclosures. ${ }^{47}$ Consumers use the very term "privacy policy" as a decisionmaking shortcut. This is the heading that firms affix to the website link or portion of a disclosure form that explains their practices regarding personal-data collection and use. But instead of reading the policies, consumers assume that a firm with a "privacy policy" has a policy of keeping consumer data private. 48

Sometimes firm efforts to sabotage disclosure are found to violate general prohibitions on unconscionable, unfair, deceptive, and abusive acts and practices (UDAAP). But UDAAP enforcement today is largely complaint driven and biased toward addressing the problems afflicting "wealthier, white, better educated, better informed" consumers ${ }^{49}$ who feel entitled to complain. Back-end enforcement often creates insufficient incentives for front-end compliance due to corporate insolvency, uncertain liability, problems of proof, dispersion of harm, and other barriers to initiating and maintaining successful adversarial actions. ${ }^{50}$ Finally, current constitutional protections for commercial speech immunize most marketing practices.

47 See Brian Roe, Alan S. Levy, and Brenda M. Derby, The Impact of Health Claims on Consumer Search and Product Evaluation Outcomes: Results from FDA Experimental Data, 18 J Pub Pol \& Mktg 89, 99-101 (1999).

48 See llana Westerman, What Misconceptions Do Consumers Have about Privacy? (Privacy Perspectives, June 3, 2013), archived at http://perma.cc/Y75J-M8VU. See also Carlos Jensen, Colin Potts, and Christian Jensen, Privacy Practices of Internet Users: Self-Reports versus Observed Behavior, 63 Intl J Human-Computer Stud 203, 226 (2005) (noting that users interpret trust marks as the presence of a quality privacy policy).

49 Stephen Meili, Consumer Protection, in Peter Cane and Herbert M. Kritzer, eds, The Oxford Handbook of Empirical Legal Research 176, 180 (Oxford 2010) (summarizing the findings of the empirical literature). See also Rebecca L. Sandefur, Access to Civil Justice and Race, Class, and Gender Inequality, 34 Ann Rev Soc 339, 347-52 (2008) (documenting race, class, and gender disparities in the likelihood that a consumer who experiences a civil justice problem will pursue a legal remedy); Arthur Best and Alan R. Andreasen, Consumer Response to Unsatisfactory Purchases: A Survey of Perceiving Defects, Voicing Complaints, and Obtaining Redress, 11 L \& Socy Rev 701, 723-24 (1977) (finding that voiced complaints tend to underrepresent complex problems, poor consumers, and racial minorities).

50 See Steven Shavell, Liability for Harm versus Regulation of Safety, $13 \mathrm{~J}$ Legal Stud 357, 360-63 (1984); Charles D. Kolstad, Thomas S. Ulen, and Gary V. Johnson, Ex Post Liability for Harm us. Ex Ante Safety Regulation: Substitutes or Complements?, 80 Am Econ Rev 888, 889 (1990). 


\section{The Regulatory Race: Product-Design Regulation}

A similar dysfunctional cycle afflicts consumer productdesign regulation. Design regulation is intended to eliminate harmful products or features without eliminating those that enhance consumer welfare. It presents a danger of being overinclusive because it effectively bans products that could be welfare enhancing for some subset of consumers. But to avoid impeding innovation or constraining consumer choice, most design rules are written narrowly. The result is that firms can evade design regulation through changes in their products that meet the letter but not the spirit of the rules. Regulators ban one product feature only to have a similar feature pop up in its place.

Any product or attribute that does not need a revamped assembly line to effectuate a change is vulnerable to this shapeshifting. For example, firms can change most consumer contract terms virtually overnight. ${ }^{51}$ The case is the same with financial products. As the former CEO of a major credit card issuer frankly explained, "Bankers will figure it out to comply and say, ... 'Tell me the rules, and then I'll outsmart you all.' . . . You make the stupid laws, I'll comply and I'll make money." ${ }_{52}$

The archetype for evading regulation through shape-shifting is high-priced, small-dollar lending, such as payday lending. When product-design regulation intended to eliminate payday lending has been implemented, firms have continued to lend at the same prices through a parade of sleights. Lenders may evade interest-rate caps by selling loans bundled with overpriced ancillary services such as insurance, "membership plans," check cashing, or credit repair, ${ }^{53}$ or by acting as "Credit Service Organizations" that charge exorbitant fees for arranging loans from other lenders. ${ }^{54}$ To escape statutory definitions of "payday loans" and to avoid the 36 percent APR cap on loans to members

51 See David Horton, The Shadow Terms: Contract Procedure and Unilateral Amendments, 57 UCLA L Rev 605, 645 (2010); Brian Grow and Robert Berner, About That New, "Friendly" Consumer Contract (Bloomberg, Apr 29, 2009), archived at http://perma.cc/76B3-LM4Q.

52 Lowell Bergman and Oriana Zill de Granados, The Card Game (PBS Frontline, Nov 24, 2009), archived at http://perma.cc/AX3A-X8J7 (quoting Shailesh Mehta, former CEO of Providian Financial).

53 See Ronald J. Mann and Jim Hawkins, Just until Payday, 54 UCLA L Rev 855, 901-02 (2007); Michael A. Stegman, Payday Lending, 21 J Econ Persp 169, 180 (2007).

54 Stegman, $21 \mathrm{~J}$ Econ Persp at 180-81 (cited in note 53). 
of the military, lenders make loans that are just over size or maturity rules, nominally structure lump-sum loans as installment loans, or drop the requirement that borrowers provide a postdated check. ${ }^{55}$ One payday lender's response to a legal challenge to its tactics to evade Ohio's ban on payday loans is telling. Rather than informing shareholders that a loss in court would end its sales in Ohio, the lender stated that it would merely "have to alter its short-term loan product in Ohio." ${ }^{6}$ A recent study provides evidence that when payday loans are effectively banned, consumers respond by shifting at least some of their borrowing to similarly high-priced pawnshop or auto-title loans. ${ }^{57}$

Even the Credit Card Accountability, Responsibility, and Disclosure Act58 ("CARD Act"), which used product-design regulation to enormously reduce the fees paid by consumers to card issuers, ${ }^{59}$ has been undercut by a variety of pricing schemes not covered by the Act. In the fine print, issuers have placed floors on variable interest rates, added new fees, broadened the definition of transactions to which existing fees apply, and increased fees not covered by the CARD Act. ${ }^{60}$ The CARD Act may be further eclipsed by industry efforts to move consumers to cards not covered by the statute. Banks are marketing prepaid debit cards heavily, especially to students, to whom they can no longer market credit cards. ${ }^{61}$ Many prepaid cards come with opaque fees

55 See Paul Kiel, How Payday Lenders Escape State Crackdowns (Mother Jones, Aug 7, 2013), archived at http://perma.cc/RGE5.ZQ8F; The Extension of High-Cost Credit to Servicemembers and Their Families *9 (CFPB, Dec 2014), archived at http://perma.cc/6JLQ-3AEC.

56 Kiel, How Payday Lenders Escape State Crackdowns (cited in note 55) (quotation marks omitted) (quoting an annual report of payday lender Cashland's parent company).

57 See Jacob Goldin and Tatiana Homonoff, Consumer Borrowing after Payday Loan Bans *19-20 (Nov 5, 2013), archived at http://perma.cc/87FA-ZBN6.

58 Pub L No 111-24, 123 Stat 1734 (2009), codified as amended in various sections of Title 15 .

59 See Agarwal, et al, 130 Q J Econ at 3-4 (cited in note 27) (estimating that, in the two years after it became effective, the CARD Act reduced fees paid by consumers by nearly $\$ 12$ billion annually).

60 See generally Joshua M. Frank, Dodging Reform: As Some Credit Card Abuses Are Outlawed, New Ones Proliferate (Center for Responsible Lending, Dec 10, 2009), archived at http://perma.cc/2UNV-FYRK. See also Oren Bar-Gill and Ryan Bubb, Credit Card Pricing: The CARD Act and Beyond, 97 Cornell L Rev 967, 997-99 (2012) (showing that fees not regulated by the CARD Act, such as cash-advance fees, increased after the passage of the statute).

61 See Catherine New, American Express Campus Edition Debuts as Prepaid Debit Card for College Students (Huffington Post, May 10, 2012), archived at http://perma.cc/YW2R-L4BA. In the year the CARD Act became effective, dollars loaded 
that consumers have difficulty avoiding and do not anticipate, similar to the fees that were reduced by the CARD Act.62 Card issuers have also been selling ordinary consumers business credit cards, which are not regulated by the CARD Act. ${ }^{63}$

Broad standards, such as UDAAP prohibitions, can be applied to the design of a product. The formative unconscionability case, after all, suggested that cross collateralization clauses securing purchase-money loans with other household goods ought not to be a feature of consumer contracts, at least those contracts with disadvantaged consumers in which such clauses tend to be written. ${ }^{64}$ UDAAP prohibitions are at times used to stop firm evasion of narrow rules.

But broad standards are also frequently rewritten by regulators and courts into narrow, evadable rules. For example, the Federal Trade Commission (FTC) recently issued a fifty-threepage handbook explaining how to design "clear and conspicuous" disclosures to avoid engaging in deceptive or unfair online advertising. ${ }^{65}$ While the handbook states that "[t]here is no set formula for a clear and conspicuous disclosure,"66 it delves into such minutiae as font size and color rules. ${ }^{67}$ In the courts, UDAAP prohibitions are applied using an "objective" reasonableness standard, which in practice relies on the subjective view of the court as to what is reasonable. Firms can then take the regulatory prescriptions and past holdings defining reasonable conduct and design products around them. Courts do not always let firms get away with this, but because unconscionability and UDAAP enforcement is largely complaint driven-thus suffering from both the biased case selection and ex post litigation weaknesses described above-firms have little reason not to engage in this type of shape-shifting.

onto prepaid debit cards increased by over 40 percent. See Dana Dratch, 6 Things to Know about Reloadable Prepaid Cards (CreditCards.com, Oct 27, 2011), archived at http://perma.cc/W6VE-475A.

62 See Consumers Continue to Load Up on Prepaid Cards (The Pew Charitable Trusts, Feb 6, 2014), archived at http://perma.cc/27VE-XX2M.

63 See Jessica Silver-Greenberg, Beware That New Credit-Card Offer (Wall St J, Aug 28, 2010), archived at http://perma.cc/LV68-4YY7.

64 See Williams $v$ Walker-Thomas Furniture Company, 350 F2d 445, 447-50 (DC Cir 1965).

65 Federal Trade Commission, .Com Disclosures: How to Make Effective Disclosures in Digital Advertising *6-7 (Mar 2013), archived at http://perma.cc/N6BQ-JJTV.

66 Id at *7.

67 Id at $* 17$. 


\section{BRinging Performance-Based Regulation to CONSUMER LAW}

Regulators might improve disclosure and design rules, but firms often quickly outpace improvements and regulators can rarely stay caught up for long. Performance-based regulation would intervene in this dysfunctional regulatory cycle and has the potential to change its direction to a virtuous one. This Part provides background on performance-based regulation, describes the benefits that it could bring to consumer law, roughs out the mechanics of both comprehension and suitability regulation, and then applies the model to a few exemplar consumer-transaction types.

\section{A. Background on Performance-Based Regulation}

What is performance-based regulation, why is it used, and how is compliance measured? This Section answers each of these questions in turn.

Regulation can be placed on a continuum, from the more prescriptive to the more performance based. ${ }^{8}$ Prescriptive (or proscriptive) regulation is typified by formal, concrete rules that dictate what firms must (or must not) do. The classic (if apocryphal) example is a mandated scrubber system for an industrial smokestack that would otherwise emit more air pollution. The regulator dictates the design of the production processes with an aim to push the regulated behavior toward the regulator's ultimate goal. In contrast, performance-based regulation sets a measurable standard closer to the regulator's ultimate goal and allows the regulated entity to choose how to meet that standard. The classic example is an air pollution emissions standard.

68 See Cary Coglianese, Jennifer Nash, and Todd Olmstead, Performance-Based Regulation: Prospects and Limitations in Health, Safety, and Environmental Protection, 55 Admin L Rev 705, 713 \& n 20 (2003). Performance-based regulation can be combined with market mechanisms to reduce total costs and promote innovation by allowing firms with lower marginal compliance costs to trade with those with higher compliance costs. See Cary Coglianese and David Lazer, Management-Based Regulation: Prescrib. ing Private Management to Achieve Public Goals, 37 L \& Socy Rev 691, 701 (2003). The proposal herein rejects the addition of market mechanisms out of a concern that they would undermine the intraconsumer fairness aim of consumer law in much the same way that tradable pollution permits might lead to pollution hot spots in disadvantaged communities. 
The labels reflect a difference of degree rather than kind. In some sense, no regulation is ever purely prescriptive; even if a particular type of smokestack scrubber were required for coalfired power plants, for example, the firm could produce power using wind turbines instead. Likewise, what has come to be called performance-based regulation does not give firms complete discretion in meeting the regulator's ultimate goal, but rather sets an intermediate target that firms must meet. For example, a regulator's ultimate goal might be to protect human health. Performance-based regulation of pollution does not set a standard keyed directly to human health or even to the amount of a toxin that enters people's bodies, but to the amount of a toxin emitted into the air, a measure that is closer to the end goal of human health than a scrubber. This approach confers on firms both more flexibility and more responsibility to determine how to meet the requirements of the law.

Performance-based regulation aspires to bring regulated firms closer to regulators' ultimate goals, with more certainty and at a lower cost than prescriptive regulation. A prescribed scrubber may or may not be successful in meeting the intermediate goal of limiting pollutant emissions to a particular level. An emissions standard will reach at least that intermediate goal, provided that emissions are measured well and the standard is enforced effectively. The flexibility that firms have in meeting performance standards means that firms can innovatively find the lowest-cost means of reaching the goal. For example, in the air pollution context, firms may still choose scrubbers or they may change other aspects of the production process. ${ }^{69}$ By aligning the firm's goal with the regulator's goal, the performance-based approach brings to bear on the regulatory problem the firm's greater knowledge of its own processes, greater facility with experimentation, and greater ability to adapt to changes in both the environment and available technology.

Performance-based regulation is sometimes erroneously conflated with coregulation, self-regulation, or even deregulation,

69 See J.R. DeShazo and Jody Freeman, Timing and Form of Federal Regulation: The Case of Climate Change, $155 \mathrm{U}$ Pa L Rev 1499, 1508 (2007) (describing performancebased regulation in the environmental context as "end-of-pipe" standards that "permit flexible compliance (perhaps by allowing installation of technology at a local facility, fuel switching, or other strategies)"). 
perhaps because performance standards are often set by regulators in close consultation with industry and thus capture may drive the standards down. ${ }^{70}$ Performance-based safety and soundness regulation has even been advocated by the banking industry, with performance measured by bank selfassessments. ${ }^{71}$ But performance ought to be assessed by regulators or independent auditors, and standards need not be watered down. In some cases the move from prescriptive standards to performance standards has stepped on the toes of entrenched industries. Building codes, for example, moved from prescriptive steel-pipe-building-material requirements to specified pressureper-square-centimeter performance-based standards ${ }^{72}$ that allowed the use of less-expensive plastic pipe, despite the "kicks and screams" of the steel industry. ${ }^{73}$

One important dimension on which performance-based regulatory systems vary in operation is the timing of compliance testing. Compliance can be measured before the performance that is the true target of the regulation, after the performance, or at regular intervals during the performance. Only the last of these can provide the full benefits of the performance-based law paradigm, including the facilitation of adaptive regulation.

Some existing performance-based-consumer law schemes employ testing only at the front end, prior to full release of the product. The testing to establish evidence of suitable product use that is a prerequisite for approving a drug for OTC sales, described in the introduction, is one example. Another comes from the European Union, where food sellers will soon be required to demonstrate "scientifically valid evidence" of the "average"

70 See, for example, Jody Freeman and Daniel A. Farber, Modular Environmental Regulation, 54 Duke L J 795, 816 n 58 (2005) (ascribing low performance standards in the regulation of sulfur dioxide to the influence of powerful "special interests") (quotation marks omitted).

71 See J. French Hill and John B. Lewis, Performance-Based Regulation: Making Banks More Competitive, 16 Banking Pol Rep 5, 8 (1997).

72 See Maureen A. Breitenberg, The ABC's of Standards Activities * 7 (National In. stitute of Standards and Technology, Aug 2009), archived at http://perma.cc/DJ6J-5J42 (contrasting performance standards with design standards and explaining that "a performance standard for water pipe might set requirements for the pressure per square centimeter that a pipe must withstand," whereas "the requirement that a pipe must be made of a given gauge of copper would be a design standard").

73 See Stephen R. Seidel, Housing Costs and Government Regulations: Confronting the Regulatory Maze 82-83 (Center for Urban Policy Research 1978); Allied Tube \& Conduit Corp v Indian Head, Inc, 486 US 492, 496-98 (1988). 
consumer's understanding of front-of-package nutrition claims through up-front consumer-comprehension testing. ${ }^{74}$

When performance is measured at only the start of performance, the regulator's goal may be met in the short term but not the long term. As discussed above, this is a weakness of the OTC regulation process, which cannot capture long-term consumeruse patterns or the effects of marketing. A similar problem afflicts modern building codes, which measure compliance with performance standards only at installation. No testing is done to determine whether, after years of weathering and settling, the materials continue to perform as desired, and the builder is not responsible for ensuring performance over time. The lack of ongoing testing can create serious problems in a performancebased regulatory system. For example, in New Zealand, performance standards in building codes without ongoing surveillance and accountability created substantial problems with leaky buildings. ${ }^{75}$

On the other hand, enforcing performance standards only ex post (when something goes wrong) may be too late to avert problems and may result in systematic underenforcement. An example of a performance standard applied ex post is the prohibition in the Lanham Act ${ }^{76}$ on deceptive advertising, ${ }^{77}$ which the courts assess by reference to survey evidence showing whether consumers were misled by the defendant's advertising. ${ }^{78} \mathrm{~A}$ similar back-end enforcement scheme has been used for the requirement that investment advisers ensure that their retail clients understand when the adviser has a conflict of interest. ${ }^{79}$ The ultimate

74 Regulation (EU) No 1169/2011 Art 35 (Oct 25, 2011).

75 See Peter J. May, Performance-Based Regulation and Regulatory Regimes: The Saga of Leaky Buildings, 25 L \& Pol 381, 397 (2003).

76 Pub L No 79-489, 60 Stat 427 (1946), codified as amended at 15 USC $\S 1051$ et seq.

7715 USC \& $1125(\mathrm{a})(1)(\mathrm{B})$.

78 See Johnson \& Johnson-Merck Consumer Pharmaceuticals Co v Rhone-Poulenc Rorer Pharmaceuticals, Inc, 19 F3d 125, 129-30 (3d Cir 1994) (explaining that, unlike an FTC plaintiff, a Lanham Act plaintiff "cannot obtain relief by arguing how consumers couid react; it must show how consumers actually do react") (emphasis in original).

79 In the 1948 proceeding of In the Matter of Arleen W. Hughes, 27 SEC 629 (1948), which found that an investment adviser violated the securities laws by failing to ensure that her clients understood her conflict of interest, the SEC explained:

It is clear from th[e] testimony that certain of registrant's clients did not understand that registrant consistently proposed to, and in fact did, sell her own securities to them. Accordingly, registrant did not fulfill her affirmative obligation to disclose the capacity in which she acted.... [N]o hard and fast rule can 
back-end performance standard is strict liability in tort, such as consumer products liability. Holding builders strictly (and even mortally) liable when a house they build later falls down and kills a resident ${ }^{80}$ gives builders incentives to use materials that will withstand the test of time. But back-end enforcement suffers from the biased case selection and ex post litigation weaknesses described above.

By contrast, the performance-based approach to consumer law promoted herein relies on ongoing periodic testing. Two areas of consumer law in which regulators today are explicitly tasked with using ongoing testing to assess compliance with performance standards are food safety ${ }^{81}$ and children's product safety. ${ }^{82}$ The former is gravely underfunded ${ }^{83}$ and the latter too new

be set down as to an appropriate method for registrant to disclose the fact that she proposes to deal on her own account. The method and extent of disclosure depends upon the particular client involved. ... The explanation must be such, however, that the particular client is clearly advised and understands before the completion of each transaction that registrant proposes to sell her own securities.

Id at 641 (emphasis added).

80 See Alfred J. Andrea and James H. Overfield, 1 The Human Record: Sources of Global History 13 (Wadsworth 7th ed 2011), quoting The Hammurabi Code, Art 229 (1904) (Chilperic Edwards, trans) ("If a builder has built a house for a man, and his work is not strong, and if the house he has built falls in and kills the householder, that builder shall be slain.").

81 The United States Department of Agriculture (USDA) and the Food and Drug Administration (FDA) perform periodic and incident-triggered testing of food samples. See 21 USC $\S 374$ (establishing FDA inspection authority); 21 USC $\S \S 603-06,608-09,615-16$ (establishing USDA inspection authority for meats); Renée Johnson, The Federal Food System: A Primer *4-7, 11-13, 16-17 (Congressional Research Service, Jan 17, 2014), archived at http://perma.cc/5RDR-LUDL; Department of Health and Human Services, Biennial Report to Congress on the Food Emergency Response Network *5 (FDA, 2013), archived at http://perma.cc/W6SZ-JENW (describing the FDA's emergency testing systems).

82 Manufacturers and importers of children's products have a duty to obtain periodic third-party safety testing. See 15 USC $\S 2063$. See also Margaret Mikyung Lee, Consumer Product Safety Improvement Act of 2008: P.L. 110-314 ${ }^{\star} 10$ (Congressional Research Service, Sept 22, 2008), archived at http://perma.cc/3QNY-M4LE (describing the third-party testing requirement).

83 The FDA estimates that it conducts unannounced compliance inspections (at which it can conduct pathogen and contaminant performance testing) of domestic food producers every five to ten years. See Johnson, The Federal Food System at *12 (cited in note 81). The Food Safety Modernization Act (FSMA) will increase the frequency of these inspections to once every three to seven years, depending on the risk posed by the facility. 21 USC $\S 350$ j. The FSMA also gave the FDA authority to implement a more thorough performance-testing system, one that would require food producers both to engage in regular pathogen testing of production facilities and finished products and to audit suppliers. 21 USC $\$ 350 \mathrm{~g}, 2201$. The FDA has proposed regulations that would require such testing. Food and Drug Administration, Current Good Manufacturing Practice and 
to assess. $^{84}$ The Gainful Employment Rule's graduateemployment benchmarks promulgated by the Department of Education for federal lending to students of for-profit schools are a form of performance testing for suitability that is ongoing, although the benchmarks are a lagging indicator of performance. ${ }^{85}$ These benchmarks are just now taking effect. ${ }^{86}$ Emissions testing provides a better model: performance is measured continuously or at regular intervals such that regulators can detect changes in performance over time and can address problems before substantial harm occurs. ${ }^{87}$

\section{B. Benefits of Successful Performance-Based Consumer Law}

More widespread use of performance-based regulation promises several benefits over prescriptive regulation for consumer law. These include the general benefits of performancebased regulation described above: firms can meet performance standards more quickly, more effectively, and at a lower cost than can regulators using prescriptive regulation, particularly over time. This Section describes additional benefits specific to comprehension and suitability standards.

1. Comprehension standards: enlisting firms to educate consumers.

A primary goal of disclosure is to give consumers the power to make welfare-enhancing marketplace decisions while retaining

Hazard Analysis and Risk-Based Preventive Controls for Human Food, 79 Fed Reg $58524,58526,58548(2014)$; id at 58565-67 (proposed rule); id at 58568-69 (proposed rule).

84 Ongoing safety testing for children's products is required only once every one to three years, and the requirement came into effect in 2013. See Consumer Product Safety Commission, Testing and Labeling Pertaining to Product Certification, 76 Fed Reg 69482, 69490 (2011); Periodic Testing (Consumer Product Safety Commission), archived at http://perma.cc/B7D2-FU6T.

85 See Department of Education, Program Integrity: Gainful Employment-Debt Measures, 76 Fed Reg 34386, 34386-34401 (2011).

86 The rules were vacated in 2012 when a court held that the loan-repayment-rate benchmark was not supported by objective criteria. See Association of Private Colleges and Universities v Duncan, 870 F Supp 2d 133, 152-55 (DDC 2012). New benchmarks were promulgated in 2014, but they did not go into effect until July 1, 2015. See Department of Education, Program Integrity: Gainful Employment, 79 Fed Reg 64890, 64890 (2014).

87 See Continuous Emissions Monitoring Fact Sheet (EPA, Apr 14, 2009), archived at http://perma.cc/8WC9-V5R9 (discussing a scheme requiring continuous monitoring); $40 \mathrm{CFR} \S 63.11220$ (discussing another scheme requiring triennial compliance testing). 
substantial autonomy in determining which transactions are welfare enhancing. One route by which disclosure is intended to achieve this goal is through increasing consumer comprehension of individual product features, of the differences among products, and, in some instances, of how consumer use of the product will likely play out over time. A more dynamic goal is for the resultant savvy consumers to use their demand to push firms to provide products that best meet consumer needs and wants at the lowest price. 88

Why might we expect comprehension standards to move us further toward these static and dynamic goals than disclosure alone? Comprehension standards would radically change firm incentives. Not only would comprehension standards capture the effects of firm marketing and sales practices that might otherwise confuse or mislead consumers, but these standards would also enlist firms to educate consumers. Firms' marketing departments would no longer have the goal of outsmarting the consumer but rather would aim to make the consumer smarter.

Firms are better situated than regulators to perform this task well, at a lower cost, and through changing conditions. Firms know more about their customers because they collect and analyze this information for marketing and productdevelopment purposes. Firms have access to their customers through marketing, sales talk, and product packaging and presentation; regulators have access only through mandated disclosures and public-education campaigns. Firms have expertise in educating consumers through marketing. In the devicemediated age of big data, firms are able to tailor marketing to ever-narrower segments of consumers and even to individual consumers' real-time circumstances. Firms can experiment more easily. Large firms already run thousands of randomized studies

88 For an example of informed consumers demanding higher quality, see Archon Fung, Mary Graham, and David Weil, Full Disclosure: The Perils and Promise of Trans. parency 50 (Cambridge 2007) (noting that the forced display of restaurant hygiene grades in Los Angeles County resulted in consumer demand for higher-graded restaurants); Richard Craswell, Static versus Dynamic Disclosures, and How Not to Judge Their Success or Failure, 88 Wash L Rev 333, 334 (2013). Whether consumers received higher quality is less clear. See Daniel E. Ho, Fudging the Nudge: Information Disclosure and Restaurant Grading, 122 Yale L J 574, 591-95 (2012) (finding that restaurant grades likely do not accurately reflect hygiene quality). 
annually; 89 Facebook alone runs over a thousand experiments each day. ${ }^{90}$ That is, the very tools firms currently use to sell products (and even to sabotage disclosures) are tools they could instead use to educate consumers.

Current hyperpersonalized real-time marketing is more sophisticated than this, but consider the following crude example. Some consumers may be more likely to comprehend the cost of credit if it is relayed to them by online video explanations from bikini-clad models rather than by government-designed disclosure documents. One study found that a photograph of even a fully clothed, attractive woman, when added to a postcard advertising short-term loans, increased demand for the loans among South African males to the same extent as a 2 percent reduction in the monthly interest rate. ${ }^{91}$ Certainly firms could experiment to determine whether the bikini method would be effective in educating consumers. Targeted marketing would ensure that few consumers who would be offended by such advertising would ever see it.

Comprehension standards allow firms to bring the full force of Madison Avenue to consumer education in a way that is not possible for the government. Political and practical constraints on the degree to which regulators can treat different consumers differently, and therefore on regulators' ability to engage in randomized experiments ${ }^{92}$ or tailor disclosures to consumer

89 See Barack Obama, 2014 Economic Report of the President *276 (Mar 2014), archived at http://perma.cc/AX37-J52F ("Indeed, some companies run thousands of randomized studies annually: by 2000 , Capital One was running sixty thousand studies annually using randomization methods, as they experimented with different strategies to determine what works. Google has also run randomized experiments in the tens of thou. sands in some years.").

90 See Eytan Bakshy, Dean Eckles, and Michael Bernstein, Big Experiments: Big Data's Friend for Making Decisions (Facebook, Apr 3, 2014), archived at http:/perma.cc/TLS3-NPDK.

91 See Marianne Bertrand, et al, What's Advertising Content Worth? Evidence from a Consumer Credit Marketing Field Experiment, 125 Q J Econ 263, 291 (2010).

92 Academics and even the president's Council of Economic Advisers have suggested that regulators engage in randomized experiments with subpopulations to test different regulatory approaches to a problem. See, for example, Michael Abramowicz, Ian Ayres, and Yair Listokin, Randomizing Law, $159 \mathrm{U} \mathrm{Pa} \mathrm{L} \mathrm{Rev} \mathrm{929,} 933$ (2011); Obama, 2014 Economic Report at ${ }^{\star 297}$ (cited in note 89 ). However, government experimentation on citizens and segmentation of citizen subpopulations raises ethical, legal, and political concerns. 
segments, ${ }^{93}$ tie one hand of the government behind its back. Public disapproval of bikini-laden public-service messages and the First Amendment commercial speech doctrine tie the other. Courts have invalidated some regulatory attempts to attain information comprehension and retention by means of required graphic photographs on packaging. ${ }^{94}$ But evoking emotional consumer responses and ensuring that consumers retain information are the bread and butter of marketing. Here, another analogy with environmental law is apt: performance standards allow the law to incentivize firms to do what the Constitution might prevent the government from requiring firms to do directly. ${ }^{95}$

Firms can also respond more quickly than the government to evolving consumer beliefs and changes in the market. Existing market and sales testing gives firms early warning of these changes, and firms can respond without competitive bidding, notice and comment, review by the Office of Information and Regulatory Affairs, or judicial review. It took the 2008 financial crisis to motivate Congress to empower and direct regulators to improve home-mortgage disclosures-disclosures that may have been effective when first formulated decades earlier (when mortgages were structured and priced nearly uniformly) but that were ineffective once the market started offering mortgages with individualized pricing and dashboard complexity. ${ }^{96}$ The CFPB then spent three years developing disclosures that increased, by about 15 percent, the proportion of subjects who understood some key mortgage features when examining the new

93 See generally Arial Porat and Lior Jacob Strahilevitz, Personalizing Default Rules and Disclosure with Big Data, 112 Mich L Rev 1417 (2014). For democraticgovernance reasons, limits on the degree to which the government can tailor legal rules and disclosures to different citizens are desirable.

94 See, for example, R.J. Reynolds Tobacco Co v Food \& Drug Administration, 696 F3d 1205, 1216 (DC Cir 2012). But see Discount Tobacco City \& Lottery, Inc v United States, 674 F3d 509, 569 (6th Cir 2012) (upholding a regulation requiring that cigarette packaging bear graphic warnings conveying the health risks of smoking).

95 See Daniel A. Farber, Environmental Trading Schemes and the Constitutional Leverage Effect, in Jody Freeman and Charles D. Kolstad, eds, Moving to Markets in Environmental Regulation: Lessons from Twenty Years of Experience 386-88 (Oxford 2006) (explaining how performance-based environmental regulation can sidestep constitutional takings concerns).

96 For a description of the mortgage market's evolution in this regard, see Willis, 65 Md L Rev at 718-28 (cited in note 44). 
disclosures in lab conditions with no distractions, marketing, or sales talk. ${ }^{97}$

Professional marketers can do much better. Marketers know how to capture consumer attention and affect consumer behavior. In February 2010, for example, an online marketing campaign for a men's body wash with sagging market share garnered 5.9 million views on its first day-which is more views than President Barack Obama's victory speech received on its first day, and orders of magnitude more than the daily views logged by the FTC's consumer-education websites. ${ }^{98}$ By the end of 2010 , the online campaign had received sixty-five million views and the product was the best-selling brand of its class in the United States. ${ }^{99}$ Professional marketing has been successfully used to promote social goals as well. 100 A meta-analysis of research on high-quality, high-intensity, paid-media anti-drunk driving campaigns credits the campaigns with reducing drunk driving accidents by over 10 percent. ${ }^{101}$ The campaigns' benefits were generally found to be at least an order of magnitude greater than their costs. ${ }^{102}$ This is not to say that all anti-drunk driving campaigns succeed. One campaign designed to encourage moderation in drinking was mistaken by many for a beer advertisement. ${ }^{103}$ But campaigns that used professional marketing techniques to develop and place the advertisements were both effective and cost effective.

97 See Know Before You Owe (CFPB), archived at http://perma.cc/Q4LW-9UEL; Know Before You Owe: Quantitative Study of the Current and Integrated TILA-RESPA Disclosures * $\mathrm{x}-\mathrm{xi}, 41$ (Kleimann Communication Group, Nov 2013), archived at http://perma.cc/5F5H.BCJT.

98 The FTC reported in 2011 that all of its websites collectively (not just those di. rected at consumers) garnered fewer than 75,000 hits each day and its videos collectively garnered fewer than 2,500 views each day. See Federal Trade Commission, The FTC in 2011: Federal Trade Commission Annual Report ${ }^{*} 49$ (Apr 2011), archived at http://perma.cc/2Y9J-HA2U.

99 See Case Study: Old Spice Response Campaign (D\&AD), archived at http://perma.cc/4GU6-9J8P.

100 See Marianne Bertrand, Sendhil Mullainathan, and Eldar Shafir, Behavioral Economics and Marketing in Aid of Decision Making among the Poor, $25 \mathrm{~J}$ Pub Pol \& Mktg 8, 16-18 (2006) (advocating the use of marketing to aid financial decisionmaking among the poor).

101 See Randy W. Elder, et al, Effectiveness of Mass Media Campaigns for Reducing Drinking and Driving and Alcohol-Involved Crashes: $A$ Systematic Review, 27 Am J Preventive Med 57, 63 (2004).

102 See id.

103 See Lawrence Wallack and David C. Barrows, Evaluating Primary Prevention: The California "Winners" Alcohol Program, 3 Intl Q Community Health Educ 307, 323 (1982). 
Many marketing efforts no doubt successfully change behavior without improving comprehension. Facing performancebased regulation, firms might opt for compliance with suitability performance standards rather than comprehension standards and use marketing to channel uncomprehending consumers to suitable products. In other cases, firms are likely to determine that increasing dashboard simplicity and usability is more cost effective than educating consumers about existing complex products. Because a product with simpler or more-intuitive features is easier to understand, comprehension standards permit firms to, in effect, lower their own bar by redesigning their products. While regulators might ban complex or counterintuitive structures and features, firms can better innovate toward dashboard simplicity and usability-particularly when this requires an increase in under-the-hood complexity. ${ }^{104}$

Performance-based standards leave firms free to decide whether consumers value a complex attribute highly enough to cover the extra educational cost that the firm will incur, or whether simplifying the product is the better course. Giving firms the power and responsibility to decide which features are worth the costs of comprehension will often be appropriate. Firms already know more about consumer valuation of product attributes than regulators and can learn more about these valuations at a lower cost.

In the past, courts have resisted applying legal comprehension commands in a manner that would require changes in product designs. ${ }^{105}$ In a notable opinion, then-Judge Samuel Alito held that when an underlying concept is difficult to understand, its disclosure meets the pertinent consumer law's command that the disclosure be "clear" if it could be understood by someone with technical expertise. When "no one" could understand the disclosure, it would not be "clear" as required by statute, but the disclosure need not be "in a form that the average consumer can understand." ${ }^{106}$ Alito explicitly based this holding

104 On the other hand, regulators are able to achieve standardization that firms cannot, and standardization facilitates-and in some cases may be key to-dashboard simplicity. This is one reason that performance-based regulation should supplement, rather than replace, disclosure and design regulation.

105 For further discussion of failures to treat clarity and conspicuousness as performance standards, see text accompanying notes 137-42.

106 Applebaum v Nissan Motor Acceptance Corp, 226 F3d 214, 220-22 (3d Cir 2000). But see Lundquist v Security Pacific Automotive Financial Services Corp, 993 F2d 11, 15 
on the premise that a clarity command ought not force a firm to alter the underlying transaction to render the transaction capable of being understood by the consumers engaging in it:

If [the requirement of the Consumer Leasing Act that the disclosure of early termination charges be clear] meant that any method of determining an early termination penalty had to be capable of explanation in a way that the average consumer could understand, [the law] would in effect impose substantive restrictions on the methods that a lessor could employ. ${ }^{107}$

The fact that the performance-based consumer law paradigm intentionally seeks this design-altering effect must be understood and accepted by both the courts and regulators. Achieving consumer comprehension requires dashboard simplicity and usability, and dashboard simplicity and usability are a function of product design. ${ }^{108}$

The effect of successful regulation through comprehension standards would be to bring products into alignment with consumer expectations, whether because consumers become educated about the product or because firms simplify the product or eliminate unintuitive features. Better-educated consumers would also be better-informed citizens, a tertiary benefit of comprehension standards. Increased dashboard simplicity and usability would reduce demands placed on consumers' attention, time, and effort in selecting products and would give consumers increased confidence in the marketplace. But the ultimate benefit of comprehension standards is increased consumer decisional autonomy: consumers would get what they think they are getting, not whatever hidden features firms can slip into the transaction.

2. Suitability standards: internalizing the cost of dashboard opacity.

Substantive product-design regulation aims to increase consumer welfare by eliminating products or product attributes

\footnotetext{
(2d Cir 1993) (finding that a lease provision that was "beyond the understanding of the average consumer" was not "clear and conspicuous").

107 Applebaum, 226 F3d at 220, citing 15 USC $\$ 1667$ a and 12 CFR $\$ 213.4$.

108 For a discussion of this phenomenon with respect to home mortgages, see Willis, $65 \mathrm{Md} \mathrm{L} \mathrm{Rev} \mathrm{at} \mathrm{820-23} \mathrm{(cited} \mathrm{in} \mathrm{note} \mathrm{44).}$
} 
that produce more costs than benefits for consumers, or by requiring products to incorporate particular terms that tend to benefit consumers. The main weaknesses of design regulation are overinclusiveness (some welfare-enhancing transactions are banned) and underinclusiveness (products shift shapes).

Why might suitability standards increase consumer welfare beyond what design regulation alone can do? First, suitability standards can mitigate the underinclusiveness problem, both at the lawmaking level and the enforcement level. The lawmaking process for suitability standards can be more nimble than product-design regulation because the former can be defined at a higher level of generality by a legislative body and then further specified by regulators. The higher level of generality in suitability standards gives regulators the ability to quickly respond to changes in product offerings that render a product unsuitable, even when the product would not violate a narrowly specified design rule.

The enforcement process for suitability standards can also be more efficient, thorough, and evenly applied than the process used for broad UDAAP rules. The Gainful Employment Rule provides a good example. The Rule-which conditioned a school's eligibility to receive federal student-loan funds on the loan-repayment rates and debt-to-earnings ratios of its former students-was promulgated in response to concerns about the rising number of students with unaffordable debt levels and poor employment prospects, due in large part to unfair and deceptive recruiting practices at some for-profit colleges and universities. ${ }^{109}$ Rather than pursuing schools for their recruiters' deceptive acts and practices through a multiplicity of ad hoc, ex post, costly, witness-intensive, unpredictable enforcement actions biased toward higher-socioeconomic-status complainants, the Rule establishes across-the-board performance standards that can be more easily applied and enforced.

Second, suitability standards can be more accurate than design regulation, thus mitigating the overinclusiveness problem. Many products have both appropriate and inappropriate uses; product-design regulation cuts both out. For example, payday loans are sometimes used to handle short-term cash flow emergencies when other options for handling the emergency are

109 See 76 Fed Reg at $34386-88$ (cited in note 85 ). 
inferior-this is an appropriate use. But payday loans are also used when long-term cash flow problems will predictably lead to repeated rollovers and deeper financial trouble - a use that both of the national payday-lender trade associations agree is unsuitable. ${ }^{110}$ Suitability standards allow and encourage firms to develop methods to channel the right products to the right consumers, satisfying the needs and preferences of a broader swath of consumers. Further, the flexibility provided by performancebased regulation avoids some of the innovation-retarding effects of prescriptive design regulation. As Google's CEO Eric Schmidt explained to regulators considering privacy regulation: "If you have to regulate, try to regulate the outcome not the technology. If there's an outcome that you don't like, don't specify in law a technical solution because technology moves forward."111

Third, successful performance-based regulation flips firm incentives. As explained above, technology facilitates the sale of consumer products with inscrutable, unsuitable features. If firms had greater responsibility for downstream uses, however, their incentives would be to design products that can be used in only welfare-enhancing ways and to channel consumers toward appropriate products.

Firms are better situated than regulators to do all these things. To channel consumers to suitable products, regulators are limited to largely ineffective product disclosure rules and public-education campaigns. As explained above, firms can use all the skills of Madison Avenue, experiment and adapt quickly, and tailor efforts to different consumer segments. ${ }^{112}$ When marketing cannot guide consumers to the right products, field-tested suitability standards would give firms an incentive to provide intermediaries (for example, salespeople or digital "choice engines"113) that would steer consumers appropriately.

110 See Is a Payday Advance Appropriate for You? (Community Financial Services Association of America), archived at http://perma.cc/F784-RFKU; Code of Conduct in Offering Access to Credit ${ }^{*} 2$ (Financial Service Centers of America, 2007), archived at http://perma.cc/J3WP.LUC2 ("[P]ayday advances are intended to satisfy short-term credit needs and are not intended to be a long term solution for ongoing financial needs.").

111 Google's Schmidt Warns Regulators against Killing Innovation (Morning Chronicle, May 9, 2012), archived at http://perma.cc/3NN9-GES6.

112 As noted above, many marketing efforts undoubtedly change behavior without improving comprehension. See text accompanying notes 31-48.

113 Richard H. Thaler and Will Tucker, Smarter Information, Smarter Consumers, 91 Harv Bus Rev 44, 54 (Jan-Feb 2013) (explaining how "choice engines" can 
Just as with comprehension standards, firms may determine that product reformulation is more cost effective than using marketing or sales to meet suitability standards. Suitability standards would give firms incentives to make innovation and complexity work for consumers, not against them. Firms are better situated than regulators to design products that are not amenable to unsuitable uses, whether by simplifying products so that consumers can sort themselves well or by eliminating features that are used unsuitably. Firms regularly redesign their physical products when it becomes apparent that consumers are misusing the products and sustaining physical injuries. Common examples include dead-man switches on lawnmowers to prevent injury to consumers who put their hands in the path of the blade ${ }^{114}$ and transformers on hair dryers to prevent injury to consumers who drop them into water. ${ }^{115}$ These redesigns may have been partially motivated by tort liability and regulation, but the redesigns also likely responded to reputational concerns and market pressure.116 When market pressure cannot be brought to bear, suitability standards could provide pressure instead.

$$
\star * *
$$

Performance-based consumer law should not replace disclosure and design regulation. Rather, each form of regulation should retain its vitality for different reasons. Disclosure performs a standardizing function that facilitates consumer comprehension. Design regulation is necessary to address harm to third parties and consumers, and it can also perform a standardizing function. With respect to particular transaction types or features, disclosure or design regulation might have a cost-

help consumers make better decisions). For an example of such a "choice engine," see the website kayak.com.

114 See Mary McMahon, What Is a Dead Man's Switch? (wiseGEEK, 2003), archived at http://perma.cc/XG6F-G5ZA.

115 See Michael deCourcy Hinds, Making a Safer Blow-Dryer: Progress, but at a Snail's Pace, NY Times 50 (Aug 27, 1988).

116 See A. Mitchell Polinsky and Steven Shavell, The Uneasy Case for Product Liability, 123 Harv L Rev 1437, 1443-50 (2010) (examining the impact of market forces, including reputational concerns, on firms' decisions to redesign products); John C.P. Goldberg and Benjamin C. Zipursky, The Easy Case for Product Liability, 123 Harv L Rev 1919, 1946-48 (2010) (stating that tort liability grants consumers a type of governmental power to demand redress and product redesign). 
benefit-calculus edge over performance-based regulation. Moreover, given the uncertainty involved when trying a new regulatory method, disclosure and design regulation ought not to be abandoned. As with any regulatory technique used in a new context, the learning curve for performance-based consumer law will be steep.

\section{Mechanics of Performance-Based Consumer Law}

As a prerequisite for establishing performance-based consumer law, there must be a legal basis for doing so. Next, a choice must be made as to whether to use a comprehension standard, a suitability standard, or both. Development of the regulatory structure then involves several interlocking components. The content of the standard (for example, what pollutant will be measured) and the benchmarks that must be reached (for example, how much of the pollutant can be produced over what time period) must be specified. A valid testing process for determining whether the benchmark is met must also be designed and implemented-for example, emission-monitoring systems must be created and put into operation. Standards, benchmarks, and testing are interdependent; only measurable benchmarks can be enforced. For example, emissions from nonpoint-source contributors to water pollution are believed to be difficult to identify and measure and are therefore regulated through prescriptive rules about runoff management processes rather than through emissions performance standards. ${ }^{117}$ Finally, sufficiently compelling enforcement sticks and carrots must be defined and administered.

This Section discusses these mechanics of performancebased consumer law in detail, notes the possibility of exemptions for small firms, and ends with the suggestion that regulators experiment with performance-based approaches through remedial decrees entered against firms charged with engaging in unfair, deceptive, or abusive practices.

\section{Legal authority.}

For over two decades, it has been the policy of the United States to favor performance-based regulation over prescriptive 
regulation. A 1993 Executive Order (which has since been reaffirmed and supplemented ${ }^{118}$ ) directed all executive agencies, "to the extent feasible, [to] specify performance objectives, rather than specifying the behavior or manner of compliance that regulated entities must adopt."119 Making this policy a reality could be accomplished through new legislation ${ }^{120}$ that establishes broad comprehension and suitability standards and explicitly gives regulators the responsibility and authority to (1) promulgate specific comprehension and suitability performance rules for consumer products and (2) mandate and regulate third-party testing. New legislation could dictate an enforcement mechanism or give regulators a menu of enforcement mechanisms from which to choose. Further, performance-based standards would ideally be part of a purposefully evolving regulatory system, in which regulators have the responsibility and authority to engage in adaptive management of the consumer marketplace. This might require a grant of legal authority to engage in modified administrative procedures. ${ }^{121}$

Even without new legislation, existing consumer law authorizes performance-based regulation in multiple places. For example, UDAAP prohibitions could be interpreted to require that firms meet certain performance standards. When consumers use products unsuitably, the sale of that product will often meet the definition of an unfair and abusive practice; when few consumers comprehend a product feature, the sale of a product with that feature will often meet the definition of a deceptive practice as well.

First, take unfairness. A practice is unfair if it is likely to cause a substantial injury to consumers that is not reasonably avoidable by consumers themselves and that is not outweighed by countervailing benefits to consumers or competition. ${ }^{122} \mathrm{~A}$

118 See Executive Order 13,563, 76 Fed Reg 3821, 3821 (2011).

119 Executive Order 12,866, 58 Fed Reg 51735, 51736 (1993). While this Executive Order formally covers only executive agencies, it is consistent with the charges of the independent agencies involved in consumer-transaction regulation (for example, the FTC, CFPB, and Consumer Product Safety Commission).

120 Recall that this Article puts aside political economy considerations. See note 11.

121 See generally Robin Kundis Craig and J.B. Ruhl, Designing Administrative Law for Adaptive Management, 67 Vand L Rev 1 (2014) (proposing an alternative to traditional Administrative Procedure Act rules for regulations that are enacted as part of an adaptive-management regulatory strategy).

122 See In the Matter of International Harvester Co, 104 FTC 949, 1073 (1984) (FTC 1980 Policy Statement on Unfairness). 
comprehension performance standard would be appropriate here, because a dashboard transaction feature that is not understood by consumers will not be reasonably avoidable by them and will rarely be outweighed by benefits to consumers, given that competition over the feature will not take place. ${ }^{123} \mathrm{~A}$ suitability standard may also be appropriate. Whether a harm is reasonably avoidable can be assessed based on what real consumers do. For example, civil justice liability waivers-classic fine print terms of which few consumers are even aware, and virtually none avoids-likely lead firms to provide suboptimally low levels of product safety, causing substantial injury to unlucky consumers. ${ }^{124}$

An abusive practice is one that, for example, "takes unreasonable advantage of-(A) a lack of understanding on the part of the consumer of the material risks, costs, or conditions of the product ... [or] (B) the inability of the consumer to protect the interests of the consumer in selecting or using [the product]." ${ }^{125}$ Consumers who do not understand material product features often cannot protect their own interests, and selling a product with material terms that consumers do not comprehend takes advantage of both this inability and the consumer's underlying lack of understanding. Unsuitable use of a product demonstrates a consumer's inability to protect her own interests, and sales of such a product take advantage of this inability. For example, a firm selling an OTC drug to consumers who are suffering symptoms for which the drug is not indicated, who use the drug excessively, or in whom the drug is contraindictated 126 is increasing its sales volume by taking unreasonable advantage of these consumers' inability to protect their own interests.

A deceptive practice is a material act or omission that is likely to mislead a reasonable member of the group of consumers to whom the firm's sales practices are directed. ${ }^{127} \mathrm{~A}$ failure to ensure

123 But note that consumers need not understand everything under the hood, provided that their understanding of dashboard features effectuates competition over underthe-hood features.

124 See Albert H. Choi and Kathryn E. Spier, Should Consumers Be Permitted to Waive Products Liability? Product Safety, Private Contracts, and Adverse Selection, $30 \mathrm{~J}$ L, Econ \& Org 734, 754 (2014).

12512 USC $\S 5531(\mathrm{~d})(2)$.

126 See Part II.D.3.

127 See In the Matter of Cliffdale Associates, Inc, 103 FTC 110, 175 (1984) (FTC 1983 Policy Statement on Deception). 
that consumers comprehend all material features of a product is thus a deceptive omission, and it is potentially amenable to a comprehension performance standard. It might even call for a suitability standard-for example, the antideception provisions of the Securities and Exchange Act of $1934^{128}$ provide legislative authority for securities suitability requirements. ${ }^{129}$

Even without new legislation or tapping UDAAP authority, there are many places in which the law already places responsibility on regulators or firms to ensure consumer comprehension and a few other places in which the law does the same for suitable use. Specifics are described in conjunction with the examples presented below.

On the other hand, Congress, regulators, and the courts sometimes eschew performance standards in favor of safe harbors and mechanically applied rules. Statutes often authorize, and sometimes command, regulators to establish safe harbors. For example, the Dodd-Frank Wall Street Reform and Consumer Protection Act ${ }^{130}$ ("Dodd-Frank Act") requires that firms originate mortgages only to consumers who have an ability to pay, a mandate that could be interpreted as a performance standard. ${ }^{131}$ But the Dodd-Frank Act also requires the CFPB to develop design rules defining a "qualified mortgage," which creates a safe harbor for compliance (or, for higher-priced mortgages, a rebuttable presumption of compliance) with the ability-to-pay rule. ${ }^{132}$ The Employee Retirement Income Security Act of $1974^{133}$ permits (but does not require) the Department of Labor (DOL) to prescribe disclosures that defined-contribution retirement plan administrators give to plan participants. ${ }^{134}$ The statute also contains language that is most naturally read as a plan participant comprehension requirement: it requires plan administrators to "take steps to ensure ... that [] participants ... are provided sufficient information ... regarding designated investment alternatives, including fees and expenses attendant thereto, to

128 Pub L No 73-291, 48 Stat 881, codified as amended at 15 USC $\S 78$ a et seq.

129 See Hanly $v$ Securities and Exchange Commission, 415 F2d 589, 596-97 (2d Cir 1969) (finding a suitability duty in $\S 10(\mathrm{~b})$ of the Securities and Exchange Act of 1934).

130 Pub L No 111-203, 124 Stat 1376 (2010).

13115 USC $\S 1639 \mathrm{c}$.

13215 USC $\$ 1639 \mathrm{c}$.

133 Pub L No $93-406$, 88 Stat 829 , codified at 29 USC $\S 1001$ et seq.

13429 USC $§ 1021$. 
make informed decisions." 135 Rather than establishing a performance standard by which plan administrators could demonstrate compliance with this comprehension requirement, DOL chose to use its discretionary authority to prescribe disclosures and gave administrators that provide these disclosures to participants a safe harbor from the requirement. ${ }^{136}$

Even when regulators do not create a formal safe harbor, courts often succumb to the attraction of easy enforceability in interpreting broad statutory language to effectuate prescriptive rules rather than performance-based standards. Most strikingly, facing the ubiquitous statutory command that information must be disclosed in a manner that is "clear and conspicuous," courts have elevated a desire for clarity in the law for their own benefit and for the benefit of firms over clarity and conspicuousness in the disclosed information for the benefit of consumers. At times, courts treat the clarity requirement as surplusage, requiring that the disclosure merely be visible - a requirement that the conspicuousness demand already includes. ${ }^{137}$ The conspicuousness requirement is often read as shorthand for prescriptive rules-such as the requirement that rules be written in a particular size and color font, set forth in a separate paragraph, or written using all caps-without any evidence that these devices lead to increased readership. ${ }^{138}$ The all-caps requirement is particularly perverse; passages in all caps are more difficult to read and less likely to be read than regular font. ${ }^{139}$

More broadly, courts currently use an "objective" standard to evaluate compliance with many consumer laws, including UDAAP prohibitions. Sometimes courts use a "vulnerable

$13529 \mathrm{CFR} \S 2550.404 \mathrm{a}-5(\mathrm{a})$.

136 See 29 CFR $§ 2550.404 a-5(b)-(c)$.

137 See, for example, Channel v Citicorp National Services, Inc, 89 F3d 379, 382 (7th Cir 1996) (interpreting "clear and conspicuous" as meaning "visible" and citing for support the Uniform Commercial Code's definition of "conspicuous" standing alone).

138 See, for example, Corbett $v$ Firstline Security, Inc, 687 F Supp 2d 124, 132 (EDNY 2009) (holding that contract terms gave consumers sufficient notice because, among other things, the terms were written in capital letters, a legible font size, and "primarily" in language understandable to a layperson); $13 \mathrm{~Pa}$ Cons Stat Ann $\S 1201$ (2003) ("A printed heading in capitals (as: NONNEGOTIABLE BILL OF LADING) is conspicuous. Language in the body of a form is conspicuous if it is in larger or other contrasting type or color.").

139 See Linda L. Lohr, Creating Graphics for Learning and Performance: Lessons in Visual Literacy 100 (Prentice Hall 2003); Miles A. Tinker, Legibility of Print 57 (Iowa State 1963). 
consumer" standard and, more frequently, a "reasonable consumer" test, but both are often assessed without reference to actual consumers. ${ }^{140}$ For example, a judge reviewing a document after the fact and knowing what she is looking for may decide whether a consumer ought to have noticed the disclosure and ought to have understood it, rather than deciding whether real consumers did notice and understand it. ${ }^{141}$ This makes litigation cheaper because it renders consumer surveys and expert battles unnecessary. ${ }^{142}$ It also makes the application of the legal rule more predictable; once a court announces that a particular formulation is clear or that a particular presentation format is conspicuous, firms can rely on those findings as a judicially created safe harbor of sorts.

Consumer testing introduces uncertainty because what is clear or conspicuous to actual consumers may vary with the firm's customer base and may change over time, due to both the actions of firms (in some cases, actions calculated to undermine the disclosure) and changes in society. Yet this variation over time in consumer comprehension, whether instigated by firms or not, is one of the very reasons why performance standards are more likely to meet consumer law's goals than prescriptive rules alone. The FTC's recent online advertising guide for businesses articulates this well: "The ultimate test is not the size of the font or the location of the disclosure, although they are important considerations; the ultimate test is whether the information intended to be disclosed is actually conveyed to consumers." 143 Without performance-based comprehension standards, the law has little ability to perform this ultimate test.

140 Recall also that in interpreting the Consumer Leasing Act discussed above, Alito used an "expert" test, interpreting "clear" as meaning intelligible to an expert, not to a consumer. See note 106 and accompanying text.

141 See, for example, UCC $\S 1-201(10)$ (defining conspicuous as "so written that a reasonable person against whom it is to operate ought to have noticed it") (emphasis added); $13 \mathrm{~Pa}$ Cons Stat Ann $\S 1201$ ("Whether a term or clause is conspicuous or not is for decision by the court.").

142 Replacing judge-made constructs of the reasonable consumer with testing of real consumers is likely to increase litigation costs in situations in which enforcement agencies and consumers are currently permitted to prove deception without reference to empirical evidence. But survey evidence is becoming less expensive to produce, and the increased accuracy that such evidence provides is likely worth the cost.

143 FTC, . Com Disclosures at * 1 (cited in note 65). 


\section{Comprehension or suitability?}

Quite a bit of legal authority already exists for comprehension standards, and philosophically, comprehension standards are close to well-accepted disclosure and antideception principles. A comprehension-based system is appropriate when consumer decisional autonomy is our paramount goal, either because that autonomy is intrinsically valuable or because it is a cost-effective way to assure consumer welfare. Further, suitability standards are not an option when suitable uses cannot be well defined and measured, whether due to technical constraints or to a lack of societal consensus on suitable use. Personal-data privacy might fall into the latter category.

But there are at least three situations in which suitability standards ought to be favored over comprehension standards. The first is when comprehension is insufficient to assure consumer welfare. Comprehension is no panacea. If desperation drives consumers to use a product unsuitably, comprehension will not help. Even knowledgeable consumers sometimes make serious mistakes due to, for example, emotion, social pressures, cognitive distortions, or inattention. The story of the New York Times financial reporter who bought a house that he could not afford with a "no-doc mortgage" 144 is a recent, notorious example. ${ }^{145}$

The second situation is when the costs of a comprehension regime exceed the costs of a suitability regime and decisional autonomy has little intrinsic value. The costs to firms of comprehension testing and meeting comprehension standards, whether through educating their customers or altering their products to make them easier for consumers to comprehend, will vary with the context. For example, assuring that a consumer understands diversification well enough to apply it to her portfolio is probably more expensive than offering her a menu and

144 No-doc mortgages are a type of mortgage that does not require any documentation of income. See Stephane Fitch, No-Doc Mortgages are Back?! (Forbes, July 2, 2010), archived at http://perma.cc/NB6A-3Q5R.

145 Edmund L. Andrews, My Personal Credit Crisis (NY Times, May 14, 2009), archived at http://perma.cc/2LTC-P8PF. See also James J. Choi, David Laibson, and Brigitte C. Madrian, Why Does the Law of One Price Fail? An Experiment on Index Mutual Funds, 23 Rev Fin Stud 1405, 1422-25 (2010) (demonstrating experimentally that even MBA students who know that they should ignore returns and focus on cost in choosing investments were unable to do so). 
accompanying marketing that will tend to lead her to a aiversified portfolio. ${ }^{146}$ Testing for whether a consumer understands diversification well enough to diversify her investment portfolio is also probably more costly to do accurately than testing for whether her portfolio is well diversified, and it is unlikely that consumers value autonomy in diversification decisions.

The story of one corrective advertising order hints that meeting comprehension standards could be costly, particularly when firms have previously misled consumers. After years of marketing suggesting that Hawaiian Punch was made up of mostly fruit juice, the manufacturer and its advertising agency were charged with deception by the FTC. The parties settled with a consent order that obligated the defendants to engage in consumer-education efforts until one of the three following benchmarks was met regarding the proportion of consumers who knew that the drink contained less than 20 percent juice: 67 percent of all fruit-drink consumers, 80 percent of prospective Hawaiian Punch customers, or 95 percent of customers who purchased Hawaiian Punch in the last month. ${ }^{147}$ After the order was issued, Hawaiian Punch began stating on its packaging that it contained "not less than 11\% natural fruit juices."148 Ten years later, the first benchmark-and only the first benchmark-was met: even among recent purchasers, only about 70 percent realized that Hawaiian Punch contained so little juice. ${ }^{149}$

However, this example might not hold lessons for performance regulation, because the defendants had little incentive to meet the benchmarks more quickly. In addition, performancebased regulation would give firms more flexibility in reaching the benchmarks. For example, a firm might choose to change the amount of fruit juice in its drink to match consumer expectations, sponsor a guess-our-fruit-juice-content contest to encourage consumers to learn the true amount, or compose a catchy advertising jingle to teach consumers its fruit juice content.

146 See Lauren E. Willis, The Financial Education Fallacy, 101 Am Econ Rev Papers \& Proceedings 429, 429-31 (2011) (finding that consumers are remarkably impervious to financial education).

147 See In the Matter of RJR Foods, Inc, 83 FTC 7, 16, 20-21 (1973).

148 William L. Wilkie, Dennis L. McNeill, and Michael B. Mazis, Marketing's "Scarlet Letter": The Theory and Practice of Corrective Advertising, $48 \mathrm{~J} \mathrm{Mktg} \mathrm{11,} 24$ (1984).

149 See id. 
Certainly firms could do better than merely adding dry text to packaging.

Evidence that consumers know more than one might expect can be found in a recent survey of Facebook users. The survey found that while over three-quarters of users admitted that they had never read the terms of service, a majority understood twenty. one of twenty-five terms that implicated privacy concerns. ${ }^{150}$ For example, most consumers knew that Facebook shares information about individual users to enable third-party targeted marketing and that Facebook could use their name and photo in an advertisement directed to their friends for a product the users had "liked" on their Facebook pages. ${ }^{151}$

Moreover, small, inexpensive changes in marketing copy can make big differences in consumer comprehension. In one recent experiment, subjects who were exposed to realistic advertisements containing "up to" claims (for example, "PROVEN TO SAVE UP TO 47\% ON YOUR HEATING BILLS!") interpreted these advertisements no differently than subjects exposed to direct claims ("PROVEN TO SAVE 47\% ON YOUR HEATING BILLS!"). ${ }^{152}$ About half of each group believed that half or more buyers could expect to save "about $47 \%$," and over a quarter of both subject groups believed that all or almost all buyers could expect to save "about 47\%." ${ }^{153}$ Adding a small-font disclaimer acknowledging that consumers saved only 25 percent on average did not change the misimpression created by the larger-font "up to" claim. ${ }^{154}$ Under a comprehension-testing scheme, firms would have to refrain from "up to" claims. This change would not cost firms anything other than lost revenue from formerly duped consumers, which is precisely the aim of comprehension performance regulation.

Not all comprehension improvements can be achieved so easily, but crucially, the cost of comprehension ought to be something that policymaking takes into consideration, and it dramatically fails to do so now. Although firms that have aided and

150 Ayres and Schwartz, 66 Stan L Rev at 600 (cited in note 8).

151 Id at 598.

152 See Manoj Hastak and Dennis Murphy, Effects of a Bristol Windows Aduertisement with an "Up To" Savings Claim on Consumer Take-Away and Beliefs *4 (May 2012), archived at http://perma.cc/784P.EJQX (emphasis omitted).

153 Id at * 11 .

154 Id. 
abetted misunderstanding ought not to be rewarded in the costbenefit analysis (CBA) process with lower benchmarks, regulators should ask whether the cost of comprehension is worth its benefits. While it is not possible to put a dollar price on the deontological value of decisional autonomy that comprehension enables, in the context of most consumer decisions, it is not priceless. ${ }^{155}$

The third situation in which suitability standards should be used is when consumers would prefer a suitability regime. For consumers, the costs of comprehension are the costs of becoming informed and, sometimes, the costs of being informed. The costs of becoming informed include time and effort, both of which may be diverted from more productive uses-including becoming informed about other transactions in which one is engaged. ${ }^{156}$ The costs of being informed include the loss of sometimes-blissful ignorance. These costs would exist in a disclosure system as well, if the system were effective. They are necessary costs of consumer decisional autonomy. ${ }^{157}$ When these costs are sufficiently high and the benefits of this autonomy are sufficiently low, suitability or design regulation placing the decision squarely in the democratic regulatory process would be preferable. Consumers do not want to understand all aspects of the transactions in which they engage and would often prefer to be able to engage in suitable transactions without spending the time and energy necessary to comprehend much about these transactions. ${ }^{158}$ In these contexts,

155 This is in contrast to political decisions (for example, voting) and personalrelationship decisions (for example, getting married), in which our constitutional and cultural commitments may make decisional autonomy priceless.

156 See Omri Ben-Shahar and Carl E. Schneider, The Futility of Cost-Benefit Analysis in Financial Disclosure Regulation, $43 \mathrm{~J}$ Legal Stud 253, 264 (2014) (describing the crowd-out effect that disclosures have, vis-à-vis other disclosures, on a consumer's attention).

157 Professors Ayres and Schwartz suggest that the cost to consumers of becoming informed ought to be reduced by: (a) allowing consumers to opt out of the comprehension regulation system, or (b) exempting firms from demonstrating comprehension of terms for which firms can show that a majority of consumers do not want to be informed about. Both are problematic loopholes. The first is problematic because confusing consumers into opting out would probably be quite easy for firms to do. See Willis, $80 \mathrm{U}$ Chi L Rev at 1185-1200 (cited in note 22). The second is problematic because it is at odds with the very consumer-autonomy reason for having comprehension standards in the first place, particularly in cases in which a minority of consumers have strong preferences that are contrary to the majority's preferences.

158 See note 3 and accompanying text. 
respecting consumer meta-autonomy requires a reduction in consumer decisional autonomy.

3. Standards, benchmarks, and testing.

a) Standards. Determining the content of performance standards is a very fact-specific enterprise. But a few general approaches to comprehension and suitability standards are described here in turn.

Comprehension standard setting requires choices about factual content and depth of understanding. Identifying what must be comprehended about any particular transaction is not easy. Every transaction has an infinite number of dimensions, and the costs and risks of many transactions are not precisely known. Take, for example, a firm's collection and use of consumers' personal information. Must a consumer comprehend what data are being collected, which parties will have access to the data, to which uses the data will be put, in which ways the data will be combined with other data about the consumer, how long the data will be retained, what methods will be used to protect the data, what record of security has been achieved in the past by these methods, or some other type of information? Further, each fact can be understood with varying degrees of specificity. For example, a comprehension standard might require consumers to understand merely that "third parties" will have access to their data or to know the identities of those parties. ${ }^{159}$

Choices must also be made about the depth of understanding demanded. Comprehension itself can range from superficial knowledge to profound appreciation. Standards aimed directly at the latter would require each firm to demonstrate that its

159 At first blush, comprehension standards might seem to pose a public-goods problem in that consumers could, in theory, use the education provided by one firm to shop at a firm that has not spent resources on education and thus has lower costs and can offer the product at a lower price. But the same theoretical case can be made about all advertising - an ad for one brand of cigarette likely increases sales of all cigarette brands, for instance. Yet this public-goods effect (or "public-bads" effect, depending on one's view of the product) has not been a death knell for advertising. So long as the information that consumers must understand to meet a comprehension standard is sufficiently specific, any public-goods effect should be no greater than for advertising. Sufficiently specific information might entail, for example, the particular uses to which a consumer's information will be put, rather than the general fact that the information will be used to “'enhance' or 'improve' users' shopping experiences." Federal Trade Commission, What's the Deal? An FTC Study on Mobile Shopping Apps *21 (Aug 2014), archived at http://perma.cc/U2LC-B4DD. 
customers understand what they need to know in order to make autonomous, welfare-enhancing decisions about the transactions they engage in with the firm at the time they engage in them. Firms would also have to demonstrate that their customers can apply this knowledge to their decisions. This requires an understanding of not only product costs and risks but also how those costs and risks are likely to play out for the consumer over time ${ }^{160}$ and how the transaction compares to available alternatives. 161

Such a deep and wide standard would be demanding for firms to meet, but less so than it might first appear. Only those aspects of transactions that are neither well advertised nor of the sort that consumers will themselves discover and account for in repeat purchasing need be part of the standard. ${ }^{162}$ Also, consumers need to know only the effect of product features, not the under-the-hood mechanics. Consumers who know that using a particular cell phone app enables retailers to tailor their prices to the consumers' financial resources do not need to also understand how the technology that facilitates this tailoring works. Furthermore, consumers need to understand only what their own experiences with the product will be. A credit card revolver who is likely to make domestic purchases would thus need to understand only the interest rate applicable to purchases, not the cost associated with foreign transactions; a jet-setting transactor would need to know about foreign-transaction fees, but not the interest rate for revolving debt. Finally, while such rigorous standards could require firms to teach consumers both information and skills, the way in which information is conveyed dramatically affects the skills needed to use that information. Consumers need minimal skills to use a well-constructed energystar rating; consumers need many skills to use a set of technical

160 See Emir Kamenica, Sendhil Mullainathan, and Richard Thaler, Helping Consumers Know Themselves, 101 Am Econ Rev Papers \& Proceedings 417, 417-18 (2011).

161 See John G. Lynch Jr and Wendy Wood, Special Issue Editors' Statement: Helping Consumers Help Themselves, $25 \mathrm{~J}$ Pub Pol \& Mktg 1, 3 (2006) (describing the tremendous importance of choice sets in influencing consumers' ultimate decisions).

162 As a practical matter, we could leave out the benefits of the transaction at issue from performance testing. Firms have market incentives to ensure that consumers understand a product's benefits. See Ayres and Schwartz, 66 Stan L Rev at 574-75 (cited in note 8 ) (suggesting that the terms that the law must ensure consumers are made aware of are only those that "sellers do not emphasize," that "generate low or negative utility for the typical consumer," and that would affect consumer purchasing decisions if consumers knew about the terms). 
energy-use specifications. Comprehension standards hold firms responsible for reaching consumers where they find them, which is where firms sell to them.

At the other end of the spectrum is a shallow, narrow standard requiring bare consumer knowledge of a small number of important product dimensions that consumers tend to underappreciate. The content of such a standard might shift from year to year as consumers learn about some dimensions and forget about others or as product changes render some dimensions less important. ${ }^{163}$ Even superficial comprehension might increase decisional autonomy as compared to the level of comprehension produced today by largely unread mandated disclosures. Moreover, superficial understanding that is cheaply demonstrated among a large proportion of a firm's customers could be correlated with deep understanding by a few customers who might drive the market toward welfare-increasing transactions for all.

Decisions about the content and depth of comprehension to test for with respect to any particular type of transaction will require choices in the face of empirical uncertainty and normative dissensus. Yet disclosure regulation requires the same choices as to which dimensions of a product to disclose and how to disclose that information. In a world of limited bandwidth, choosing which information should be understood and how well depends on judgment, and that judgment must be exercised no matter whether the regulatory scheme employs disclosure rules or comprehension standards. As a first cut, comprehension standards might simply import the content of existing disclosure mandates.

For suitability, three approaches to standard setting are discussed here. The first is a standard that defines the conditions under which particular product features are suitable or unsuitable for a consumer. This parallels the OTC-drug actualuse testing, which examines whether the drug is indicated or contraindicated for the consumers who selected it. ${ }^{164} \mathrm{~A}$ variation

163 See id at 582-85 (suggesting that mandated disclosures ought to cover transaction features of which consumers are unaware and thus ought to change over time to reflect changing consumer knowledge).

164 Sometimes this is described as a separate self-selection study, but at other times it is collapsed into the actual-use study. See Leonard-Segal, et al, $49 \mathrm{~J} \mathrm{Am} \mathrm{Pharmacists}$ Assoc at 671-72 (cited in note 5). 
is to allow firms to publicly define suitable uses, with some regulatory oversight. Firms might have better access to information that would demonstrate which conditions make a product welfare enhancing for consumers, and publicity might be sufficient to ensure that firms account for consumer welfare.

Ultimately, this approach requires regulator judgment about which products or attributes are appropriate for which consumer situations. Sometimes we will lack the societal normative consensus necessary for such judgments. Is using a payday loan to cover an arguably discretionary expense-a honeymoon, for example-a suitable use? The law ought not to engage in such judgments. But even the payday-lending trade associations agree that high-cost short-term lending is appropriate only for individuals who have an infrequent need for cash rather than a chronic shortfall. 165

Winnowing infrequent from chronic cash needs is both empirically and normatively challenging, but design regulation must meet the same challenges. For example, the Dodd-Frank Act's requirement that a lender originate home mortgages only to borrowers who the lender reasonably and in good faith ascertains have the ability to repay the loan ${ }^{166}$ reflects an implicit determination that homeowners should not use mortgages on their principal dwellings to speculate on real-estate prices. Most states that permit payday lending limit loans to $\$ 500$, an implicit determination that payday borrowing is suitable only for small financial needs. ${ }^{167}$ Suitability standards would make explicit the judgment calls that design regulation often leaves implicit.

A second approach would, in effect, apply systems now used ex ante as decision aids to assess suitability ex post. These decision aids range from simple infomediaries like kayak.com, ${ }^{168}$ to choice engines used to help consumers make complex decisions (like choosing an optimal health insurance plan ${ }^{169}$ ), to those that

165 See note 106 and accompanying text.

166 See 15 USC $\$ 1639$ c.

167 See Payday Loans and Deposit Advance Products *9 (CFPB, Apr 24, 2013), archived at http://perma.cc/RAA9.XRBQ.

168 See Thaler and Tucker, 91 Harv Bus Rev at 50-52 (cited in note 113).

169 See Predictive Analytics for Personalized Health Insurance Decision-Making (Picwell, 2014), archived at http://perma.cc/9B6R.7TT8. For an explanation of how such a decision aid could be used alongside state health-insurance exchanges to save consumers 
help consumers engage in affective forecasting and resolve value conflicts so as to make medical-treatment decisions. ${ }^{170}$ They can operate in an individualized manner, eliciting consumer preferences and subjective weightings of those preferences. ${ }^{171}$ In the context of suitability testing, these decision-aid systems would be used diagnostically to determine whether consumers had selected an appropriate transaction, rather than to help consumers select an appropriate transaction. This approach would allow for more heterogeneous preferences and relieves the regulator from ascribing preferences to consumers. However, validating such systems is tricky. ${ }^{172}$

A third possibility is to measure suitability using ex post outcome measures that correspond well with ex ante suitability. A model would be the Gainful Employment Rule, referenced above. ${ }^{173}$ The Rule conditioned a for-profit school's eligibility for federal student-loan funds on its former students' ability to meet specified loan-repayment rates and debt-to-income ratios. Without such a performance requirement, these schools and their student customers had severely misaligned incentives. Students were unable to ex ante determine for themselves whether the education offered was suitable. Schools had profit motives to enroll as many students as possible without necessarily providing students a suitable education. A court invalidated one portion of the Rule but rejected a general challenge to the use of performance standards to assess whether a school was "prepar[ing] its students for gainful employment" as required by the statute. ${ }^{174}$ The court explained that "the adequacy of a program's preparation is difficult to measure-and it is reasonable to consider students' success in the job market as an indication of whether those students were, in fact, adequately prepared." 175

\footnotetext{
billions of dollars a year, see Eric J. Johnson, et al, Can Consumers Make Affordable Care Affordable? The Value of Choice Architecture, 8 PLOS ONE 1, 5 (2013).

170 See generally An Introduction to Patient Decision Aids, 347 Brit Med J 27 (2013).

171 See Peter Ubel, Beyond Comprehension: Figuring Out Whether Decision Aids Improve People's Decisions, in Eldar Shafir, ed, The Behavioral Foundations of Public Policy 351, 354 (Princeton 2012).

172 See Glyn Elwyn, et al, Developing a Quality Criteria Framework for Patient Decision Aids: Online International Delphi Consensus Process, 333 Brit Med J 417, 418-19 (2006).

173 See note 109 and accompanying text.

174 Association of Private Colleges and Universities, 870 F Supp 2d at 149-55. See also 20 USC $\S 1088(\mathrm{~b})(1)(\mathrm{A})(\mathrm{i})$.

175 Association of Private Colleges and Universities, 870 F Supp 2d at 147.
} 
Outcome measures might be particularly cost effective when the firm has an ongoing relationship with the consumer and can alter the outcome directly. For example, payday lenders might meet a suitability standard that limits sustained reborrowing by doing workouts with consumers whose borrowing would otherwise not meet the standard. ${ }^{176}$ The unattractiveness of such workouts would then compel the lenders to ex ante select borrowers who are more likely to be able to repay the loan promptly or restructure the loan-repayment schedule to increase the likelihood of on-time repayment.

b) Benchmarks. In most cases, firm performance will be measured through testing samples of the firm's customers, which in turn will require benchmarks against which to assess compliance. ${ }^{177}$ Complete decisional autonomy would require 100 percent comprehension of the costs, benefits, and risks by 100 percent of consumers. Completely welfare-enhancing transactions would require that 100 percent of transactions be suitable. Lower benchmarks would permit tradeoffs between consumer law's goals and regulatory cost minimization.

Ideally, one would determine the costs and benefits of making the marginal transaction meet the performance standard and set the benchmark where benefits just outweigh costs, ${ }^{178}$ but reasonable forecasts of these costs and benefits will initially be difficult to come by. For costs, the regulator would need to play out each possible firm response-changes in marketing, sales processes, product terms, or consumer choice architecture-as the true cost is only the least expensive of these. Measurement challenges would plague estimates of benefits as well, including not only the benefits of increased consumer autonomy and welfare but also tertiary benefits such as more informed citizens; reduced demands placed on consumers' attention, time,

176 The payday-lenders trade associations recommend such workouts as best practices. See What Is an Extended Payment Plan? (Community Financial Services Association of America), archived at http://perma.cc/3BSQ-9UR8; FiSCA Best Practices (Financial Service Centers of America), archived at http://perma.cc/T5EX-J44L.

177 As explained below, in a few cases, it might be appropriate to test all of a firm's customers, but usually sampling would be used. See notes 190-92 and accompanying text.

178 Not all regulators that would be involved in setting consumer law performance standards are executive agencies subject to the Office of Management and Budget's formal CBA requirements, but most are charged with considering at least some costs and benefits in the rulemaking process. See, for example, 12 USC $\S 5512(\mathrm{~b})(2)(\mathrm{A})(\mathrm{i})$ (charging the CFPB with considering "the potential benefits and costs to consumers and [firms]"). 
and effort in selecting products; increased confidence in the marketplace; and a reduction in regressive cross subsidies from lower- to higher-wealth consumers. ${ }^{179}$ The cost to firms of testing and the cost to regulators of administering the regulation might be quantifiable, but weighing them against the likely benefits would require tradeoffs among incommensurate values.

Three alternatives to CBA-based benchmarks are market structure-based benchmarks, relative-performance-based benchmarks, and lab-based benchmarks.

A market structure-based approach, applicable only to comprehension standards, would ask what proportion of consumers (or segments of consumers) must understand each cost, benefit, and risk so as to tame the market. ${ }^{180}$ Is this a market in which comprehension by 10 percent of consumers can drive all firms to provide all consumers with good products? The answer depends on whether the savvy shoppers have the same needs, preferences, and use patterns as the rest; whether the products are commodities or made to order; and whether firms can distinguish among consumers of varying comprehension levels in a cost-effective manner. ${ }^{181}$ As firms engage in greater segmentation more inexpensively, the proportion of consumers that must comprehend the transaction increases. If it is a market in which it is cost effective for the firm to segment consumers and exploit uninformed market segments until 90 percent of consumers meet comprehension standards, a standard that requires 90 percent of a firm's customers to understand the product makes sense.

Another potential benchmarking system is a comparative one. As compared to customers of other firms selling the same product, is the comprehension level of a given firm's customers and the suitability level of the firm's transactions above or below the median for firms in this market? A market-median benchmark would tend to ratchet up over time, at least to the point at which the costs to firms of meeting the standard exceed the costs

179 For a discussion of how we might correct CBA to account for distributional con. cerns, see Matthew D. Adler, Well-Being and Fair Distribution: Beyond Cost-Benefit Analysis 108-11 (Oxford 2012).

180 Ayres and Schwartz suggest a population benchmark of 50 percent of consumers accurately understanding each attribute tested. Ayres and Schwartz, 66 Stan L Rev at $576 \mathrm{n} 80$ (cited in note 8). While appealing as a democratic sort of standard, the 50 percent number lacks any justification based in autonomy, welfare, or intraconsumer fairness.

181 See Cruz and Hinck, 47 Hastings L J at 672-75 (cited in note 15). 
of not meeting the standard. However, entire markets could be performing so poorly-for example, perhaps only 5 percent of consumers know that they will incur an overdraft fee when they are deciding whether to engage in the transaction that will trigger the fee-and ratcheting up might happen so slowly that relative performance benchmarks will not advance consumer law's goals by much.

A third way to answer the benchmarking question is to demand, at a minimum, something close to what regulators can achieve in the lab. For comprehension, the theory behind such a benchmark would be that otherwise firms have incentives to impair consumer comprehension, rather than enhance it. For example, the CFPB's new mortgage disclosures might be supplemented or replaced with comprehension standards that measure comprehension of the same key mortgage features that the CFPB measured in its consumer testing. Success might be defined as meeting a distribution of comprehension levels in the field comparable to those obtained in the lab. This would be technology forcing because the real world is more distracting than the lab. But given that some of the comprehension levels obtained in the lab are low, ${ }^{182}$ once again these benchmarks might be quite low.

For suitability, the benchmark might be the results that regulators can obtain when they give consumers decision aids ex ante. This approach is analogous to the way in which emissions standards are often selected in practice: regulators determine the emissions levels achievable using the best widely available technology and then set performance standards to reflect those levels. ${ }^{183}$ Here, regulators would determine what the best decision aids can accomplish and would require firms to meet the same level of decision quality. Firms might then employ these or other decision aids in the field, or use other methods-such as choice architecture, targeted marketing, product packaging, or salespeople - to match consumers to the right transactions.

182 See, for example, Loretta Garrison, et al, Designing Evidence-Based Disclosures: A Case Study of Financial Privacy Notices, 46 J Consumer Aff 204, 221-22 (2012) (finding that, in a test of new privacy disclosures developed by regulators as a safe harbor, just over 40 percent of subjects were able to compare information-sharing practices of financial institutions, choose the lower-sharing bank, and give a reason that was an accurate statement about which bank shared less).

183 See Freeman and Farber, 54 Duke L J at 819 (cited in note 70). 
In the end, when marginal costs and benefits cannot be measured well, selecting the right benchmark will not be a precise scientific enterprise. But regulators and courts routinely engage in analogous benchmark setting. In the OTC context, the FDA has rejected OTC applications for drugs with a 24 percent incorrect self-selection rate and accepted applications for drugs with a 5 percent incorrect self-selection rate in actual-use testing, although the agency has provided no rationale for these numbers. ${ }^{184}$ In Lanham Act cases, courts typically require that some amount more than 7.5 percent, but still as low as 15 percent, of surveyed consumers be deceived to prove a falseadvertising claim. ${ }^{185}$

Regulators who employ disclosure and design regulations do not avoid deciding what proportion of the consumer population will comprehend products or use them suitably, although they sometimes avoid explicit examination of these questions. When regulators do attempt to estimate these numbers, their ex ante projections are likely to be poor. Retrospective CBA more often than not demonstrates that earlier cost-benefit projections were far off the mark. ${ }^{186}$ Good projections of costs and benefits are impossible without randomized trial deployment of regulation, and even these studies are valid only to the extent that conditions during the trial are the same as they will be upon market-wide deployment of the regulation. This is unlikely in

184 See R. William Soller, Philip V. Chan, and Christopher Shaheen, OTC Considerations for Expanding Access to Nonprescription Medicines: A Critical Synthesis of Questions from the Food and Drug Administration to Its Advisory Committees on Rx-to-OTC Switch, 2 SelfCare 117, 126-27 (2011). Given that the costs and risks presented by unsuitable use will vary, benchmarks ought to vary correspondingly. See id at 138 (explaining that in OTC-drug preapproval testing the FDA demands greater consumer comprehension of dose limits and contraindications that present more risk).

185 See, for example, Johnson \& Johnson-Merck Consumer Pharmaceuticals, 19 F3d at 134 (using a 7.5 percent benchmark); Novartis Consumer Health, Inc $v$ Johnson \& Johnson-Merck Consumer Pharmaceuticals Co, 290 F3d 578, 594 (3d Cir 2002) (using a 15 percent benchmark).

186 See, for example, James K. Hammit, Are the Costs of Proposed Environmental Regulations Overestimated? Evidence from the CFC Phaseout, 16 Envir Resource Econ 281, 288-93 (2000) (finding that actual costs of banning CFCs were much lower than projected); Winston Harrington, Richard D. Morgenstern, and Peter Nelson, On the Accuracy of Regulatory Cost Estimates, $19 \mathrm{~J}$ Pol Analysis \& Mgmt 297, 306-07 (2000) (retrospectively reviewing the costs of twenty-one Occupational Safety and Health Administration and Environmental Protection Agency rules and finding that prospective CBA significantly overestimated and underestimated costs in seven and nine cases, respectively). 
the consumer space, because firms will respond differently to a market-wide requirement than they will to a trial. For example, firms systematically alter their advertising of medications to omit warnings after they have OTC-sales approval. ${ }^{187}$

Performance standards paired with a requirement that the agency engage in adaptive management by continually monitoring performance-testing results and adjusting performance standards in response is more defensible than traditional disclosure or design regulation on this score. Evidence-based evolution of performance benchmarks means they can be made less arbitrary as new information informs regulators about actual costs and benefits, as these change over time. ${ }^{188}$

c) Testing. Who should conduct performance testing, when should they conduct it, how should they conduct it, and whom should they test? This Section addresses each of these questions in turn.

To ensure integrity and accuracy, performance testing should generally be conducted by third-party, accredited auditors paid for by firms but assigned randomly. Random assignment is necessary to avoid the problems with ratings agencies that surfaced during the mortgage crisis, in which the testing firm is beholden to, and thus biased toward, the firm hiring it. Such randomized auditor assignments are not unprecedented. For example, before 1994, the Federal Housing Authority used a "fee panel" system that assigned appraisers on a rotational basis, ensuring home appraisals free of lender bias. ${ }^{189}$ Beyond ensuring integrity and accuracy, third-party testing and government oversight would protect consumer privacy and prevent firms from using testing data to prey on consumers. Consumers who test poorly might otherwise be targets for higher prices, as consumers who give indicia of being poor price shoppers are today.

187 See notes 280-83 and accompanying text.

188 This suggests that judicial review ought to occur after the deployment of performance-based regulation, when costs and benefits can be better measured. See Jerry L. Mashaw and David L. Harfst, The Struggle for Auto Safety 245 (Harvard 1990) (making a similar suggestion for judicial enforcement review of auto-safety regulations).

189 See J. Kevin Murray, Issues in Appraisal Regulation: The Cracks in the Foundation of the Mortgage Lending Process, 43 Loyola LA L Rev 1301, 1319-20 (2010). 
As for timing and frequency, recall that performance-based consumer law seeks to avoid the bias inherent in complaintdriven enforcement. Therefore, testing should be conducted:

- on a regular, periodic basis (parallel to child product safety testing);

- on a periodic basis that varies with the results of previous performance testing (akin to nuclear power plant safety performance testing); or

- episodically, triggered by objective indicators of poorly understood features or unsuitable transactions (similar to much US food-safety testing).

The particular methodology used for testing can be worked out only contextually, depending on the content of the standard and the practical limits imposed by costs and by the necessity of formulating a valid test. For comprehension, testing will depend on the depth of understanding tested. Facial knowledge might be assayed using a simple true/false or multiple-choice test. Applied understanding might be assessed by analyzing whether objective reasons given by a consumer for a product choice reflect an accurate or inaccurate understanding of the product. Suitability-testing methodology will reflect the performance standard selected. If the standard establishes a set of indications and contraindications for particular transaction features, compliance can be measured using self-reported or third-party data (such as credit reports). For a subjective-utility standard, conjoint analysis or other preference-elicitation techniques would be appropriate. When the standard is based on the performance of a particular product type or feature over time, auditors might examine data that the firm collects for business purposes in its interactions with its customers, such as data on customer repayment history.

In selecting among performance standards and testing methodologies, objectivity, reliability, accuracy, and cost are all important considerations. Overly subjective interpretations by auditors of open-ended customer responses could introduce inconsistencies in treatment both among consumers and among 
firms. ${ }^{190}$ But the use of in-depth consumer-testing methods in the OTC-drug actual-use studies demonstrates that this can be done.

Consumer testing and auditing of firm records for transaction suitability are becoming cheaper and more accurate for many of the same technological reasons that firms are becoming better at sabotaging disclosures and evading design rules. Computer processing and storage costs are going down and the ubiquity of sensors, data collection, and intermediating devices that could be used for consumer testing is increasing. Nonetheless, the deeper the comprehension standard, the more burdensome it is for firms to test and for consumers to be tested. Suitability testing could require expensive, time-consuming, in-depth consumer interviews.

But inexpensive, painless, objective testing of consumer factual knowledge could be surprisingly powerful. During the mortgage bubble, for example, a major problem was that consumers buying mortgages with adjustable monthly payments either did not know the payments would change or did not know how much they would change.191 Comprehension testing for these two facts would not have been difficult, yet it might have helped consumers steer clear of unaffordable mortgages-and it almost certainly would have been more efficacious than the new mortgage disclosure forms the CFPB has developed. ${ }^{192}$

Further, sufficient information to make valid inferences will often be possible with small random or stratified (to capture subpopulations ${ }^{193}$ ) samples of consumers. An alternative would be to test only the most-vulnerable customers; if they

190 See Ho, 122 Yale $\mathrm{L} J$ at $638-42$ (cited in note 88) (attributing inconsistent restaurant sanitation grades in New York City to, for example, inspector variation in the application of subjective standards).

191 See Lauren E. Willis, Will the Mortgage Market Correct? How Households and Communities Would Fare If Risk Were Priced Well, 41 Conn L Rev 1177, 1241-45 (2009).

192 As previously explained, these disclosures have a small salutary effect in the lab-an effect that is likely to disappear once the stressors and distractors of real life are added. See note 97 and accompanying text.

193 See, for example, Leonard-Segal, et al, $49 \mathrm{~J} \mathrm{Am} \mathrm{Pharmacists} \mathrm{Assoc} \mathrm{at} 671$ (cited in note 5) (suggesting that actual-use OTC-drug-sales tests should include "a low literacy cohort as determined by a validated literacy testing instrument such as the REALM (Rapid Estimate of Adult Literacy in Medicine) test”). 
comprehend a product and use it suitably, less-vulnerable populations likely will as well. ${ }^{194}$

Testing is likely to annoy consumers. However, the fact that consumers accept having to click through computer software warning screens and terms of service on websites before getting on with their lives is some evidence that over time consumers will accept testing as incidental to a well-regulated marketplace. When samples or subpopulations are tested, firms might financially compensate them for their efforts, thus distributing the cost more evenly across the firm's customer pool. Firms will also pass their own testing costs on to consumers in the form of higher prices. However, recall that one of the underlying problems that performance-based consumer law seeks to address is regressive cross subsidization. Performance-based regulation ought to redistribute from, for example, consumers who receive free checking to those who currently pay overdraft fees, even if the result is an increase in across-the-board monthly account fees. Thus, any consideration of costs must be tempered by the welfare benefits of redistribution from higher-to lower-wealth consumers. ${ }^{195}$

The costs to regulators of enforcing performance-based consumer law and actively engaging in adaptive management to improve that law's performance would be high. ${ }^{196}$ Firms would pay for performance testing of consumers and transactions in most cases, and so the lab-based disclosure testing that regulators currently perform could be jettisoned (except when lab testing is used to set benchmarks). But performance-based consumer law would require regulators to continuously monitor the performance of the testing-perhaps by means of random audits of firm records and in-depth interviews of consumers-to ensure that third-party audits of firms accurately reflect customer comprehension and transaction suitability. The additional costs imposed on regulators by performance-based consumer law, including monitoring third-party auditors and engaging in enforcement actions, are likely higher than the

194 This alternative echoes the unsophisticated-consumer test used in some areas of consumer law. See note 14.

195 See Adler, Well Being and Fair Distribution at 114-19 (cited in note 179).

196 See Holly Doremus, et al, Making Good Use of Adaptive Management *5-6 (Center for Progressive Reform, Apr 2011), archived at http://perma.cc/C5LV-AFSV (discussing the cost of adaptive environmental regulation). 
costs of developing and enforcing disclosure or design rules. The premise of this Article is that the benefits of more-efficacious regulation would likely outweigh these costs in many instances.

\section{Enforcement levers.}

Various levers could be used to enforce performance-based consumer law. The mildest would be to institutionalize periodic, field-based performance testing as a regulatory tool for determining which firms, products, and product features to investigate for UDAAP violations. Consumer law regulators use performance measures to focus their examination and enforcement resources today, although the measures used vary in how systematically they capture performance. For example, regulators use bank Home Mortgage Disclosure Act data, examining application and denial rates and the sales rates of higher-priced mortgages by race, sex, and census tract, to single out relatively weak performers for further Equal Credit Opportunity Act and Fair Housing Act scrutiny. ${ }^{197}$ The FTC and the CFPB both have complaints databases that the agencies use to identify patterns among products or firms that suggest UDAAP violations. ${ }^{198}$ The results of comprehension and suitability performance testing could provide an indicator that is both more reliable and fairer than consumer complaints, which, as noted, are biased toward the problems of higher-socioeconomic-status consumers. Knowing that this testing would be used this way would give firms an incentive to achieve high performance levels.

In contrast, the most demanding enforcement mechanism would be transaction-related consequences. For comprehension performance standards, meeting the standard could be a precondition for enforcing a tested contract term, collecting a tested fee, or retaining a tested type of personal data. When comprehension testing of all relevant customers is feasible, an elegant enforcement mechanism would be for the enforceability of each

197 See Office of the Comptroller of the Currency, et al, Interagency Fair Lending Examination Procedures (Aug 2009), in Consumer Financial Protection Bureau, CFPB Supervision and Examination Manual *237, 250-53, 268-69, 271 (Oct 1, 2012), archived at http://perma.cc/YD7Y-WNNY.

198 For an overview of the FTC's complaint database, see The FTC's Consumer Sentinel Network (FTC), archived at http://perma.cc/993P-8ANF. For an explanation of how complaint data are used by the CFPB, see How We Use Complaint Data (CFPB), archived at http://perma.cc/D4HW-TFEW. 
term to hinge on how the individual consumer comprehends that term. So, for example, a firm could be required to demonstrate that a consumer comprehended a back-end fee, a forum-selection clause, or a personal-data collection practice at the time of contracting as a precondition for imposing that fee, demanding the use of that forum, or collecting those data.

Testing a sample of a firm's customer population permits a coarser enforcement system. An exclusionary rule of sorts could prevent firms from benefiting from a term contained in any transaction consummated prior to the date on which the firm demonstrates that the benchmark proportion of its customers comprehend the term. Firms would then be required to periodically reaffirm consumer comprehension of a term, perhaps annually for those terms that barely meet the benchmark and less frequently for terms that beat the benchmark. ${ }^{199}$

A similar enforcement mechanism for a suitability standard would be to prohibit a firm from taking payments from a consumer until the firm demonstrates that the transaction is suitable for the consumer, akin to a contingency fee. Such a pay-forperformance rule would be useful when firms are better equipped than consumers to determine ex ante whether the transaction is likely to provide benefits to the consumer. For example, firms selling debt-settlement services have far better information than consumers about the value (if any ${ }^{200}$ ) of what they are selling. A suitability requirement might require debtsettlement firms to demonstrate that a consumer has improved her financial position-net of the firm's fees and taxes related to the settlements-with respect to the debt she started with, before collecting any fee.

A third potential enforcement scheme would be a freestanding obligation for firms to demonstrate through testing samples of their customers either that their customer population meets

199 See Reactor Oversight Process ${ }^{*} 6$ (US Nuclear Regulatory Commission, Dec 2006), archived at http://perma.cc/K65U-CXYR (explaining that all but the most severe nuclear power plant safety-performance-standard violations are enforced this way, and that the extent to which a plant meets performance standards determines the frequency with which it will face reinspections in the eighteen months following the initial inspection).

200 The industry is rife with programs that do not appear to benefit consumers. See Rachel Abrams and Jessica Silver-Greenberg, Companies That Offer Help with Student Loans Are Often Predatory, Officials Say (NY Times, July 13, 2014), archived at http://perma.cc/7BDL-6SC7. 
the comprehension performance benchmark or that their transactions with those customers meet the suitability performance benchmark. Failure to meet one of the benchmarks could constitute prima facie or even conclusive evidence of a UDAAP violation. The virtue of such strong sanctions would be that the enforcement apparatuses for UDAAP violations already exist. However, this system would give firms no incentive to outperform the benchmark. ${ }^{201}$ It would be better to incrementally tax firms for failing to meet the benchmarks and incrementally reward firms for exceeding the benchmarks. ${ }^{202}$ Taxes might take the form of fines; rewards might include lengthening the interval before the firm's next performance test. ${ }^{203}$

\section{Exemptions.}

Compliance with performance-based consumer law could be costly for firms. While firms can effectively lower their own performance bar by redesigning their products to make them easier to understand and more likely to be selected and used suitably, the burden on small- and even medium-sized firms might in some cases outweigh the benefits of performance-based regulation. ${ }^{204}$ Firms with fewer transactions will need to have a larger proportion of their customers tested to ensure representative sampling. In these situations, the regulator ought to pay for the testing or exempt smaller businesses from performance standards, just as small-scale polluters are sometimes exempted from emissions standards. ${ }^{205}$ As discussed further below, information

201 See Freeman and Farber, 54 Duke L J at 815 (cited in note 70) (discussing how cap and trade aims to solve this issue in the emissions context).

202 In practice, this appears to be what occurs in the pollution context. See 42 USC $\S 7524(\mathrm{~b})$, (c)(2) (mandating that civil liability and penalties for the vehicle and engine requirements of Title II of the Clean Air Act take into account the gravity of the violation); Clean Air Act Mobile Source Civil Penalty Policy-Title II of the Clean Air Act, Vehicle and Engine Emissions Certification Requirements *11-12 (EPA, Jan 2009), archived at http://perma.cc/PSJ2-CD9X (defining "gravity" to include the amount of excess emissions).

203 If the taxes and rewards are set correctly, this scheme would carry efficiency benefits as well. See Louis Kaplow and Steven Shavell, On the Superiority of Corrective Taxes to Quantity Regulation, 4 Am L \& Econ Rev 1, 6 (2002).

204 See Ayres and Schwartz, 66 Stan L Rev at 581-82 (cited in note 8) (limiting their proposal for requiring firms to test consumer comprehension to "mass-market" sellers, which they define as having more than five hundred employees or more than $\$ 20$ million in annual retail sales).

205 See, for example, Ohio Rev Code Ann § 3704.03(T)(4) (exempting smaller emission sources-those producing fewer than ten tons per year of emissions-from "best 
gleaned from the performance testing of other firms offering similar products can nonetheless inform the adjustments that the regulator makes to other regulations, such as disclosure and product-design rules. Large firms could thus serve as experimental labs to improve the regulation of all firms.

\section{Experimentation.}

As a precursor to wholesale adoption of performance-based consumer law, comprehension or suitability requirements could be used remedially in settlement contracts or court orders. Remedial injunctions and consent decrees often contain analogous performance benchmarks. ${ }^{206} \mathrm{~A}$ series of remedial orders would build on the experience of the Hawaiian Punch case to help regulators determine how best to make the performance-based consumer law paradigm work.

Meeting a comprehension performance target is a particularly apt remedy for deception and meeting a suitability target is an equally apt remedy for unfair or abusive practices. For example, the FTC recently found that a national retailer had deceived consumers when it loaded tracking software on consumers' computers and hid the depth to which the tracking would go on the seventy-fifth line of a scroll-down disclosure. ${ }^{207}$ The case was resolved by means of a consent decree containing precise time and manner rules for how the retailer must disclose the information in the future. ${ }^{208} \mathrm{~A}$ more effective decree would have required the retailer to demonstrate, through third-party random-sample testing of its users, that users generally

available technology" emission-reduction requirements under the Ohio State Implementation Plan of the federal Clean Air Act).

206 See, for example, Swann v Charlotte-Mecklenburg Board of Education, 402 US 1, 22-31 (1971) (upholding specified racial-integration benchmarks ordered by the district court in the form of an equitable remedy); Brown v Plata, 131 S Ct 1910, 1944-45 (2011) (upholding a district court order giving California two years to meet a performance benchmark for its inmate population density of 137.5 percent of prison design capacity); Stipulation and Order of Settlement and Dismissal, United States $v$ Westchester County, New York, Civil Action No 06-2860, *6 (SDNY filed Aug 10, 2009) (ordering the defendant county to "within seven (7) years of the entry of this Stipulation and Order, ensure the development of at least seven hundred fifty (750) new affordable housing units").

207 Complaint, In the Matter of Sears Holdings Management Corp, FTC Docket No C-4264, *2-4 (FTC filed Aug 31, 2009) (available on Westlaw at 2009 WL 2979770).

208 Decision and Order, In the Matter of Sears Holdings Management Corp, FTC Docket No C-4264, *3-5 (FTC filed Aug 31, 2009) (available on Westlaw at 2009 WL 2979770). 
understood what the retailer was collecting from them and how the retailer could use that information. The retailer would then have been both required and empowered to determine the best way to inform its customers-perhaps by showing them a short video clip or animation, by requiring them to pass a quiz as a condition of activating the software, or perhaps by using different methods to reach different types of consumers. Such a performance standard would have given the retailer an interest in ensuring that its consumers were well informed, rather than an interest in foiling the consumer comprehension to which the FTC's disclosure time and manner requirements aspire.

Another example comes from the CFPB, which resolved charges of unfairness, deception, and abuse with a decree requiring a payday lender to stop pressuring consumers to reborrow rather than pay off their loans. ${ }^{209} \mathrm{~A}$ surer cure would have been to require the lender to demonstrate, through third-party examination of its records, that consumers were not reborrowing at a high rate. The lender could then have met the benchmark by, for example, engaging in workouts with borrowers who were having difficulty with repayment, restricting its lending to borrowers who presented evidence that they would be able to repay the loans when they came due, or requiring repayment according to an installment schedule that closely tracked what the borrower would likely be able to repay. ${ }^{210}$

As with any new regulatory method, there are bound to be snags in operation. Studying the implementation of performancebased consent decrees would help regulators foresee and thus forestall such snags.

\section{Applications}

This Section fleshes out more specifically how performancebased regulation might work in a few exemplar contexts. The

209 Consent Order, In the Matter of ACE Cash Express, Inc, File No 2014-CFPB0008, *11-15 (CFPB filed July 10, 2014) (available on Westlaw at 2014 WL 4472891).

210 Analysis of borrower surveys and data from loan performance in Colorado, which requires lenders to allow borrowers to repay small-dollar loans with small, affordable payments on a fully amortizing installment schedule, demonstrates that "monthly loan payments exceeding 5 percent of a borrower's individual gross monthly income are unaffordable." Payday Lending in America: Policy Solutions *4 (The Pew Charitable Trusts, Oct 2013), archived at http://perma.cc/QM4L-F8U9. See also generally Trial, Error, and Success in Colorado's Payday Lending Reforms (The Pew Charitable Trusts, Dec 2014), archived at http://perma.cc/TE4Y-YDYE. 
descriptions below are not intended to be blueprints but rather starting points to begin the discussion about how to apply performance-based regulation to consumer transactions.

\section{Personal-data collection and use.}

The marketplace currently does not ensure that the interests of consumers and firms are well aligned when it comes to firms' collection and use of personally identifiable consumer information. Firms successfully shroud data collection to keep it nonsalient, if not invisible. ${ }^{211}$ Privacy competition is limited, both because consumers cannot winnow false from accurate claims about privacy protection ${ }^{212}$ and because telling consumers that their privacy is being protected heightens their privacy concerns $^{213}$ - a state of mind rarely conducive to business. Decisional autonomy is absent here; apart from a few high-profile types of collection and use, ${ }^{214}$ consumers are largely clueless about what information is collected about them, by whom, and how it is used. ${ }^{215}$ Privacy-control interfaces are so difficult to use that even consumers who try to control what information is shared about them usually fail. ${ }^{216}$ Consumer law's goal of maximizing

211 See, for example, Jeremy Singer-Vine, How Dataium Watches You (Wall St J, Dec 7, 2012), archived at http://perma.cc/JP3Q-QKVU (describing the remarkable lengths to which one firm goes to conceal its tracking code, which logs which pages of websites a consumer views, "what parts of the page were clicked, which dropdown options were selected, and what information (such as name, email address, and phone number) [was] entered in [] forms").

212 See Lauren E. Willis, Why Not Privacy by Default?, 29 Berkeley Tech L J 61, 128-29 (2014); Joseph Bonneau and Sören Preibusch, The Privacy Jungle: On the Market for Data Protection in Social Networks *29-33 (Workshop on the Economics of Information Security, 2009), archived at http://perma.cc/6AH4-FZUH (surveying the privacy practices and policies of forty-five social networking sites, finding a broken market for privacy, and postulating that the optimal policy for social networking sites involves making minimal references to privacy and even obfuscating the language in privacy policies so that sites need not compete on privacy).

213 See Leslie K. John, Alessandro Acquisti, and George Loewenstein, Strangers on a Plane: Context-Dependent Willingness to Divulge Sensitive Information, $37 \mathrm{~J}$ Consumer Rsrch 858, 859-60 (2011).

214 See, for example, Ayres and Schwartz, 66 Stan L Rev at 600 (cited in note 8).

215 See Joseph Turow, et al, The Federal Trade Commission and Consumer Privacy in the Coming Decade, 3 I/S: J L \& Pol Info Socy 723, 732-33 (2007-2008) (summarizing research showing that "[c]onsumers [m] isunderstand [o]nline [d]ata [c]ollection").

216 See generally Michelle Madejski, Maritza Johnson, and Steven M. Bellovin, A Study of Privacy Setting Errors in an Online Social Network *5 (PERCOM Workshops, Oct 2012), archived at http://perma.cc/3RUX-C272 (reporting findings demonstrating 
consumer welfare is probably also not being met. It is possible that what is good for Google is good for consumers, but without market forces or regulation ensuring this alignment of interests, there is no reason to believe that it exists.

Suitability standards may not make sense here, for two reasons. First, privacy is an arena in which consumers may have very heterogeneous preferences. ${ }^{217}$ Second, even if information privacy preferences are not very heterogeneous, ${ }^{218}$ privacy remains an arena without political consensus on what information ought to be collected by whom and for what purposes. Thus, at this moment in our society's understanding of privacy, comprehension standards should be used. ${ }^{219}$

a) Legal authority. The Privacy Bill of Rights, should it become law, would be an excellent starting point for comprehension standards. This document declares that consumers have the rights to: (a) "easily understandable and accessible information about privacy ... practices," and (b) "control over what personal data companies collect from them and how they use it." 220 Firms have correlative duties: (a) to explain what data they collect and how they use it "[a]t times and in places that are most useful to enabling consumers to gain a meaningful understanding of privacy risks and the ability to exercise [personal control],"and (b) to "offer consumers clear and simple choices, presented at times and in ways that enable consumers to make meaningful

that social media-website users who adjust privacy settings do not successfully limit in formation sharing in the manner that they intend).

217 See generally Ponnurangam Kumaraguru and Lorrie Faith Cranor, Privacy Indexes: A Survey of Westin's Studies (Carnegie Mellon Institute for Software Research International, 2005), archived at http://perma.cc/B3NW-R2AA (summarizing the work of Alan Westin, who conducted over thirty surveys regarding privacy between 1978 and 2004 and found considerable variation in privacy preferences).

218 See, for example, Jeff Fox, 85\% of Online Consumers Oppose Internet Ad Tracking, Consumer Reports Finds (Consumer Reports, May 27, 2014), archived at http://perma.cc/DX5U.VSWX (finding that most consumers oppose having their online activities tracked for advertising purposes); Turow, et al, 3 I/S: J L \& Pol Info Socy at 729 (cited in note 215) (finding that "[c]onsumers [c]are [d]eeply about [p]rivacy").

219 On the other hand, if sufficient numbers of consumers share information, other consumers may be forced to do so as well, regardless of their preferences. See Scott R. Peppet, Unraveling Privacy: The Personal Prospectus and the Threat of a Full-Disclosure Future, $105 \mathrm{Nw}$ U L Rev 1153, 1157-58 (2011). These third-party effects might require suitability or design regulation of practices regarding consumer-data collection and use.

220 Consumer Data Privacy in a Networked World: A Framework for Protecting Privacy and Promoting Innovation in the Global Digital Economy *47 (The White House, Feb 2012), archived at http://perma.cc/CR88-X8VT (propounding a "Consumer Privacy Bill of Rights" designed to guide legislative and agency action). 
decisions about personal data collection, use, and disclosure."221 Consumer comprehension is indispensable to making these rights and duties a reality.

Although new authority would be optimal, existing UDAAP law discussed above provides some support for comprehension requirements. ${ }^{222}$ More-specific authority exists in two contexts. First, regulations implemented under the Children's Online Privacy Protection Act of $1998^{223}$ (COPPA) require that websites used by children give parents a description of the website's data collection and usage practices in a notice that is "clearly and understandably written" and "prominent" 224 so that parents can exercise their rights to decide whether to permit the websites to collect their children's data. To date, the FTC has sought to ensure that these standards are met through prescriptive rules about the placement, typeface, and language of the notices. ${ }^{225}$ These disclosure design rules have been ineffectual; firms can easily distract consumers from the disclosures even when they are designed as directed. ${ }^{226}$

The FTC likely has authority to put comprehension performance standards in place that would potentially be more effective at ensuring that parents understand their rights. COPPA directs the FTC to promulgate regulations to ensure that websites "provide notice" of what information they collect from children and how they use it and "obtain verifiable parental consent" for this collection and use. ${ }^{227}$ Comprehension testing could assess whether parents have received notice and have consented

221 Id.

222 Most commercial collection of consumer data is governed primarily by UDAAP law. See Daniel J. Solove and Woodrow Hartzog, The FTC and the New Common Law of Privacy, 114 Colum L Rev 583, 585-86 (2014).

223 Pub L No 105-277, 112 Stat 2681-728, codified at 15 USC $\S 6501$ et seq.

22416 CFR $\$ 312.4$.

225 See The Children's Online Privacy Protection Rule: A Six-Step Compliance Plan for Your Business *3 (FTC, 2013), archived at http://perma.cc/77F8-2BP5 ("Make those links clear and prominent. Consider using a larger font or a different color type on a contrasting background."); id ("To comply with COPPA, your privacy policy should be clear and easy to read. Don't add any unrelated or confusing information.").

226 See Joseph Turow, Privacy Policies on Children's Websites: Do They Play by the Rules? *12 (Annenberg Public Policy Center, 2001), archived at http://perma.cc/7DM E-DDFV (showing how children's websites follow the regulations about the placement of privacy-policy links yet are able to surround the links with distracters or otherwise reduce the links' visibility).

22715 USC $\S 6502(\mathrm{~b})(1)(\mathrm{A})(\mathrm{i})-(\mathrm{ii})$. 
to the information collection and use to which they think they have consented.

Second, the Gramm-Leach-Bliley Act 228 (GLBA) requires financial institutions to provide consumers with "clear and conspicuous" disclosures about data collection and use, as further specified by regulation. ${ }^{229}$ The GLBA requires the federal banking regulators to develop a safe harbor model form that "(A) [is] comprehensible to consumers ...; (B) provide[s] for clear and conspicuous disclosures; [and] (C) enable[s] consumers easily to identify the sharing practices of a financial institution and to compare privacy practices among financial institutions." ${ }^{230}$ However, the model form that the regulators have developed performs poorly: even in the lab, only 40 percent of consumers understand these disclosures at even a basic level. ${ }^{231}$ Given that regulators have been unable to develop a form that meets the requirements of the statute, regulators ought to promulgate and enforce comprehension performance standards instead.

b) Comprehension standards. To make informed, autonomous choices about transactions in which their (or their children's) personal data are obtained by firms, consumers need to know what information is being collected and how firms will use it. This knowledge must be fairly concrete-a consumer cannot make an informed decision about sharing based on a vague admonition that a firm may collect information about consumers to improve its services.232 Testing for every possible use, however, might prove unwieldy, and some uses might be so universally desired that comprehension is unnecessary. For example, consumers probably do not need to know that their information is used to complete their online transactions. However, consumers are likely to have varying preferences about the use of their

228 Pub L No 106-102, 113 Stat 1338 (1999), codified in various sections of Titles 12 and 15 .

22915 USC $\S 6803(\mathrm{e})(2)(\mathrm{B})$.

23015 USC $\S 6803(\mathrm{e})(2)(\mathrm{A})-(\mathrm{C})$.

231 See Garrison, et al, $46 \mathrm{~J}$ Consumer Aff at 221-22 (cited in note 182) (finding that only about 40 percent of consumer subjects tested were able to accurately compare different information-sharing practices of two institutions using the model forms).

232 See Dieter Bohn, UK and Germany Join France in Demanding Google Rewrite Its Privacy Policy (The Verge, July 6, 2013), archived at http://perma.cc/YZ5T-H9KG (reporting that EU countries have found Google's privacy policy "too vague" for users to understand how their data will be used). 
personal information for targeted advertising or "price optimization" ${ }^{233}$ (that is, price discrimination) purposes.

Knowing what data firms collect and how they use it is not enough for fully informed decisions. Consumers must also understand attendant costs, risks, and benefits. ${ }^{234}$ But these are contested and experienced differently by different consumers. ${ }^{235}$ Testing for comprehension of these personalized costs and risks could require psychological inquiries not amenable to objective, affordable, noninvasive testing mechanisms. Thus, the inquiry should be limited to bare, objective facts about collection and use. This approach accords with current disclosure requirements. For example, California law requires websites and online services to disclose only: (1) "the categories of personally identifiable information that the operator collects ... about individual consumers," (2) "the categories of third-party persons or entities with whom the operator may share that personally identifiable information," and (3) "whether other parties may collect personally identifiable information about an individual consumer's online activities over time and across different Web sites when a consumer uses the operator's Web site or service."236

Firms could meet a performance standard for personal-data collection and use in creative ways that extend well beyond the dry, textual disclosures currently mandated by California law. Cartoons, infographics, personalized messages, and the like are bound to educate more consumers more effectively.

c) Testing and enforcement. Given that only factual knowledge would be tested, online machine-graded tests could be used. To ensure impartiality, testing should be performed by the government or independent third parties. Prior to collecting personal data, a firm would need to disclose to the testing entity what data it collects and how it will use that data. The firm

233 See text accompanying note 25 .

234 Knowledge also is not enough, because decisionmaking biases are endemic to the privacy arena. See Willis, 29 Berkeley Tech L J at 74-77 (cited in note 212) (surveying biases that commonly influence privacy decisions).

235 For examples of how consumers experience the effects of data collection differently, see Lior Jacob Strahilevitz, Toward a Positive Theory of Privacy Law, 126 Harv L Rev 2010, 2021-22 (2013).

$236 \mathrm{Cal}$ Bus \& Prof Code $\S 22575(\mathrm{~b})(1)$, (b)(6). California law requires websites to "conspicuously post" these disclosures; posts that use large fonts, capital letters, or contrasting colors and posts that include a link to the privacy policy on the homepage are both examples of ways that companies can satisfy this requirement. See Cal Bus \& Prof Code § 22577(a)-(b). 
would then need to give the testing entity access to consumers before collecting the data.

Firms could motivate consumers to perform well on the test by preventing uninformed consumers from engaging in certain transactions with the firm or from obtaining access to web content, "free" apps, or other benefits for which the consumer would otherwise pay with personal data. Alternatively, firms could charge noncomprehending consumers a monetary fee for this access. Such actions by firms would prevent savvy consumers from feigning ignorance so as to avoid data collection while continuing to obtain (now truly) free benefits that other consumers would be paying for with their personal data.

Other aspects of testing depend on the desired enforcement mechanism. To limit firms to collecting from each consumer only the data that the consumer demonstrably understands is being collected and only for the purposes that the consumer demonstrably understands, testing for knowledge of every type of data collected and every use would have to be conducted on every consumer (or parent).237 This would be costly, particularly for consumers. Firms often collect a large number of types of information for a large number of uses. Thus, a lengthy test would be needed unless the testing requirement deterred firms from collecting many data types or engaging in many types of uses.

If samples of consumers were tested, each might be asked three or four questions randomly drawn from the complete list of questions about the firm's data collection and use. Sampling would dramatically reduce testing costs but would foreclose a tailored enforcement mechanism. Instead, a cruder penalty would need to be imposed, such as not allowing firms to collect information until a specified proportion of consumers accurately answered questions about the firm's collection and use of that specific information. Firms might be required to periodically revalidate consumer comprehension.

It is not obvious what proportion of sampled consumers ought to understand a firm's data collection and use practices to validate these practices. Using CBA to set the benchmark is problematic because the direct benefit of consumer comprehension is

237 The only exception would be for personally identifiable data that are used to identify each consumer's testing results and guide the firm's subsequent treatment of the consumer's data. 
an increase in decisional autonomy, which is not quantifiable. Consumer knowledge here would facilitate privacy-based consumer choices about doing business with firms, but the value of facilitating these choices is not measurable. The cost of testingboth the cost to firms paying third parties to test and the cost to consumers in time spent answering questions - can probably be estimated well, but the cost to firms of educating consumers to the point at which they can pass the test probably cannot be estimated. ${ }^{238}$

d) Dynamic effects. The secondary, dynamic effects of consumer privacy-comprehension standards are likely to be several. First, consumer comprehension might solve part of the market-failure problem: firms would stop collecting personally identifiable data and eliminate uses of that data when consumers do not receive sufficient value in exchange.239 Consumer comprehension would facilitate firm competition over privacy practices (rather than privacy image).

Second, firms might limit the number of types of information and uses in which they engage-in effect, simplifying the consumer's decision problem-so as to increase the likelihood that consumers would pass the test. Lower collection levels would have positive effects on data security and identity theft.

Third, consumer comprehension testing would force firms to decide how they will use their customers' information prior to collecting it. Tying firms' hands could prevent innovative usesalthough if the new uses truly enhance consumer welfare, then firms might educate old customers about these new uses.

Finally, educating consumers about what is happening with their data might spark deeper thinking about the substantive privacy rules that consumers would like to govern their data and perhaps motivate and empower them to address the issue in the democratic process. Performance-based regulation might thus be a bridge to thoughtful substantive regulation.

238 To the extent that ignorance is bliss and knowing that one's data are being collected and used creates a negative feeling of being subjected to the Panopticon, increased knowledge itself might be a cost borne by consumers. But the cost of knowledge is one inherent in consumer decisional autonomy. See notes 156-57 and accompanying text.

239 See Mary Graham, Regulation by Shaming, The Atlantic Monthly 36, 38 (Apr 2000) (explaining how the Toxic Release Inventory shamed companies into reducing their toxic releases); Craswell, 88 Wash L Rev at 334 (cited in note 88) (calling disclosures that produce such responses from firms "dynamic" disclosures). 
2. Consumer credit products: overdraft.

The sale of consumer credit products is another area in which the interests of firms and consumers are poorly aligned. Financial products can be designed in such a multitude of complex and shifting ways that it is easy for firms to shroud costs. At times, the price of the product is clear but the relative prices of alternatives are not. Some fees are avoidable in theory but are structured to be undetected at the moment they are incurred. Other price components depend on risks that are easier for firms than for consumers to predict. Simple illiteracy and innumeracy limit many consumers' abilities to assess the costs or benefits of financial products well. Finally, financial desperation and concomitant limited cognitive-willpower bandwidth can prevent well-considered decisionmaking.

One product that has drawn particular concern is debit card overdraft. An overdraft is, in effect, a high-cost, small-dollar, short-term loan. It occurs when a checking account holder withdraws more from her checking account than is available and the bank, for a fee, covers the withdrawal with its own funds. Some prepaid debit cards also permit consumers to overdraft, for a fee. ${ }^{240}$ In a large data set analyzed by the CFPB, the median amount that led to an overdraft charge and the typical length of time before the account holder came current for overdrafts occasioned by debit card use were $\$ 24$ and three days, respectively; ${ }^{241}$ during the same period, the median fee was $\$ 34.242$ These numbers imply an APR of over 17,000 percent. ${ }^{243}$ The law treats overdraft as a discretionary service rather than as a loan, and so banks are not required to disclose the APR (nor would it be easy for them to do so, given the complexity of their fee structures and the variability in the timing of repayment). ${ }^{244}$ Checking

240 See Consumers Continue at ${ }^{*} 9-10$ (cited in note 62 ). On prepaid debit cards, overdraft is called "shortage." See Analysis of Reloadable Prepaid Cards in an Environment of Rising Consumer Banking Fees *16-17 (Bretton Woods, Mar 2011), archived at http://perma.cc/29D4-FTR3.

241 See Data Point: Checking Account Overdraft *5 (CFPB, 2014), archived at http://perma.cc/5A3Y-MKYR.

242 See CFPB Study of Overdraft Programs: $A$ White Paper of Initial Data Findings *52 \& n mmm (CFPB, June 2013), archived at http://perma.cc/ZNJ7-TV2E

243 This figure was derived using an APR calculator. For an APR calculator, see Overdraft APR Calculator (CSGNetwork.com), archived at http://perma.cc/KN54-NWDF.

244 See Willis, $80 \mathrm{U}$ Chi L Rev at 1176, 1182 (cited in note 22). 
account overdraft fees amounted to $\$ 32$ billion in 2012 , or 61 percent of checking account-fee revenues. ${ }^{245}$

The current law on checking account overdraft consists of an ineffective nudge paired with a disclosure. Banks cannot charge account holders overdraft fees on automated teller machines (ATMs) or nonrecurring debit transactions unless the account holder affirmatively opts out of the default and opts in to the overdraft service. ${ }^{246}$ Consumers need to opt out only once; after that, the overdraft product becomes a part of the account. No law targets prepaid-debit card overdrafts; these must be disclosed as any other fee in the fine print that is incident to the card. ${ }^{247}$

Empirical evidence about overdraft transactions indicates that none of the goals of consumer law-decisional autonomy, consumer welfare, and distributional fairness-is being met. Overdraft fees are disproportionately paid by poorer account holders and subsidize free checking for wealthier account holders. ${ }^{248}$ Over half of all consumers incurring overdraft fees do not believe that they opted out of the default and into the service. ${ }^{249}$ Most consumers overdraw their accounts unintentionally and many do not realize it until they receive their account statements. ${ }^{250}$ Those consumers who believe they have opted into the service hold serious misconceptions; most consumers erroneously believe that the service prevents them from bouncing checks and that without it, they could incur declined-debit card fees. ${ }^{251}$ Finally, a majority of overdrafts appear to be incurred by consumers who, at the time of the overdraft-incurring transaction, either have cash sitting in another liquid account or could have tapped a credit card cash advance several orders of magnitude

245 See Carter Dougherty, Consumers Using Overdraft Coverage Risk Fees, U.S. Says (Bloomberg, June 10, 2013), archived at http://perma.cc/73LR-LKRJ.

246 The opt-in and disclosure requirements do not apply to prepaid debit card overdraft.

247 See Analysis of Reloadable Prepaid Cards at *17 (cited in note 240) ("A majority of [prepaid debit card issuers] do not disclose shortage fees, except to refer to 'applicable fees."').

248 See Willis, 80 U Chi L Rev at 1178, 1184-85 (cited in note 22).

249 See Overdrawn: Persistent Confusion and Concern about Bank Overdraft Practices *5 (The Pew Charitable Trusts, June 2014), archived at http://perma.cc/AL2Q-ACBB.

250 See id at *9 (finding that reading an account statement was the most common way that consumers discovered that they had overdrawn their accounts, with about onethird learning of the overdraft this way).

251 See Willis, 80 U Chi L Rev at 1188-89 (cited in note 22). 
cheaper than overdraft.252 Even for those consumers who do not have a cheaper means of payment readily available, overdrafts are frequently charged on discretionary purchases. It is inconceivable that many consumers, particularly low-income consumers, would knowingly and routinely choose to pay a $\$ 34$ fee on a $\$ 24$ purchase instead of waiting three days. ${ }^{253}$ A majority of consumers who have had transactions declined, a majority of those who have been charged overdrafts, and even a majority who knowingly opted into the overdraft service say that they would prefer that their debit card transactions be declined rather than incur an overdraft fee. ${ }^{254}$

a) Legal authority.255 The Dodd-Frank Act gives the CFPB authority to establish comprehension and suitability standards for consumer financial products, including overdraft. The CFPB's statutory objectives include ensuring that: (1) "consumers are provided with timely and understandable information to make responsible decisions about financial transactions"; (2) "consumers are protected from unfair, deceptive, or abusive acts and practices and from discrimination"; and (3) "markets for consumer financial products and services operate transparently and efficiently to facilitate access and innovation." 256

Performance-based regulation could go a long way toward achieving these objectives. The CFPB has rulemaking, ${ }^{257}$ examination, ${ }^{258}$ and enforcement ${ }^{259}$ authority to achieve them. The

252 See Victor Stango and Jonathan Zinman, What Do Consumers Really Pay on Their Checking and Credit Card Accounts? Explicit, Implicit, and Avoidable Costs, 99 Am Econ Rev Papers \& Proceedings 424, 424-25 (2009). However, it is important to note that the population studied was slightly wealthier than the US population. See id at 424 . While there may be reasons that consumers would choose to use overdraft despite these circumstances, if consumers do not know they are incurring overdraft charges, one can hardly argue that they are intentionally choosing to use it.

253 See, for example, Eugene Jones, Wen S. Chern, and Barry K. Mustiful, Are LowerIncome Shoppers as Price Sensitive as Higher-Income Ones? A Look at Breakfast Cereals, J Food Distribution Rsrch 82, 88 (Feb 1994) (finding that low-income consumers are more sensitive to cereal prices than high-income consumers).

254 See Overdrawn at * 12 (cited in note 249 ).

255 In related work, I explain in more detail the CFPB's authority to deploy performancebased standards. See generally Lauren E. Willis, The Consumer Financial Protection Bureau and the Quest for Consumer Comprehension (Loyola-LA, May 14, 2015), archived at http://perma.cc/EM3C-ZA6X.

25612 USC $\S 5511(\mathrm{~b})$.

257 See 12 USC $\$ \S 5512,5531(b)$.

258 See 12 USC $\S \S 5514-15$. 
statute contains additional language further authorizing comprehension standards. It tasks the CFPB with promulgating and enforcing

rules to ensure that the features of any consumer financial product or service, both initially and over the term of the product or service, are fully, accurately, and effectively disclosed to consumers in a manner that permits consumers to understand the costs, benefits, and risks associated with the product or service, in light of the facts and circumstances. ${ }^{260}$

In practice, performance-based regulation would likely be scaled down from these sweeping goals, perhaps focusing on the key attributes that can make some financial products unfair, deceptive, and abusive.

b) Standards, testing, and enforcement. Overdraft is opaque to consumers in part because price structures and billing practices are not intuitive. Nearly half of the banks in a recent survey were found to engage in transaction reordering (ordering daily transactions from largest to smallest instead of sequentially), which baffles consumers ${ }^{261}$ but maximizes the number of overdraft fees consumers incur. ${ }^{262}$ Fee structures vary widely: some banks charge a flat fee per overdraft, others charge tiered fees depending on the number of overdrafts, some charge a fee for each day the account remains overdrawn or after some specified period has passed and the account has not been brought current, others do not charge for small overdrafts, and so forth. ${ }^{263}$ Overdraft fees on prepaid debit cards are especially opaque, in part because many consumers understand prepaid cards as being a way to live within one's means and avoid checking accountoverdraft and credit card-over-the-limit fees. ${ }^{264}$

To deal with this opacity, comprehension standards might require banks and card issuers that extend overdraft loans to

259 See 12 USC $\S \S 5563-64$.

26012 USC $\$ 5532(a)$.

261 See Gutierrez $v$ Wells Fargo Bank, N.A., 730 F Supp 2d 1080, 1123 (ND Cal 2010) (finding that checking account holders "could not reasonably have expected that [their] bank would transform what would ordinarily be one overdraft into as many as ten").

${ }^{262}$ See Checks and Balances: 2014 Update *3 (The Pew Charitable Trusts, Apr 2014), archived at http://perma.cc/S8SV-AVFP.

263 See Data Point at *52-54 (cited in note 241 ).

264 See Why Americans Use Prepaid Cards: A Survey of Cardholders' Motivations and Views *13-14 (The Pew Charitable Trusts, Feb 2014), archived at http://perma.cc/R7JD-NDLB. 
demonstrate that their account holders understand how those fees are structured and billed. This would drive banks and issuers to educate consumers or to make their pricing structures more intuitive. If firms discover that industry-wide standardization is needed for consumers to comprehend overdraft pricing, they could ask regulators to impose such standardization through design prescriptions.

Another contributor to the inability of consumers to make good, autonomous decisions about overdraft is its invisibility at the moment it is incurred. Consumers are not informed in real time that they are about to incur an overdraft and therefore are not given the choice at that moment to decline the product. Consumers may not know the account balance their bank will assign them at any moment because deposits take varying amounts of time to clear, holds can be placed on account funds without the consumer's knowledge, banks reorder transactions within a single day, and account balance statements can be inaccurate. ${ }^{265}$ In addition, particularly for poorer consumers under the stress of financial scarcity, overdraft fees might be out of mind at the moment when they are incurred due to insufficient cognitivewillpower bandwidth and a hyperfocus on immediate financial demands. ${ }^{266}$

While the law might respond with a disclosure rule to address this, banks are particularly adept at preventing disclosure rules from informing consumers. ${ }^{267} \mathrm{~A}$ requirement that banks demonstrate that consumers know that they are about to incur an overdraft fee (and know the size of the fee) before incurring it would stimulate banks to instead use their creativity to develop the best methods for informing consumers, whether it be through text messages, cell phone calls, ATM-screen warning messages, or warning messages on the card readers at checkout

265 See Bank Fees: Federal Banking Regulators Could Better Ensure That Consumers Have Required Disclosure Documents prior to Opening Checking or Savings Accounts *21 (US Government Accountability Office, Jan 2008), archived at http://perma.cc/5RGW-K74K (explaining that transaction clearing time varies). See also id at *62 ("Debit card industry representatives explained that the account balance that is used to authorize a debit card transaction - and which would be displayed to the consumer-may not necessarily reflect the true balance in the consumer's checking account at the time of the transaction.").

266 See Mullainathan and Shafir, Scarcity at 64-66 (cited in note 21).

267 See Willis, 80 U Chi L Rev at 1224-25 (cited in note 22). 
counters. Third parties could test consumers for comprehension with just two questions:

- "Which, if any, of the following recent transactions overdrew your account? [listing transactions]" and

- "How much were you charged in fees as a result of this transaction?"

If every customer who had recently overdrawn her account were tested every time she overdrew it, correct answers could be a prerequisite to retaining overdraft fees. If samples of customers were tested, failures to perform to benchmark could result in refunds of fees over a look-back period. Because overdraft is a particular problem for the poor, the performance standard might apply only to consumers with average daily account balances below a specified amount, and thus only these consumers would be tested.

c) Dynamic Effects. A substantive effect of overdraftcomprehension testing would be to require banks to predetermine the fee they will charge a consumer before she incurs it. This would effectively prevent banks from reordering transactions and using other complex fee structures. For consumers to exercise decisional autonomy, banks must make overdraft fees simple at the dashboard.

Overdraft comprehension regulation might also drive overdraft out of the market. One industry consultant has opined that if consumers were warned of the fee each time they attempted to overdraw their accounts, so few consumers would overdraw that it would "effectively kill overdraft services." 268 While regulators have been studying overdraft transactions since at least 2007, comprehension performance standards would empower consumers to vote with their feet. 269

268 Ron Lieber and Andrew Martin, Overspending on Debit Cards Is Painful, but Not for Banks, NY Times A1, A20 (Sept 9, 2009) (reporting the opinion of Michael Moebs, an economist who advises banks and credit unions).

269 Performance standards also might send small banks that are currently dependent on overdraft revenue out of business. See Carter Dougherty, Banks Face Hit from CFPB on $\$ 30$ Billion in Overdraft Fees (Bloomberg, Aug 1, 2014), archived at http://perma.cc/3QQB-4K7U (noting that some small banks depend on overdraft fees for as much as 15 percent of their total revenue). If that result would harm consumers, regulators ought to find another way to keep small banks in business rather than through the use of hidden overdraft fees. 
3. OTC drugs in the postapproval period.

Firm and consumer interests are better aligned in the OTCdrug market than in the privacy and consumer-credit contexts. Firms have reasons beyond potential tort liability 270 to ensure that customers do not suffer unpleasant side effects or injuries directly attributable to their drugs. Reports of such problems spread quickly and consumers will avoid these drugs. But many dangers of OTC drugs are incremental increases in risk that manifest only rarely, such as when the patient is using multiple medications or has other risk factors. When damages are rare or injury causation is complex, reputational effects might not take hold. Incentives for firms to prevent excessive, ineffective, and even contraindicated OTC-drug use are thus attenuated.

Drug misuse rates must be low to pass a preapproval OTCdrug actual-use study. ${ }^{271}$ But when polled, consumers report high rates of knowing and intentional misuse of OTC medications after the drugs have been approved for OTC use:

[A] third of Americans say they take more than the recommended dose of a nonprescription medicine, believing that it will increase the effectiveness of the product. Of these consumers, two thirds (69 percent) say they take more than the recommended amount at a single time; three fifths (63 percent) report taking the next dose sooner than directed; and two fifths (44 percent) say they take more than the recommended number of doses in a day. 272

These numbers likely understate misuse due to social desirability bias. Moreover, they do not include unintentional OTC-drug misuse, the prevalence of which is also quite high. One study

270 See Hutto v McNeil-PPC, Inc, 79 S3d 1199, 1209-10 (La App 2011) (finding that a manufacturer could be liable for failing to adequately warn consumers of OTC-drug dangers even when the manufacturer included all warnings required by the FDA). But see Pliva, Inc v Mensing, 131 S Ct 2567, 2573-79 (2011) (holding that state law failureto-warn claims were preempted by FDA regulations that do not permit manufacturers of generic drugs to alter their labels on their own initiative).

271 For example, in the actual-use study that led to OTC approval for ibuprofen, less than 8 percent of consumers exceeded the correct daily-dose amount and less than 4 percent exceeded the correct dosing duration. See Meeting Topic: NDAC Meeting on Risks of NSAIDs (FDA), archived at http://perma.cc/68P4-P66N.

272 The Attitudes and Beliefs about Over-the-Counter Medicines: A National Opinion Survey Conducted for the National Council on Patient Information and Education * 3 (National Council on Patient Information and Education), archived at http://perma.cc/3K4D.XXVC. 
found that when subjects were presented with the labels of multiple OTC medications containing acetaminophen, nearly half demonstrated that they would exceed the recommended dose by simultaneously taking two products, posing a danger of liver failure. ${ }^{273}$

Consumers also frequently state that they use OTC medications for durations that exceed the duration specified on the label. ${ }^{274}$ For example, OTC proton pump inhibitors are used by many consumers for periods far exceeding the recommended short-term therapy. ${ }^{275}$ Long-term use of proton pump inhibitors is associated with an increased incidence of anemia, bone fractures, and infections. ${ }^{276}$ But preapproval actual-use studies are too brief to capture this kind of excessive use. For instance, none of the actual-use studies supporting the OTC application for the proton pump inhibitor omeprazole exceeded four weeks in duration. ${ }^{277}$

a) Legal authority. Current law specifically directs the FDA to require postmarketing studies of prescription drugs in some circumstances, but this law does not apply to OTC drugs. ${ }^{278}$ At times, the FDA obtains commitments from firms to engage in

273 Michael S. Wolf, et al, Risk of Unintentional Overdose with Non-prescription Acetaminophen Products, $27 \mathrm{~J}$ General Internal Med 1587, 1587 (2012). See also Sujit S. Sansgiry, Anagha Nadkarni, and Theresa Doan, Misuse of Over-the-Counter Medications among Community-Dwelling Older Adults and Associated Adverse Drug Events, $1 \mathrm{~J}$ Pharm Health Serv Rsrch 175, 175 (2010) (noting that 18 percent of respondents who returned the survey gave responses indicating that they had recently misused OTC drugs).

274 See Kennon Heard, Nonprescription Analgesics: Misunderstood and Abused, 41 Emergency Med 25, 26 (May 2009).

275 See Roni Caryn Rabin, Combating Acid Reflux May Bring Host of Ills (NY Times, June 25, 2012), archived at http://perma.cc/7RNC-5NKA; FDA Drug Safety Communication: Possible Increased Rish of Fractures of the Hip, Wrist, and Spine with the Use of Proton Pump Inhibitors (FDA, Mar 23, 2011), archived at http://perma.cc/K8LT-GHMY ("FDA acknowledges that consumers, either on their own, or based on a healthcare professional's recommendation, may take these products for periods of time that exceed the directions on the OTC label.").

276 See Rabin, Combating Acid Reflux (cited in note 275).

277 See Application for Omeprazole-Magnesium MUPS Tablets to be Marketed Overthe-Counter *2 (FDA), archived at http://perma.cc/7GCC-66Z8 (displaying an overview of the five actual-use studies conducted to support the OTC application for omeprazole). See also Approval Package for Prilosec OTC (Center for Drug Evaluation and Research, June 20, 2003), archived at http://perma.cc/KJZ3-73JE (approving the drug for OTC switch based on these five actual-use studies and additional labeling studies).

278 See 21 USC § 355(o). 
postapproval testing as a condition of receiving OTC approval,279 but more explicit regulatory authority from Congress would be helpful here.

b) Standards, testing, and enforcement. Why does consumer behavior with respect to OTC drugs postapproval differ from consumer behavior during preapproval actual-use studies, which take place while the drug is for the most part available only by prescription? One factor may be changes in marketing. After a drug is moved from prescription to OTC status, advertisements for the drug contain more false statements, ${ }^{280}$ promote more benefits, ${ }^{281}$ and no longer explain specific risks of using the drug. ${ }^{282}$ Another factor is that as the OTC drug becomes more familiar, consumers are less careful about their use of it.283 While firms may not create the misimpression of safety that contributes to overuse, they benefit from increased sales.

Adverse health effects of OTC drugs are sufficiently dangerous and societal consensus that consumers ought to follow OTCdrug directions is sufficiently strong that the performance standard in this context should be suitable use. Postapproval suitability testing would capture the effects of marketing and

279 See Angelo DePalma, Post-marketing Surveillance: Better Late Than Never (Pharmaceutical Commerce, May 20, 2005), archived at http://perma.cc/9YA8-QRAM ("While safety has always been FDA's top priority, the agency is increasingly requesting specific follow-up studies, even for over-the-counter products. Approximately threefourths of recent New Chemical Entity approvals include at least one post-marketing commitment (PMC). Through PMCs, applicants agree to conduct post-approval studies on safety, efficacy, or use."); Julie Aker, Getting Approval for an Rx-to-OTC Switch Involves Real-World Consumer Research (Applied Clinical Trials, May 1, 2002), archived at http://perma.cc/KS95-JLFU ("[Researchers] may also design long-term studies to evaluate [consumer] compliance over time after the new OTC product is on the market.").

280 See Adrienne E. Faerber and David H. Kreling, Content Analysis of False and Misleading Claims in Television Advertising for Prescription and Nonprescription Drugs, $29 \mathrm{~J}$ General Internal Med 110, 110 (2013) (finding that 2 percent of televised prescription drug advertisements contained false statements, whereas 7 percent of OTC.drug advertisements did so).

281 See Adrienne E. Faerber and David H. Kreling, Content Analysis of Television Advertising for Drugs That Switch from Prescription to Over-the-Counter: Balancing Information and Appeals, 46 Drug Info J 226, 231 (2012).

282 See Adrienne E. Faerber and David H. Kreling, Now You See It. Now You Don't: Fair Balance and Adequate Provision in Advertisements for Drugs before and after the Switch from Prescription to Over-the-Counter, 27 Health Commun 66, 71-72 (2012).

283 See Amanda B. Bower, Stacy Landreth Grau, and Valerie A. Taylor, Over-theCounter vs. Prescription Medications: Are Consumer Perceptions of the Consequences of Drug Instruction Non-compliance Different?, 37 Intl J Consumer Stud 228, 231 (2013) (suggesting that consumers are less concerned about adherence to directions for familiar OTC drugs). 
changes in consumer beliefs that might otherwise lead consumers to purchase and use the drug excessively or even when contraindicated. Testing methods and benchmarks could be borrowed from the preapproval actual-use testing. The consequence of failing to ensure that an adequate proportion of consumers were using the drug properly-a proportion that would vary depending on the seriousness of the health consequences of improper use-could include fines, limits on higher-dose OTC formulations, or suspension of OTC status for the drug. ${ }^{284}$

\section{Other applications.}

Performance-based consumer law could be employed in a host of other scenarios in which firm and consumer interests are currently poorly aligned.

For example, comprehension standards could be explored for civil justice waivers in standard-form consumer contracts, such as arbitration clauses, class action and jury-right waivers, clauses shortening limitations periods, damages waivers, and indemnity provisions. Firms regularly use these waivers to change the background procedural and substantive rules of the civil justice system that apply to their interactions with consum. ers. Few consumers understand that this is happening, or even that it is legally possible. ${ }^{285}$ Although some jurisdictions invalidate some waivers in the consumer law context, most allow the waivers but require them to be clear, conspicuous, or the like. ${ }^{286}$

284 For a similar proposal, see generally H-G Eichler, et al, Adaptive Licensing: Taking the Next Step in the Evolution of Drug Approval, 91 Clinical Pharmacology \& Therapeutics 426 (2012) (advocating an adaptive-management approach for the regulation of the performance of prescription drugs).

285 See Zev J. Eigen, The Devil in the Details: The Interrelationship among Citizenship, Rule of Law and Form-Adhesive Contracts, 41 Conn L Rev 381, 422 (2008) (finding that substantial proportions of employees did not believe that arbitration clauses in their employment contracts were binding); Debra Pogrund Stark, Jessica M. Choplin, and Eileen Linnabery, Dysfunctional Contracts and the Laws and Practices That Enable Them: An Empirical Analysis, 46 Ind L Rev 797, 813-20 (2013) (finding that consumers do not understand waivers of remedies in real-estate contracts); Jeff Sovern, et al, "Whimsy Little Contracts" with Unexpected Consequences: An Empirical Analysis of Consumer Understanding of Arbitration Agreements ${ }^{\star} 50-53$ (Feb 19, 2015), archived at http://perma.cc/VX9Z-RFHC (finding that many consumers do not believe arbitration clauses are binding and that only 9 percent of consumer survey respondents, when given a contract containing an arbitration clause, realized both that the contract had the clause and that the clause would preclude them from suing the firm in court).

286 See Scientific Components Corp v Isis Surface Mounting, Inc, 539 F Supp 2d 653, 663 (EDNY 2008) (stating that the parties' intent to agree to a fee-shifting clause had to 
Testing could be done in a fairly superficial manner as suggested for personal-data collection and use. For example, firms that place damages caps in their contracts could be required to demonstrate that their customers know that if the product is defective and causes the consumer damages, a court can award her no more than the cap in compensation. Benchmarks and enforcement could also mimic those used for privacycomprehension standards.

The inability of consumers to choose low-fee retirement investments ${ }^{287}$ and diversify their portfolios well ${ }^{288}$ after decades of disclosure rules and investor education suggests that this is another arena in which performance standards should be tried. Concrete feedback on investment choices comes primarily at retirement-far too late for consumers to use the feedback to learn. Understanding fund costs and knowing that one ought to pick investments based on cost rather than returns is not enough to convince even MBA students to ignore returns, 289 but if firms selling retail investments were required to demonstrate

be "unmistakably clear" from the language of the contract); Stelluti $v$ Casapenn Enterprises, $L L C, 1 \mathrm{~A} 3 \mathrm{~d} 678,689-90$ (NJ 2010) (stating that a damages waiver must "reflect the unequivocal expression of the party giving up his or her legal rights that this decision was made voluntarily, intelligently and with the full knowledge of its legal consequences"); BJ's Wholesale Club, Inc v Rosen, $80 \mathrm{~A} 3 \mathrm{~d}$ 345, 351 (Md 2013) (stating that a waiver of damages for future negligence must be clear and specific); Corbett, $687 \mathrm{~F} \mathrm{Supp}$ $2 \mathrm{~d}$ at 132 (stating that a clause shortening a limitations period must "sufficiently alert" consumers that the limitations period has been shortened); Fairfield Leasing Corp $v$ Techni-Graphics, Inc, 607 A2d 703, 705-06 (NJ Super 1992) (stating that waiver of a jury trial must be "conspicuous").

287 While many low-cost (under 0.5 percent expense ratio) funds with diverse risk profiles exist, 66 percent of employees' $401(\mathrm{k})$ mutual-fund investments are in funds with higher expenses. See 2014 Investment Company Fact Book: A Review of Trends and Activities in the U.S. Investment Company Industry (Investment Company Institute, 2014), archived at http://perma.cc/7A4M-HGGM. See also Jill E. Fisch and Tess WilkinsonRyan, Why Do Retail Investors Make Costly Mistakes? An Experiment on Mutual Fund Choice, 162 U Pa L Rev 605, 609 (2014) (finding that consumers have a limited ability to identify low-cost options and lack the understanding that cost ought to be a consideration when picking investments); 401(k) Participants' Awareness and Understanding of Fees *6 (AARP, 2011), archived at http://perma.cc/8EDM-9UAM (finding that 71 percent of surveyed plan participants did not know that they were paying fees).

288 Many consumers either do not diversify, or diversify naively (in other words, they divide their retirement contributions evenly over the offered funds). See Julie Agnew, Pierluigi Balduzzi, and Annika Sundén, Portfolio Choice and Trading in a Large 401(k) Plan, 93 Am Econ Rev 193, 193 (2003) (finding that most asset allocations in retirement accounts are "either 100 percent or zero percent in equities"); Fisch and Wilkinson-Ryan, $162 \mathrm{U} \mathrm{Pa}$ L Rev at 609 (cited in note 287) (finding widespread naive diversification).

289 See Choi, Laibson, and Madrian, 23 Rev Fin Stud at 1422-25 (cited in note 145). 
consumer comprehension of costs, they would be forced to deemphasize returns so as to draw attention to costs. Many would also have to simplify their fee structures to facilitate consumer comprehension. To help firms meet their comprehension obligations and to solve collective action problems, regulators might promulgate a complementary investment fund "price tag" disclosure that would assist firms in communicating fees in a simple, standardized, easily comparable manner. ${ }^{290}$

In contrast, comprehension of risk diversification is likely to be so costly to achieve that a suitability performance standard would be preferable. Because the risk suitability of any investment depends on the consumer's portfolio, a performance standard could be imposed only on firms that, in effect, sell consumers a good chunk of their portfolios, such as defined contribution retirement plan sponsors. A suitability standard might require plan sponsors to demonstrate that plan participants in the lower half of the income distribution, who are likely to have most of their nonhousing investments in the plan, have in-plan investments that meet a diversification performance benchmark. Regulators would have to make judgment calls about how to measure diversification and then either decide what constitutes an acceptably diversified portfolio or collect industry-wide data and set benchmarks based on relative performance.

Requiring plan sponsors to demonstrate the diversification suitability of plan participants' portfolios would require changes in current law. ${ }^{291}$ But meeting the performance standards might not prove to be all that difficult. About half of all plan sponsors have already nudged their participants toward diversification by removing employer stock as an investment choice, adding welldiversified fund offerings, and automatically enrolling participants in those offerings.292 Performance-based regulation would

\footnotetext{
290 However, disclosure alone would be insufficient for all the reasons that disclosure rules fail.

291 Plan sponsors are generally relieved of any fiduciary duties to participants with respect to any loss or erstwhile breach of fiduciary duty that results from a participant's exercise of control over the assets in her account. See 29 USC $\S 1104$ (c)(1)(A)(ii).

292 See Jeffrey R. Brown and Scott J. Weisbenner, Building Retirement Security through Defined Contribution Plans *26, 57 (Dec 2013), archived at http://perma.cc/9GM7-AEFJ (documenting that, as automatic enrollment has spread, the diversification of new hires' portfolios has improved dramatically, increasing investments in balanced funds and decreasing investments in employer stock). See also id at *20 (noting that just under half of all $401(\mathrm{k})$ plans had an automatic-enrollment feature as of 2011).
} 
give the firms that lag behind an incentive to engage in these and other innovative practices. For example, sponsors might design the choice architecture of the plan to accommodate naive diversification, such as through offering a small number of investments that would, in equal shares, create a welldiversified portfolio. Alternatively, a sponsor might arrange a larger menu of investments into risk groupings and advise participants to invest in all the groupings. Experimentation would guide sponsor strategies over time. Graduated penalties or rewards for meeting performance benchmarks would encourage continued innovation.

Yet another example is payday lending. There is widespread consensus that consumer law's goals are not being met for borrowers who renew their borrowing repeatedly. As noted above, even the payday-lender trade associations agree that "a payday advance is inappropriate when used as a long-term credit solution for ongoing budget management." ${ }^{293}$ But the CFPB recently found that nearly half of borrowers took out more than ten loans in a year, ${ }^{294} 15$ percent of loan sequences were ten or more loans long, ${ }^{295}$ and loans to many borrowers persisted for an entire year. ${ }^{296}$ Suitable use rather than comprehension is key here. Welfare-reducing choices are primarily driven by desperation and associated cognitive-willpower bandwidth limitations. Over one-third of borrowers report that they would have taken a loan on any terms. ${ }^{297}$ A performance standard might require lenders to demonstrate that borrowers have the ability to pay the loan without reborrowing before the end of the pay period in which the loan becomes due. A pool-based suitability measure might permit only a very limited proportion of a firm's customers to engage in sustained use or might place the benchmark at the median proportion of customers who engage in sustained use throughout the industry.

Many other consumer transactions might benefit from performance-based regulation. Each application of the performance-

293 Is a Payday Advance Appropriate for You? (cited in note 110).

294 See CFPB Data Point: Payday Lending ${ }^{*} 21$ (CFPB, Mar 2014), archived at http://perma.cc/M9QN-QS96.

295 See id at ${ }^{*} 11$.

296 See id at * 14 .

297 See How Borrowers Choose and Repay Payday Loans: Payday Lending in Ameri$c a{ }^{*} 19$ (The Pew Charitable Trusts, 2013), archived at http://perma.cc/W37D.BZHH. 
law paradigm must be tailored to the particulars and practicalities of the context, and valid testing techniques must be developed for each application. Moreover, each application must be adjusted as data come in from consumer field-testing.

\section{WHY PERFORMANCE-BASED TOOLS COULD FAIL, AND WHY WE SHOULD ESTABLISH AND IMPLEMENT THEM ANYWAY}

This Part anticipates potential stumbling blocks in successfully implementing performance-based consumer law. It then argues that comprehension and suitability standards offer secondorder benefits that make trying the approach worthwhile.

\section{A. Performance-Based Consumer Law: Objections and Replies}

Why is performance-based regulation so rare in consumer law today? One reason could be a lack of imagination; the conventional wisdom is that one can neither legislate comprehension nor save people from their own "stupidity." 298 One aim of this Article is to suggest that this reasoning is wrong. It is true that developing performance-based standards and maintaining a fair and accurate system for evaluating compliance are not easy tasks, but the tools for doing so are getting better as datacollection and data-analysis techniques improve. ${ }^{299}$ The following Section describes the major challenges to performance-based consumer law: evasion, discrimination, and stagnation. All of these afflict disclosure and design regulation as well, but the challenges they present are more transparent for performancebased regulation.

\section{Evasion.}

Firms will look for strategies to pass performance tests without necessarily meeting the comprehension and suitability goals of the standards. Consumers could prove to be willing

298 See Thomas A. Durkin and Gregory Elliehausen, Disclosure as a Consumer Protection, in Thomas A. Durkin and Michael E. Staten, eds, The Impact of Public Policy on Consumer Credit 109, 126 (Kluwer 2002) ("Simply stated, it is not possible to legislate comprehension of anything."); Bob Secter, Gov. Ventura Still Twisting Heads: Insiders Surprised by His Effectiveness (Chicago Tribune, May 19, 1999), archived at http://perma.cc/ZP9K-HDSY (quoting then-Governor of Minnesota Jesse Ventura as say. ing that government "can't legislate against stupidity").

299 See Bryant Walker Smith, Proximity-Driven Liability, 102 Georgetown L J 1777, 1782-84 (2014) (describing some of these developments). 
coconspirators, to avoid expending time and effort on taking tests. If firms condition transactions on their customers first passing the test, consumers will have even more reasons to cheat.

Two strategies seem likely for evading comprehension testing. The first is for firms (or fellow consumers spontaneously) to help consumers cheat by, for example, placing answers to all possible questions online. But that would likely increase consumer knowledge about the transaction, which is precisely the goal of the performance standard. One step away from this strategy might be a firm not only informing its customers that their contract contains an arbitration clause, for example, but also persuading them that arbitration is better for the consumers than litigation. Putting third-party effects aside, this too is not problematic: if arbitration is better than litigation, the customer should choose it, and if it is not better, yet the customer has been fooled into thinking it is, the right public policy response may then be to ban the clause. Without comprehension standards, the arbitration clause can be slipped silently into a contract with an unwitting consumer, and the firm avoids public engagement with the question whether the clause should be permitted. Comprehension standards would thrust an evaluation of transaction features currently controlled entirely and silently by firms squarely into public discussion, facilitating democratic control.

On the other hand, one could imagine poorly constructed tests that might allow a firm to teach its customers the right way to answer the questions without teaching them about the underlying substance of the transaction. A parallel here would be to firms' responses when emissions performance standards were originally rolled out: firms built higher smokestacks so that the emissions monitors at ground level would produce lower readings, allowing the firms to pass the tests without reducing their emissions. Regulators responded by changing the manner in which emissions performance was calculated, by taking both the ground level emissions readings and the height of the smokestack into account. ${ }^{300}$

300 See Air Quality: Information on Tall Smokestacks and Their Contribution to Interstate Transport of Air Pollution *2 (US Government Accountability Office, May 2011), archived at http://perma.cc/BHM5-DUCB. 
To address such sleights, comprehension tests ought to be fashioned so as to impede consumers from mindlessly reaching correct answers. Take personal-data collection and use. To correct for the reflexive "I agree" click, the test would need to include control questions (questions that ask about data collection and use not engaged in by the firm) and questions in flipped format (in other words, questions asked in the negative such that "no" or "false" is the correct answer). For a firm that uses individual consumer information to target marketing and sells consumer information to third parties without use restrictions, for example, the test might ask the following true/false questions:

- "This firm will use information about you to determine which web pages to show you." (Answer: false)

- "This firm will not use information about you to sell you products." (Answer: false)

- "This firm will sell your information to other firms that can use that information to determine what price to charge you for products." (Answer: true)

Regulators should also regularly test the testing itself, for example, through in-depth interviews with small samples of consumers.

Suitability tests will encounter evasion attempts that parallel the tactics used by firms to foil design rules. Just as firms design high-cost, small-dollar, short-term loans to fall a few dollars or a few days outside the definition of a regulated payday loan and thus avoid design rules that restrict payday lending, firms might sell products to consumers for whom the products are not suitable, even though the customer (just barely) meets the indications/contraindications suitability test imposed on the transaction. Performance regulations will need to evolve to meet challenges as they are discovered. But, particularly if paired with adaptive regulation, suitability standards can adapt more quickly than design rules can.

\section{Discrimination.}

Performance standards could have adverse class, race, age, and gender impacts. For comprehension testing, variations in literacy and numeracy as well as the experiences of stereotype 
threat and test aversion could cause testing disparities. ${ }^{301}$ As noted, firms might explicitly exclude consumers who provide incorrect answers to incentivize consumer effort on the test. To the extent that comprehension testing captures a true ability to selfselect products well, this disparate impact reflects social inequality and does not increase it. But if results are driven by test aversion or general literacy that does not correlate well with consumer decisional autonomy and welfare, these disparate impacts are a cost of comprehension standards. Further, to the extent that firms use segmented marketing to divert test-averse and low-literacy consumers away from their products, and to the extent that the segmentation relies on variables that correlate with disadvantaged status and do not correlate perfectly with test performance, the marketing could have additional adverse impacts.

Disclosure mandates produce similar disparate effects. When disclosures are effectively used at all, the effective users are high-literacy consumers, with concomitant socioeconomic effects. ${ }^{302}$ Well-off consumers derive disproportionate indirect benefits from disclosures as well, in that the poor decisions of consumers who are not helped by disclosures often subsidize the consumers who use disclosures well. ${ }^{303}$

But rather than reinforce or amplify social and wealth disparities, performance regulation might narrow them. If comprehension standards lead to increased fee salience, the consumers who will benefit most will be those for whom fees are now the least salient; these tend to be low-socioeconomic-status consumers. ${ }^{304}$ Consumer experience with the CARD Act is telling. ${ }^{305}$

301 See Claude M. Steele and Joshua Aronson, Stereotype Threat and the Intellectual Test Performance of African Americans, 69 J Personality \& Soc Psych 797, 808 (1995) (finding racial disparities in test performance that are uncorrelated with ability); $\mathrm{Na}$ tional Assessment of Adult Literacy: Demographics; Race/Age (Institute of Education Sciences, National Center for Education Statistics), archived at http://perma.cc/33T2 -KHU5 (finding literacy differences by race and age).

302 See, for example, Russell L. Rothman, et al, Patient Understanding of Food Labels: The Role of Literacy and Numeracy, 31 Am J Preventive Med 391, 394 (2006) (finding that income and education were positively correlated with accurate food-label use and that being African American or female was negatively correlated with accurate foodlabel use).

${ }^{303}$ See Ben-Shahar and Schneider, More Than You Wanted to Know at 178-80 (cited in note 3) (explaining how disclosures can help rich and well-educated consumers at the expense of poor and poorly educated consumers).

304 See Mullainathan and Shafir, Scarcity at 173-76 (cited in note 21). 
That statute curtailed the use of nonsalient back-end fees, meaning that issuers were forced to show consumers more of the price of credit in the salient annual fee and APR. The result was a dramatic decline in back-end fees paid by the lower part of the credit-score distribution, which maps roughly onto low socioeconomic status, and a slight increase in annual fees, which are paid by all consumers. ${ }^{306}$ The previously existing regressive cross subsidy was therefore partially eliminated. Comprehension standards might have the same effect.

Suitability performance measures could also have disparate effects, but these effects again might benefit society. For example, if a suitability standard specifies that certain products are unsuitable for high-risk consumers and risk is inversely correlated with socioeconomic status, then suitability prescreening, whether by firms or by regulators, will have a disparate effect. If the screening is accurate, the disparate effect is beneficial; without the screening, more members of low-socioeconomic-status groups might have purchased unsuitable products and suffered as a result. But if the screening is inaccurate, disproportionate numbers of low-socioeconomic-status consumers could be prevented from engaging in transactions that would have benefited them.

The Gainful Employment Rule has grappled with this issue because low-socioeconomic-status students disproportionately enroll in for-profit schools subject to the Rule, and ending federal funding will eliminate some of these schools-thus reducing college enrollment for low-socioeconomic-status students. However, without the Rule, low-socioeconomic-status students would disproportionately pay for a worthless education.

Again, substantive design regulation can have disparate effects too. If a product is banned that would have disproportionately harmed (or benefited) low-socioeconomic-status consumers, the ban has a disparate beneficial (or detrimental) effect. Performance-based regulation would not necessarily result in larger disparate effects. Instead, it would make these effects more apparent.

Finally, the enforcement structure for performance-based consumer law would produce fairer outcomes than prescriptive

305 See Part I.C.

306 See Agarwal, et al, 130 Q J Econ at 52 (cited in note 27). 
rules with complaint-driven enforcement. As previously explained, those who complain tend to be better off than those who do not. In contrast, enforcement in a performance-based system is based on tests of all consumers or random samples thereof, or even on tests of only (or an oversampled slice of) vulnerable consumers. Firms thus would have an incentive to ensure comprehension and suitable use with respect to all their customers, not only those most likely to complain.

\section{Stagnation.}

Another potential objection to performance-based consumer law is that it could impede innovation that might have benefited consumers. Comprehension and suitability standards avoid some of the brute limits on innovation imposed by productdesign regulation. But performance standards could chill innovation because it always takes time for consumers to understand a new product or feature and to determine for themselves whether a new product or feature is suitable for their needs and preferences. The question, then, is how the learning period ought to be regulated.

When a performance standard is put into place, firms' first responses will likely be innovations that help consumers understand products and use them suitably, such as through dashboard simplification of the products. Imagine a firm that then wants to bring a new product to market that could benefit consumers but which consumers will require some time to understand. Performance-based regulation, at least when firms have the option of meeting comprehension or suitability standards, would likely lead firms to aim for suitable use of the new product achieved through channeling appropriate consumers toward the product and channeling consumers for whom the new product is not suitable away from the product. After general comprehension of the new product has developed among consumers, the firm might switch to meeting comprehension requirements. For each product-design change, the cycle might repeat.

This cycle is common in markets in which consumers have good information and thus firms and consumers have well- 
aligned interests. ${ }^{307}$ If consumers understand that they (or others like them) have had a bad experience with a new product and are able to use that understanding to make future shopping decisions, firms will have every reason to ensure that only consumers for whom an innovative product is suitable buy it. Otherwise, the new product would quickly garner a bad reputation and demand would evaporate. As consumers become more familiar with a product over time, firms can rely more on consumer comprehension and self-selection and reduce their channeling efforts. Performance-based consumer law would bring this virtuous cycle to product purchases for which consumer and firm interests would otherwise not be well aligned.

\section{B. Benefits of Trying Performance-Based Consumer Law}

Performance-based consumer law might fail to produce dramatic gains in consumer comprehension or marked declines in unsuitable use. Alternatively, it might produce increased comprehension or suitability but only at a very high cost. However, information gleaned through the exercise of developing and implementing comprehension standards could yield valuable dividends for other, more-tractable forms of regulation.

\section{Benefits of establishing standards.}

Establishing performance standards would promote clarity on regulatory goals, deeper thinking about the value of consumer decisional autonomy, and dialogue on the suitability parameters of various products. ${ }^{308}$ Take overdraft, for example: What is the goal in regulating this product? Is it to stoke competition over this account feature, which is currently lacking because consumers do not consider overdraft when they open their accounts? Is it to eliminate mistaken use, meaning situations in which consumers, had they known about the fee, would have chosen instead either not to engage in the transaction or to use a different method of payment? Is it ultimately to minimize the

307 See generally Vijay Mahajan and Eitan Muller, When Is It Worthwhile Targeting the Majority Instead of the Innovators in a New Product Launch?, 35 J Mktg Rsrch 488 (1998) (describing diffusion-of-innovation marketing cycles).

308 See Coglianese, Nash, and Olmstead, 55 Admin L Rev at 716 (cited in note 68) ("[T]he decision to consider using performance standards can offer benefits simply in terms of 'shaking things up' or focusing the policy dialogue on the ultimate objectives and the underlying uncertainties."). 
incidence of this high-cost credit product? Each goal implies a different performance standard. The first calls for a comprehension standard applied at the opening of the account; the second, a comprehension standard applied when the fee is incurred; the third, a suitability standard or even a ban.

Developing comprehension standards would spotlight the choices that regulators implicitly make when mandating disclosures. While fact after fact can be stuffed into a disclosure, comprehension standards require judgment calls about what consumers really need to know to make good decisions, tempered by a realistic assessment of what consumers can actually understand. Take consumer retirement investments, for example. Fleshing out what consumers need to know to engage in good portfolio risk diversification exposes the enormity of the burden placed on consumers. One implication is that consumers should not make these decisions at all and that alternative methods, rather than disclosure, are needed to protect retail investors.

Establishing suitability standards requires similar judgments regarding what uses of products are suitable. This requires a dialogue that occurs surprisingly rarely. For example, those who debate payday loan bans appear to assume that no uses are suitable or that all uses are suitable, without delving into which uses they are imagining. Some consensus on suitable uses would facilitate more-informative disclosure and perhaps more-focused product-design regulation. Even without reaching agreement, an open discussion could provide information that would be helpful in the democratic process or that could be used in assessing whether individual products or terms are unfair, deceptive, or abusive.

\section{Benefits of field-testing consumers.}

Field-testing for comprehension and suitability would give regulators, lawmakers, and the citizenry a tremendous amount of information about how the marketplace is actually functioning. This information could level the regulatory playing field, increase regulator accountability, and empower consumers in their roles as both consumers and citizens. Ultimately, this information is necessary for law that is grounded in reality rather than in models or myths about how the market functions.

Today, firms-for their own purposes-collect data on how consumers understand and use their products. Regulators 
obtain this information on a sporadic and partial basis, such as through ad hoc surveys, investigative news reports, and consumer complaints. This data-collection process is often insufficiently comprehensive to give regulators the information they need to formulate policy based on what is truly happening in the marketplace. Moreover, when they do receive performance data, regulators do not envisage themselves as having the responsibility to respond decisively and fix problems revealed by the data.

For example, in 2003, well before the mortgage meltdown, regulators knew from market reports that banks were "mass market[ing]" option adjustable-rate mortgages (ARMs) as "affordability products" to homeowners who, in a few short years, would not be able to make the monthly payments. ${ }^{309}$ By 2005 , regulators knew, again from market reports, that consumers with option ARMs were defaulting at a very high rate. ${ }^{310}$ Regulators waited another year before their first tentative responses: (a) "guidance" suggesting that lenders sell the product only to borrowers who could make the higher payments that would become due, ${ }^{311}$ and (b) their first consumer-education pamphlet on option ARMs. ${ }^{312}$ But regulators did not use their power to police unfair or deceptive acts or practices to rein in sales of the product.

Without an institutionalized system of their own consumertransaction data collection, regulators did not conceive their role as requiring prompt responsive action. When the problem surfaced in 2003, regulators sat back to allow firms and consumers to take care of themselves. Even in 2005, as defaults spiked, one banking regulator explained his agency's inaction as follows:

309 John C. Dugan, Remarks by John C. Dugan, Comptroller of the Currency, before the Consumer Federation of America ${ }^{*} 10$ (Dec 1, 2005), archived at http://perma.cc/W5HK-K4LH. On more than 70 percent of option ARMs outstanding in 2005-2006, homeowners made only the minimum payment, guaranteeing that their payments would increase dramatically within a few years. See Mara Der Hovanesian, Nightmare Mortgages, Business Week 70, 73 (Sept 11, 2006).

310 See Susan Schmidt Bies, Remarks by Governor Susan Schmidt Bies at the National Bankers Association Annual Convention (Board of Governors of the Federal Reserve System, Oct 12, 2005), archived at http://perma.cc/X7PW-ZURY.

311 Department of the Treasury, Interagency Guidance on Nontraditional Mortgage Product Risk, 71 Fed Reg 58609, 58610-11 (2006).

312 See Agencies Provide Consumer Information on Nontraditional Mortgage Loans (FDIC, Oct 18, 2006), archived at http://perma.cc/9XG5-X6RZ (announcing the availability of a consumer handbook entitled "Interest-Only Mortgage Payments and PaymentOption ARMs-Are They for You?"). 
"We have the most vibrant housing and housing-finance market in the world, and there is a lot of innovation. Normally, we think that if consumers have a lot of choice, that's a good thing." ${ }_{13}$ Regulators' models and myths about the market, rather than data, dictated policy.

Lawmakers and citizens currently lack sufficient information on the effectiveness of regulation. Performance testing would reveal not only which market transactions are not meeting regulatory goals but also which regulations and regulators are failing to meet regulatory goals. Comprehension testing, for example, would expose limits on what consumers can be expected to comprehend and the concomitant limits on regulators' ability to rely on disclosure to facilitate consumer decisional autonomy. If demographic data were collected, testing would also reveal the distributional effects of consumer law. Provided that performance-testing results were made publicly available, these results could help citizens put pressure on legislators and regulators to improve regulation.

Finally, testing never merely reveals information about people; it also changes them. For example, comprehension testing for privacy policies would almost certainly raise awareness and understanding of those policies, potentially both changing consumer behavior and motivating consumers to enter the political process to set an agenda for substantive privacy regulation. Suitability testing for payday loans, if deployed using consumer testing, would educate consumers about suitable and unsuitable high-cost-loan use; this would give consumers information that they could use in their roles both as consumers deciding whether to take a payday loan and as citizens deciding whether to support payday loan regulation.

\section{A cumulative benefit: crowding in better regulation.}

As with any regulatory response to a problem, there is always the possibility that performance-based consumer law will crowd out better regulation. Resources of regulators and policymakers who seek to improve the consumer law landscape are limited. But on closer analysis, the process of developing and

313 Edmund L. Andrews, A Hands-Off Policy on Mortgage Loans (NY Times, July 15, 2005), archived at http://perma.cc/4F62-385Q (quoting Steve Fritts, then Associate Director for Risk Management Policy at the Federal Deposit Insurance Corporation). 
implementing performance-based consumer law seems particularly likely to crowd in improved regulation. ${ }^{314}$ Regulatory opportunity costs are likely to be outweighed by regulatory synergies. This potential is most likely to be realized if performance-based consumer law is deliberately paired with adaptive management-a mandate that regulators regularly review, and take action in response to, incoming data about how current law is performing.

a) Improved disclosure and related regulation. Performancebased consumer law could improve disclosure mandates in at least four ways. First, regulators would learn how best to educate consumers by observing the successes and failures of firms' educational efforts. Rather than spending years developing disclosures in laboratory conditions with limited external validity, regulators could observe the results of firms' field-testing of various messaging forms. While not all of these forms will be available to regulators (for example, the bikini method suggested above ${ }^{315}$ ), some will be.

Disclosure mandates could also benefit from performancebased consumer law because standardized disclosure formats would help firms reach performance standards. During the regulatory development of disclosures, firms today have an interest in sabotaging disclosure's potential effectiveness. The existence of performance standards would spur firms to determine when and how disclosure can best serve a coordinating and educational function and could cause firms to advocate for the necessary changes.

Third, establishing comprehension standards would demonstrate the boundaries of disclosure's effective use. If a product is so confusing or counterintuitive that firms cannot make consumers understand it, no regulator will be able to achieve consumer comprehension. This would suggest that other forms of

314 However, the performance-based consumer law discussed here is in some tension with public health approaches suggested by Professor Sugarman and his coauthor Sandman. See note 10. Comprehension and suitability standards could reinscribe consumer law's focus on individual-consumer decisional autonomy and individual-consumer welfare. But it may be that at least some problems in consumer law ought to be approached from a public health or social cost perspective instead. This Article suggests adding performance-based regulation to the consumer law toolbox, supplementing rather than supplanting other approaches. But performance-based regulation could have a crowding-out effect on the public health approach.

315 See text accompanying note 91 . 
regulation are needed instead, such as suitability standards, design rules, or learned intermediaries placed between the consumer and the product. For example, OTC-drug performance testing can reveal when a prescribing doctor ought to screen, guide, and monitor consumer use of a drug. Alternatively, some incomprehensible features might simply be banned, as the law has done for some complex credit card billing and paymentallocation practices. ${ }^{316}$

Fourth, performance standards may well be necessary to facilitate the latest innovation in disclosure: smart disclosure. The idea is that firms will, in real time, publicly release complete price, feature, and performance data for all of the firms' products and release to individual customers their own past product-use history. Consumers can then input their past use data and their individual preferences into online- or mobile-app choice engines that can recommend the products that will best meet those preferences. ${ }^{317}$ In theory, smart disclosure would facilitate consumer decisional autonomy and welfare, particularly for those consumers who are currently the least able to use disclosures well.

But without performance regulation, firms are likely to outsmart smart disclosure as they do with Internet search engines today. ${ }^{318}$ Firms might withhold or misreport data so as to move their offerings to the top of choice-engine recommendation lists and to keep profitable consumers. ${ }^{319}$ Choice engines could become corrupted, using consumer data to target consumers for particular products or pricing tricks rather than being used by

316 See Ben S. Bernanke, Financial Innovation and Consumer Protection (Board of Governors of the Federal Reserve System, Apr 17, 2009), archived at http://perma.cc/DD9H-3GCK (explaining that, no matter how the Federal Reserve Board attempted to explain the credit card-issuer practices of allocating payments to the portion of the balance carrying the lowest interest rate and of double-cycle billing, both were unintelligible to consumers).

317 See Cass R. Sunstein, Memorandum for the Heads of Executive Departments and Agencies: Informing Consumers through Smart Disclosure (Office of Information and Regulatory Affairs, Sept 8, 2011), archived at http://perma.cc/LN83-LX7E.

318 See Nick Bilton, Friends, and Influence, for Sale Online (NY Times, Apr 20, 2014), archived at http://perma.cc/9NVW-A83D; David Segal, The Dirty Little Secrets of Search (NY Times, Feb 12, 2011), archived at http://perma.cc/5ZUJ-U7UJ.

319 See Treasury Report Recommendations to Curb Predatory Home Mortgage Lending *6-7 (Department of Housing and Urban Development, 2000), archived at http://perma.cc/JN75-XFLF (noting that some subprime-mortgage lenders failed to report positive payment history to credit bureaus, which prevented profitable customers from refinancing at a lower rate). 
consumers to locate the best products and cheapest pricing. ${ }^{320}$ Suitability standards could give firms incentives to participate in smart disclosure without cheating or exploiting loopholes. If one goal of firms were to ensure that their customers buy the products most suited to their needs-and particularly if benchmarks were set at what decision aids can produce in the labsmart disclosure could help them meet that goal.

b) Improved design regulation. Performance-based regulation has the potential to suggest improvements in design rules as well. Results from comprehension testing would illuminate when comprehension (and thus disclosure) is insufficient, and thus when suitability standards or design rules are needed. Suitability-standard performance data could then help regulators to compare the relative costs and benefits of performance standards versus design rules.

Further, just as performance-based regulation would lead firms to determine when standardized disclosures are needed and could incentivize firms to advocate for these disclosures, it could do the same for standardized terms. Consumer comprehension of mutual-fund fees, for example, seems unlikely if firms can structure these fees in innumerable ways. To meet consumer-comprehension and suitable-use benchmarks, firms themselves would need the universe of potential fee structures to be limited and standardized. Design regulation could solve the collective action problem that would otherwise prevent firms from establishing fee-structure standardization on their own.

Finally, as firms react to the implementation of performancebased regulation, they are likely to experiment with and discover product-design changes that regulators might then look to in establishing industry-wide design rules. Tort liability can lead to product-design changes that tell regulators what product designs are feasible and regulators can use this feasibility information to develop good design rules. ${ }^{321}$ Comprehension and suitability standards might have a similar effect. The performance-regulation paradigm gives firms the discretion to decide

320 See Dana Mattioli, On Orbitz, Mac Users Steered to Pricier Hotels (Wall St J, Aug 23, 2012), archived at http://perma.cc/UA9S-4XSX.

321 See Jon S. Vernick, et al, Role of Litigation in Preventing Product-Related Injuries, 25 Epidemiologic Rev 90, 96 (2003) (describing the cycle in which tort litigation acts in advance of regulators, reveals industry information during discovery, attracts public attention, and leads to regulatory change). 
when product simplification is the best way to meet benchmarks and when complex features are sufficiently valued by consumers such that education is worth the payoff. Firms' choices would provide regulators with market-tested product designs on which to base design-regulation decisions.

c) Adaptive management. The crowding in of better disclosure and design regulation could be a spontaneous response to performance-based consumer law, as regulators and legislators observe firm educational efforts and product-design changes and receive data on the (in)effectiveness of disclosure and the (un)suitability of consumer product use. But regulatory improvements are more likely to occur more quickly if regulators are given the power and responsibility to systematically review and respond to performance data. "Adaptive management" or "smart governance" refers to a system in which regulators have the responsibility and authority to routinely review the performance of regulation and to make continuous adjustments to steer regulation closer to its goals. ${ }^{322}$ While a fulsome treatment of the application of adaptive management to consumer law is beyond the scope of this Article, an important benefit of performance-based regulation is that the data it would produce would facilitate adaptive management. It is thus in keeping with what Professor William Simon calls a postbureaucratic vision of administrative law, in which regulators govern through the use of auditing and continuous adaptation to diverse and changing environments, rather than with static rules enforced through the adjudication of individual complaints. ${ }^{323}$

Like performance-based regulation, adaptive management has been conflated with "collaborative" regulation that has produced regulatory gridlock instead of adaptation, but there is no necessary link between adaptive regulation and deregulation. ${ }^{324}$ Instead, regulators could use the test results produced

322 "Smart governance" is the term frequently used for adaptive management in the public sector. See, for example, $21^{\text {st }}$ Century Regulation: Putting Innovation at the Heart of Payments Regulation *2 (PayPal and eBay), archived at http://perma.cc/Z87S-WUNE. "Total quality management" is one of the terms used in the private sector. See, for example, Barrie G. Dale, Ton van der Wiele, and Jos van Iwaarden, eds, Managing Quality 1 (Blackwell 2007).

323 See William H. Simon, The Organizational Premises of Administrative Law, $78 \mathrm{~L}$ \& Contemp Probs 61, 69-70 (2015).

324 See Doremus, et al, Making Good Use of Adaptive Management at *3 (cited in note 196). 
by performance-based regulation to iteratively revisit the question of how poorly understood consumer product features and unsuitably used products ought to be regulated.

\section{CONCLUSION: PUTTING CONSUMERS AT THE CENTER OF CONSUMER LAW}

At one level, performance-based consumer law is a technocratic exercise - one that seeks to engineer an alignment of incentives between consumers and firms when the market fails to do so. It also seeks to let firms do what firms do best and let regulators do what only regulators can do. Big data and the prevalence of technological devices intermediating consumer transactions bring us to a place in which performance-based regulation is both more possible and more necessary, given that firms use these tools to analyze and experiment with real consumers so as to adaptively manage the design and marketing of consumer products in real time.

Performance-based consumer law takes recent regulatory trends toward empirically informed lawmaking to a new level by harnessing our improving abilities to measure what is happening in the world. It recognizes that with new empirical techniques, the law need not rely on regulatory and judicial models or myths about the "reasonable," "average," or even "vulnerable" consumer. Instead, we can measure what actual consumers know and do so as to ground the law in a more objective measure of what is reasonable. Performance-based consumer law is ambitious about what the law should attempt.

But performance-based consumer law is also circumspect about what the law can achieve. It does not imagine that by expecting consumers to act "reasonably," the law will make them do so. It does not imagine that new empirical tools will lead regulators to scientifically produce a perfected set of legal rules. Instead, the performance-based legal paradigm conceives of regulation as a purposeful experiment-one that provides institutionalized monitoring and feedback about its own utility, which can inform regulators, policymakers, and citizens, thereby helping regulation evolve over time. Performance-based consumer law thus facilitates adaptive management of the consumer marketplace.

This experimental approach to regulation will require both technical changes in administrative law and a new vision of how 
law ought to be made. CBA will no longer be a single, penultimate step before a regulatory finale but instead a continual Bayesian process taking place alongside evolving regulation.

Performance-based consumer law also overcomes the longstanding consumer law divide between regulation of the consumer transacting process and regulation of the substance of consumer transactions. Comprehension and suitability standards, while facially reflecting this duality, reject it. To regulate the process of transacting, we must grapple with the substance of transactions. Consumer decisional autonomy demands dashboard product simplicity and usability, which necessarily imply substantive restrictions on product design. Conversely, for consumers to select suitable products independently requires simple, useable information from firms during the transaction process.

At a deeper level, performance-based consumer law adopts and nurtures a new-or perhaps an old-normative perspective. Comprehension and suitability standards situate consumers and citizens as principals, and firms and regulators as their agents. The performance paradigm does not fight new governance, but sings it in a regulatory rather than a deregulatory key. ${ }^{325}$ This works against some recent trends in consumer law jurisprudence, including cases which have awarded firms the power to unilaterally set and modify consumer contract terms ${ }^{326}$ and have distended the First Amendment to constrain the government's power to protect consumers. ${ }^{327}$ But it is consonant with the goals of recent legislation governing consumer law, including both the Dodd-Frank Act and the CARD Act.

Currently, firms take consumers where they find them-and sometimes take them for a ride. Performance-based consumer

325 See Cristie Ford, New Governance in the Teeth of Human Frailty: Lessons from Financial Regulation, 2010 Wis L Rev 441, 483-87.

326 For an extensive discussion of such cases, see Horton, 57 UCLA L Rev at 623-44 (cited in note 51).

327 See Sorrell v IMS Health Inc, 131 S Ct 2653, 2672 (2011) (applying the First Amendment to strike down a state law prohibiting the sale by pharmacies of physicians' prescription records to pharmaceutical companies for marketing purposes); R.J. Reynolds Tobacco Co v Food \& Drug Administration, 696 F3d 1205, 1221-22 (DC Cir 2012) (applying the First Amendment to strike down disclosures viscerally warning consumers about the dangers of smoking); National Association of Manufacturers $v$ Securities and Exchange Commission, 748 F3d 359, 373 (DC Cir 2014) (applying the First Amendment to strike down the requirement that firms using conflict minerals publicly disclose whether the minerals they use have been found to have conflict-free origins). 
law reflects the normative position that the law should take consumers where it finds them, rather than imagining or requiring consumers to be more or less than they are--but we can know where consumers are only by testing them. 


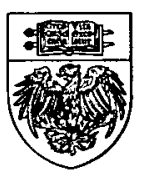

